\title{
Identification and characterization of Campylobacter jejuni factors relevant for the infection process
}

\author{
Dissertation \\ zur Erlangung des Doktorgrades \\ der Mathematisch-Naturwissenschaftlichen Fakultäten \\ der Georg-August-Universität zu Göttingen
}

Vorgelegt von

Javid Iqbal Dasti

aus

Pakistan

Göttingen, 2007 
Referent: Professor Dr. Uwe Gross

Korreferent: Professor Dr. Wolfgang Liebl

Tag der mündlichen Prüfung: 


\title{
Identification and characterization of Campylobacter jejuni factors relevant for the infection process
}

\author{
Dissertation \\ Submitted for the acquisition of Doctorate degree in Biology \\ Faculty of Biological Sciences \\ School of Natural Sciences and Mathematics \\ George August University \\ Göttingen, Germany
}

Submitted by

Javid Iqbal Dasti

From

Pakistan

Göttingen, 2007 
The experimental part of this $\mathrm{PhD}$ thesis was conducted under the direct supervision of Prof. Dr. Uwe Gross in the Institute of Hygiene and Medical Microbiology

Georg-August-University of Göttingen

Göttingen-Germany

2007

"Funding for this project was kindly provided by DFG via Graduate College 335" 
To my parents

and

all those individuals working for the peace and prosperity of mankind. 
I hereby declare that this thesis entitled "Identification and characterization of Campylobacter jejuni factors relevant for the infection process" is my own work and that, to the best of my knowledge, it contains no material previously published or written by another individual or any material which to a substantial extent has been accepted for the award of any other degree or diploma of this institution or any other institute of higher education, except where due acknowledgment has been made in the text.

Göttingen, 29.05.2007 


\section{List of Publications}

1. Dasti, J. I., Pohl, S., Lugert, R., Weig, M., Groß, U., and Schmidt-Ott. R. (2007). Role of plasmid encoded tet $(\mathrm{O})$ gene in tetracycline resistant clinical isolates of Campylobacter jejuni and C. coli. J. Med. Microbiol 56: 833-837

2. Dasti, J. I., Lugert, R. Schmidt-Ott, R. and Groß, U. (2007). Signature-tagged transposon Mutagenesis identifies Campylobacter jejuni genes involved in motility and stress response. (In preparation)

\section{Abstracts}

1. Dasti, J. I., Schmidt-Ott, R., Pohl, S., Lugert, R., Weig, M., and Gross, U. (2006). Campylobacter coli: Antimicrobial resistance and role of plasmid encoded tet $(\mathrm{O})$ gene in tetracycline resistant clinical isolates. 58. Jahrestagung der Deutschen Gesellschaft für Hygiene und Mikrobiologie.V. p.1-4. 10.2006, p. 94

2. Dasti, J.I., Simon, V., Lugert, R., Weig, M., Schmidt-Ott, R., and Groß U. (2007). Transposon mutagenesis identifies genes involved in flagellar biosynthesis of Campylobacter jejuni.14th International Workshop on Campylobacter, Helicobacter and Related Organisms, zoonoses and public health, V.2-5.09.2007, p P86

3. Dasti, J.I., Lugert, R., Schmidt-Ott, R., Weig, M., and Groß U. (2007). Characterization of genes associated with motility of Campylobacter jejuni. 59. DGHM-Jahrestagung mit FEMS Satellitensymposium "Life inside Cells" 30-4. 10. 2007, p.56

Note: A part of this work was presented on the forum of 58. Jahrestagung der Deutschen Gesellschaft für Hygiene und Mikrobiologie e.V. 


\section{ACKNOWLEDGMENTS}

I am unable to find suitable words to pay my humble gratitude to God who gave me a chance to understand some of the basic principles of a part of his boundless creation and I became aware of my limitations "Elhamdulilah". To complete a doctoral thesis needs guidance, support and encouragement. The German poet, dramatist, novelist, and scientist Johann Wolfgang von Goethe (1749-1832), who embraced many fields of human endeavor and is known as genius of all ages, once said "Correction does much, but encouragement does more. Encouragement after censure is as the sun after a shower". I am grateful to my supervisor Prof. Dr. Uwe Gross for his enormous support and encouragement. He has been a great source of inspiration and an example of dedication to professional life throughout my $\mathrm{PhD}$ work. My special thanks go to Dr. Ruprecht Schmitt-Ott, who taught me how to work with Campylobacter and helped me to develop a certain degree of discipline which is essential for a student of science. I wish to thank my supervisory and exam committee members, Prof. Dr. Uwe Gross, Prof Dr. Wolfgang Liebl, Prof. Dr. Detlef Doenecke and PD. Dr. Wilfried Kramer for their advice and suggestions during my doctoral research work. Thanks must be granted to Deutsche Forschung Gemeinschaft, Prof. Dr. Gerhardt Burkhardt, Prof. Dr. Helmut Eiffert, Dr. Raimond Lugert, Dr. Michael Hopper, Dr. Michael Weig and Mr. Achim Fittger for their support and valuable discussions.

I lack words to appreciate enormous support and contribution of my parents throughout my studies. I am also thankful to my brothers Aftab Iqbal Dasti, Junaid Iqbal Dasti, Jumshaid Iqbal Dasti and my dear sister Asma Iqbal Dasti for their jolliness and fun loving nature which made our home full of life. My friends who had the most profound impact on my life deserve my especial gratitude, Albert de Boer, William Christofer Lamana, Kathrine Lamanna and Mathew Robinson. I would like to extend my special thanks to few very dear friends and colleagues, Shariq, Bashar, Johannes, Diana, Anke, Valeska, Karin, Andrea, Dr. Carsten, Dr. Wolfgang and especially to Ahmed Saleh who always helped me.

A gesture of appreciation goes to Dr. Frau Zimmermann for her warm thoughts and cooperation. I would like to express my sincere gratitude to my friend Asif Abdul Rehaman for his guideline and encouragement, especially during the first years of my PhD work.

Last but not least, I would like to thank all the people in the lab and in the department of Medical Microbiology for their friendliness and cooperation which made me feel like being part of a family outside my home country in the beautiful town of Goettingen. 


\section{TABLE OF CONTENTS}

LIST OF FIGURES AND TABLES I

ABBREVIATIONS II

SUMMARY III

1 INTRODUCTION 1

$\begin{array}{ll}1.1 \text { Campylobacteraceae } & 1\end{array}$

1.1.1 History and taxonomy of the family Campylobacteraceae 1

1.1.2 Morphology and biochemical properties of Campylobacter 3

1.1.3 Culturing and identification of Campylobacter 4

1.1.4 Epidemiology of Campylobacter $\quad 7$

$\begin{array}{ll}\text { 1.1.5 Antibiotic resistance and sensitivity } & 9\end{array}$

1.2. Pathogenesis 9

1.2.1 Campylobacter in the post-genomic era 9

$\begin{array}{ll}\text { 1.2.2 Flagella } & 10\end{array}$

$\begin{array}{ll}1.2 .3 \text { Chemotaxis } & 11\end{array}$

1.2.4 Adhesion and invasion 11

$\begin{array}{ll}1.2 .5 \text { Toxins production } & 13\end{array}$

$\begin{array}{ll}\text { 1.2.6 Response to stress } & 14\end{array}$

$\begin{array}{ll}\text { 1.2.7 Bile tolerance } & 15\end{array}$

$\begin{array}{ll}1.3 \text { Models } & 16\end{array}$

$\begin{array}{ll}1.4 \text { Genetics of C. jejuni and gene manipulation } & \mathbf{1 7}\end{array}$

$\begin{array}{ll}1.5 \text { Aims of study } & 21\end{array}$

2 MATERIALS AND METHODS 21

$\begin{array}{ll}2.1 \text { Materials } & 21\end{array}$

$\begin{array}{ll}2.1 .1 \text { Equipment } & 21\end{array}$

2.1.2 Bacterial cell culture media and additives 22

2.1.2.1 Bacterial cell culture media 22

2.1.2.2 Antibiotics (disc) 22

2.1.2.3 Antibiotics (Powder) 22

2.1.2.4 Chemicals and reagents 23

2.1.2.5 DNA standards 23

2.1.2.6 Membranes and filters 24

2.1.2.7 Enzymes 24

$\begin{array}{ll}\text { 2.1.2.8 Bacterial strains } & 24\end{array}$ 
2.1.3 Vectors 25

$\begin{array}{ll}\text { 2.1.4 Oligonucleotide primers } & 26\end{array}$

$\begin{array}{ll}2.2 \text { Methods } & 30\end{array}$

$\begin{array}{ll}2.2 .1 \text { Media and growth conditions } & 30\end{array}$

2.2.2 Biochemical and molecular characterization of strains 30

2.2.2.1 Biochemical characterization $\quad 30$

2.2.2.2 Genomic and plasmid DNA preparation $\quad 30$

2.2.2.3 Quantification of DNA 31

2.2.2.4 PCR and southern blot analysis of the hipO gene 31

2.2.3 Drug resistance of Campylobacter isolates 32

2.2.3.1 Antibiotic resistance and tetracycline MICs determination 32

2.2.3.2 Detection and localization of the tet $(\mathrm{O})$ gene in C. coli isolates 33

2.4 Genetic modification of Campylobacter jejuni 33

2.4.1 Construction of EZ::TN transposon elements 33

2.4.2 Competent cells of E. coli and C. jejuni for electro-transformation 37

$\begin{array}{ll}2.4 .3 \text { Electroporation } & 37\end{array}$

2.4.4 Amplification of the transposons 38

2.4.5 Cross hybridization of tags $\quad 39$

2.4.6 In-vivo transposition $\quad 40$

2.4.7 Verification of randomness of the transposon insertions 41

2.5 Screening of C. jejuni mutants 41

2.5.1 Sensitivity to sodium chloride and sodium deoxycholate 41

2.5.2 Motility assay 41

2.5.3 Transmission electron microscopy 42

2.6 In-vivo screening of C. jejuni mutants 42

2.6.1 Mice infection assay $\quad 42$

2.6.2 Analysis of $\operatorname{Tn} 5 \mathrm{kan} \AA$ insertions 43

3. Results 44

3.1 Species identification of thermophilic Campylobacter strains 44

3.2 Antibiotic resistance and the role of plasmids in C. jejuni and C. coli 47

3.3 In-vivo transposition of E. coli and C. jejuni 51

3.4 Random insertions of EZ::TNkan ${ }^{\circledR}$ in the chromosome of C. jejuni 52

3.5 Isolation of non-motile mutants of C. jejuni 54

3.6 Isolation of an osmo-sensitive mutant 56 
3.7 Screening for the sodium deoxycholate sensitivity

3.8 Optimization of infection dose for BALB/c mice 57

3.9 Application of signature tagged mutagenesis of C. jejuni in-vivo 61

4 Discussion $\quad 65$

4.1 Genotypic and phenotypic diversity of Campylobacter spp. 65

4.2 Antibiotic resistance in C. jejuni and C. coli 67

4.3 Construction of transposon and in-vivo transposition of the C. jejuni 69

$\begin{array}{ll}\text { 4.4 Isolation of non-motile mutants of C. jejuni } & 73\end{array}$

4.5 Isolation of an osmo-sensitive mutant of C. jejuni 75

4.6 In-vivo screening model 76

$\begin{array}{ll}5 \text { References } & \mathbf{7 8}\end{array}$

$\begin{array}{ll}6 \text { Appendix } & 100\end{array}$

$\begin{array}{lr}\text { Curriculum } & 104\end{array}$ 


\section{List of Figures and Tables}

Figure 2.1 Construction of EZ::TN transposon element 34

Figure 2.2 EZ::TN ${ }^{\mathrm{TM}}$ transposon construction vector 36

Figure 2.3 Cross hybridization of tags $\quad 40$

Figure 3.1 Species identification of thermophilic Campylobacter strains $\quad 47$

Figure 3.2 Antibiotic resistance and the role of plasmids in C. jejuni and C. coli 48

Figure 3.3 Correlation of tetracycline resistance of C. jejuni isolates 49

and presence of the tet $(\mathrm{O})$ gene

Figure 3.4 HindIII-digested C. coli plasmid DNA 50

Figure 3.5 In-vivo transposition of E. coli and C. jejuni 51

Figure 3.6 Transposons used to generate STM mutants 52

Figure 3.7 Random insertions of EZ::TNkan ${ }^{\circledR}$ in the chromosome of C. jejuni 53

Figure 3.8 Isolation of non-motile mutants of C. jejuni 54

Figure 3.9 A model of the regulation of flagellar biosynthesis of C. jejuni 55

Figure 3.10 Electron micrographs of the C. jejuni B2 56

$\begin{array}{ll}\text { Figure 3.11 Gross pathology of C. jejuni infection } & 60\end{array}$

Figure 3.12 Microscopic analysis of liver post C. jejuni infection 61

Figure 3.13 Application of signature tagged mutagensis of C. jejuni in-vivo 62

Figure 3.14 Tag-specific PCR 63

Figure 3.15 The general scheme for the screening of a pool of STM mutants 63

Figure 4.1 The structure of the Tn5 transposase/DNA complex 71

Table 2.1 Oligonucleotide kan ${ }^{\circledR}$ primers $\quad 26$

$\begin{array}{ll}\text { Table 2.2 Oligonucleotide tag-specific (TS) primers } & 27\end{array}$

Table 2.3 Oligonucleotide amplification and sequencing primers 28

Table 2.4 Oligonucleotide primers for the confirmation of mutants 29

Table 3.1 Characterization of hippurate hydrolase positive C. jejuni isolates $\quad 44$

Table 3.2 Characterization of tetracycline-resistant Campylobacter isolates $\quad 47$

Table 3.3 Optimization of infection dose for BALB/c mice 58

Table 3.4 Infection dose of B2 and NCTC11828 strains of C. jejuni 59 


\section{AbBreviations}

$\mathrm{Ab}$.

Absorbance

ADP

Adenosine dinucleotide

AIDS

Acquired immunodifficieny syndrome

Amp

Ampicillin

AP

Alkaline phosphatase

BLAST

Basic Local Alignment Search Tool

Bp

Base pairs

BSA

Bovine serum albumin

DNA

Desoxyribonucleic acid

dNTP

Dinucleotide phosphate

EDTA

Ethylenediaminetetraacetic acid

$\mathrm{g}$

force of gravity

gDNA

Genomic DNA

HEPES

4-(2-hydroxyethyl)-1-piperazineethanesulfonic acid

$\mathrm{Kb}$

Kilo base pair

$\mathrm{kDa}$

Kilo Dalton

LB

Luria broth

mRNA

Messenger ribonucleic acid

ORF

Open reading frame

PAGE

Polyacrylamide gelelectrophoresis

PBS

Phosphate buffered saline

PCR

polymerase chain reaction

$\mathrm{RE}$

Restriction enzyme

RNA

Ribonucleic acid

Spp.

Species

TAE

Tris Acetate EDTA

TEMED

$\mathrm{N}, \mathrm{N}, \mathrm{N}, \mathrm{N}$-Tetramethyl-Ethylenediamine

Tet

Tetracyclin

tRNA

Transport RNA

$\mathrm{U}$

Unit

UV

Ultraviolet 


\section{Summary}

Campylobacter jejuni is the most frequent bacterial cause of foodborne-illness in the developed world including Germany, where the reported number is 60,000 cases in a year. Despite the recent completion of its genome sequence, little is known about the pathogenesis of the disease caused by this bacterium. Different factors are reported to be contributing in this lack of understanding of the pathogenesis of campylobacteriosis, likewise, the unavailability of an efficient system of experimental genetics, the lack of appropriate animal models for the disease, and the genetic diversity of Campylobacter strains. Epidemiological and phenotypical studies suggest that strains of C. jejuni vary in their colonization and invasion abilities and most likely in their virulence potential.

By considering all these factors we collected lab strains, NCTC11168, NCTC11828, 81-176 and eighty-three clinical isolates and more precisely determined them by combining biochemical and molecular markers; 74 isolates (89.2\%) were identified as C. jejuni, including 7 atypical C. jejuni isolates that failed to hydrolyse hippurate, and 9 isolates $(10.8 \%)$ as C. coli. The prevalence of tetracycline resistance (Tcr), tetracycline minimal inhibitory concentration (MIC), and tet(O) gene localization were also investigated in 83 Campylobacter isolates. Tcr was detected in 6 out of 9 Campylobacter coli isolates $(67 \%)$ and 13 out of 74 C. jejuni isolates (18\%). Tcr was low levelled for C. coli (MIC: $16 \mu \mathrm{g} / \mathrm{ml}$ for all strains) and high levelled for C. jejuni (MIC: $>256$ for all strains). Both, low levelled and high levelled Tcr was associated with the presence of the tet(O) gene. In $C$. jejuni, tet $(\mathrm{O})$ was plasmid-encoded in 54\%, whereas in C. coli, tet $(\mathrm{O})$ seems to be located on the chromosome. Transposon mutagenesis of $C$. jejuni chromosomal DNA was performed by using the in-vivo transposition method, which produced a random transposon mutant library consisting of 660 individual mutants. The BALB/c mouse model was optimized for an in-vivo genetic screen of the random mutants. The first genetic screen of $C$. jejuni mutant library identified 3 mutants defective for their flagellar motility, an important virulence determinant of C. jejuni. Chromosomal DNA sequencing of these mutants revealed a single insertion in each of the two genes $c j 0793$ and cj0955c, respectively. Furthermore, the analysis of sequenced DNA proved one of these genes, $c j 0955$, coding for unknown functions and the second gene, cj0793, was identified as the two component sensor, which is known as a central factor for flagellar motility. In addition, electron microscope analysis revealed flagellated and non-flagellated 
non-motile mutants of $C$. jejuni. The second genetic screen of $C$. jejuni revealed an osmosensitive mutant with an insertion in the gene cj0009 encoding the NADPH-dependent glutamate synthase small subunit.

Overall, this study proved that the PCR based in-vivo transposon mutagenesis is an effective method to generate large number of mutants of $C$. jejuni and can be successfully applied to investigate virulence-associated apparatus of this important bacterial pathogen. 


\section{Introduction}

\subsection{Campylobacteraceae}

\subsubsection{History and taxonomy of the family Campylobacteraceae}

Campylobacter was first described in 1880 by Theodor Escherich (Friedman et al., 2000). In 1886, Escherich published a series of articles in the Münchener Medizinische Wochenschrift in which he described spiral bacteria in the colons of children who had died of what he called 'cholera infantum'. Unfortunately, these articles, published in German, remained unrecognized for many decades until his findings were presented by Kist at the Third International Workshop held in Ottawa in 1985. In 1909, two veterinarians, McFadyean and Stockman described the association of a microorganism with epizootic abortion in ewes (cited by Franco, 1988). Few years later, it was shown that the same vibrio can be found in infectious abortions in sheep and pregnant cows (Fox, 1982; Franco, 1988), and the same microaerophilic spirillum bacterium was isolated by Smith in 1919 from aborted calf tissues (Smith and Taylor, 1919). Due to its comma-shaped morphology, Smith and Taylor proposed the name "Vibrio fetus" and the disease was called vibrionic abortion (Fox, 1982; Butzler, 1984; Franco, 1988; Skirrow, 1977). In 1931, a new "vibrio" was reported that caused dysentery in calves during the winter and its name was proposed as Vibrio jejuni (cited by Butzler, 1984; Franco, 1988).

The three identified vibrio microorganisms - V. jejuni, V. coli, and V. fetus-were named in association with specific diseases in animals (Butzler, 1984). However, Campylobacter were not generally recognized as fecal pathogens in humans until the late 1970s, occasional isolation of " $V$. fetus" had been obtained from blood or other normally sterile body fluids. In 1947, in France the organism was isolated from a woman who had suffered from septic abortion (Vinzent et al., 1947), but an event that took place in Illinois in May 1938 is now regarded as the first well documented incident of the human Campylobacter infections. It was a model investigation of a milk-borne outbreak of diarrhea that affected 355 inmates of two adjacent state institutions (Levy, 1946).

Recent reports showed that Campylobacter jejuni is the most common bacterial cause of food-borne disease in most of the industrialized countries with an estimated 2.5 million cases per year in the United States alone (Friedman et al, 2000). 
For many years, the taxonomic study of Campylobacter was fraught with difficulty because it mainly relied on phenotypic character, which is difficult to standardize. In 1957, King was grouping the Vibrio bacteria and the clinical entities of bovine vibrionic abortions started to be better understood. In the same year, the first taxonomic differentiation of Vibrio started when he demonstrated that catalase-positive microaerophilic Vibrios could be differentiated by their ability to grow at different temperatures (Butzler, 1984). At this time, a sporadic abortion was very common among pregnant cows and these abortions probably resulted from the establishment of $V$. fetus in the intestinal tract of the cows. A second type of sporadic abortion was reported with reduced conception rates, which indicated a case of infectious infertility. The strains of "vibrio" causing this infectious infertility were identified in 1959 by Florent in Belgium (Florent, 1959). He named these strains, V. fetus var. venerealis, after showing that this type of abortion was transmitted venereally from symptomless bulls to cows and that infertility was the major consequence of the infection (Butzler, 1984). In 1963, Sebald and Véron classified these microaerophilic bacteria as a new genus called Campylobacter (Hébert et al., 1982). Ten years later, the first comprehensive taxonomy of Campylobacter was published by Véron and Chatelain and they recognized the microorganisms Vibrio jejuni and Vibrio coli in their classification system of the genus, later these names were accepted by the International Committee of Systematic Bacteriology (Skerman et al., 1980; Skirrow and Benjamin, 1980).

For a long time, it was not possible to distinguish between $C$. jejuni and C. coli, both bacteria were grouped together as C. fetus ssp. jejuni and nobody really knew about the difference of $C$. jejuni and C. coli. However, now it is possible to distinguish C. jejuni from C. coli, and even also two biotypes of C. jejuni (Harvey, 1980). In the 8th edition of Bergey's Manual of Determinative Bacteriology (Buchanan and Gibbons, 1974), the genera Spirillum and Campylobacter constituted the family Spirillaceae. This grouping of different taxa in one family was based on a number of morphological features. Since the phylogenetic relationship of these organisms was still unknown, the use of the family name Spirillaceae was abolished and the genus Campylobacter was considered to belong to the class of Proteobacteria (Vandamme and Ley, 1991). Goodwin et al. (1989) purposed the first step in the revision of Campylobacter taxonomy. They outlined genotypic and phenotypic arguments to exclude C. pylori from the genera Campylobacter and Wolinella 
and proposed a novel genus called Helicobacter to accommodate both C. pylori and C. mustelae and later, Vandamme et al. (1991) completely revised the taxonomy and nomenclature of the genus Campylobacter and related bacteria. Campylobacter, together with Wolinella and "Flexispira" and two generically misnamed Bacteroides species, were found to represent a separate, sixth rRNA superfamily sensu De Ley (De Ley, 1978), within the group of the gram-negative bacteria. This lineage is now better known as the epsilon sub-division of the proteobacteria. On the bases of enormous genotypic and phenotypic differences, Vandamme and Ley proposed that the genera Campylobacter and Arcobacter should be included in a separate family, named Campylobacteraceae (Vandamme and Ley, 1991).

\subsubsection{Morphology and biochemical properties of Campylobacter}

The name Campylobacter is derived from the Greek word "Kampylos," which means curved. Campylobacter spp. are non-spore-forming and gram-negative bacteria. They can be spiral, curved or occasionally straight rods, with size ranging from 0.2 to $0.8 \mu \mathrm{m}$ wide and 0.5 to $5 \mu \mathrm{m}$ long. Campylobacter may appear as spiral, $\mathrm{S}_{-}, \mathrm{V}-$, or comma-shaped forms and may also be found in short or occasionally long chains. As Campylobacter cells begin to age, they become coccoid in shape (Moran and Upton, 1987). The cells are highly motile by means of single or occasionally multiple flagella at one or both ends (Ursing et al., 1994). Extremely rapid, darting motility of comma-shaped cells can be seen with a phase contrast microscope. According to On et al. (1995), the number of flagella should not be considered as an important taxonomic criterion for the Campylobacter genus because of high variation in the flagellar arrangement of certain species or strains. Both mono- and biflagellated cells of the same general shape and size within the same culture of strain have been observed (On et al., 1995). It has been speculated that genetic changes as a result of spontaneous mutation and other mechanism such as natural or plasmid-borne transformation may cause considerable phylogenetic diversity which is observed within the genus. These microaerophilic organisms grow best in an atmosphere containing 5 to $10 \%$ oxygen and an optimum temperature for their growth ranges from 30 to $42^{\circ} \mathrm{C}$. Colony morphology should not be used as an important distinguishing factor because several factors including bacterial strain, basal medium, level of moisture on the surface of the 
agar, incubation temperature and incubation time may affect colony morphology of this organism. Colony morphology is quite variable, from a thick translucent white growth to spreading film-like transparent growth which can be visible on the plating media within 24 to 48 hours of incubation (Franco, 1988). It is difficult to isolate this organism from fecal specimens without using selective techniques because campylobacters tend to multiply slower than other enteric bacteria (Franco, 1988).

Campylobacter do not ferment carbohydrates and usually obtain energy from amino acids or tricarboxylic acid cycle intermediates. Typical biochemical reactions include the reduction of fumerate to succinate, negative methyl red, acetoin, and indole production. Most species reduce nitrate and are oxidase positive but only C. jejuni is hippurate positive. C. jejuni is quite sensitive to drying and storage at room temperature, but at refrigeration temperatures and appropriate humidity, large number of bacteria may survive. Enzymes expressed by $C$. jejuni such as superoxide dismutase (SOD), catalase, peroxidase, glutathione synthetsae, and glutathione reductase may have a vital role in providing protection against oxygen toxicity (cited by Crushell et al., 2004). Campylobacter can be distinguished from Arcobacter due to its key features which include; Arcobacter grows at $15^{\circ} \mathrm{C}$ but not at $42^{\circ} \mathrm{C}$, its optimal temperature for aerobic growth is $30^{\circ} \mathrm{C}$, and its $\mathrm{G}+\mathrm{C}$ content of the DNA ranges from 27 to $30 \mathrm{~mol} \%$ (Ursing et al., 1994), while in Campylobacter it ranges from 28 to $46 \mathrm{~mol} \%$.

\subsubsection{Culturing and identification of Campylobacter}

There is lack of consensus on the issue of the standard culturing medium for the growth of Campylobacter in the laboratory. Special requirements for growth temperature, gaseous environment and nutrient-rich basal medium are major obstacles to develop an optimum medium for this fastidious organism. Another difficulty is over-growth of coliform bacteria, Proteus spp., yeasts and molds within a Campylobacter culture (Goossens and Butzler, 1992; Stern et al., 1992; Jeffrey et al., 2000). When setting the formulation of selective medium, the rate of the recovery of the desired organism is a crucial parameter. An ideal Campylobacter medium should provide excellent recovery and substantial selectivity against background flora with an easy and quick differentiation of bacterial species. It should be cost effective, easy to prepare and it must have good shelf life with a 
possibility to minimize the risk of contamination of the medium, especially, when adding supplements following heat-steam sterilization.

Most importantly, the medium should allow the organism to grow into isolated and distinct colonies without inducing swarming. By different researchers and laboratories a wide variety of media have been used and modified for isolation of Campylobacter; such as Skirrow formulation, Butzler's Agar, Campylobacter Blaser Agar, Preston, Semisolid Blood-free Selective Medium (SSM), Campylobacter Thioglycollate medium, CampyBrucella Agar Plate (Campy-BAP), Campylobacter Cefoperazone Desoxycholate Agar (CCDA), Abeyta-Hunt-Bark Agar (Campy-FDA), Brucella Broth with 0.16\% Agar, SemiSolid Campylobacter Medium, Skirrow formulation, Butzler's Agar, Preston, Semisolid Blood-free Selective Medium (SSM), and Campy-Cefex (Wang et al., 1980; Bolton and Coates, 1983; Goossens and Butzler, 1992; Stern et al., 1992; Hunt and Abeyta, 1995; Hunt et al., 1998; Jeffrey et al., 2000). Above mentioned media differ in several aspects, for example, the amount of basal medium, concentration of antibiotics, presence or absence of growth enhancers such as horse or sheep blood and presence of special components like charcoal. All these nutrient-rich media support growth of a large number of fastidious organisms without much selectivity towards Campylobacter spp. Skirrow formulation was the first selective medium developed specifically for Campylobacter spp. which contained a nutrient base, 7\% lysed horse blood and a combination of antimicrobials such as trimethoprim, polymyxin B and vancomycin. Camyplobacter was able to grow well on this media but predominated growth of fecal background flora and Proteus spp. became a problem (Goossens and Butzler, 1992). After the development of Skirrow's medium, Campy-BAP was developed which contains a Brucella agar base, instead of the blood agar base found in the Skirrow medium, and 10\% sheep blood. To suppress the growth of some gram-negative organisms present in fecal flora, especially Pseudomonas spp., trimethoprim is added to the medium and other antimicrobial agents such as cefoperazone, and polymyxin B. Vancomycin and rifampin can be used to inhibit growth of gram-positive bacteria. Moreover, the use of cycloheximide and amphotericin B is recommended to suppress the growth of yeast. Another Campylobacter medium is Butzler's Agar, which contain Columbia agar base instead of the Brucella agar. It is necessary to add $5 \%$ defibrinated sheep blood, cefoperazone, rifampicin, amphotericin B and colistin to the 
Butzler's agar.The United States Department of Agriculture (USDA) developed the Campy-Cefex medium. The major differences in the medium, as compared to others like CCDA and Campy-BAP is the lack of blood, the incorporation of sodium metabisulfite, sodium pyruvate and the addition of lysed horse blood with FBP a mix of ferrous sulfate $\left(\mathrm{FeSO}_{4} .7 \mathrm{H}_{2} \mathrm{O}\right)$. This medium is more effective in recovering $C$. jejuni (Stern et al., 1992). It has been known that the incorporation of FBP to solid media can enhance the growth of Campylobacter.

In one study, five different selective media Skirrow's, Butzler's, Blaser's, Campy-BAP and Preston's were compared for the isolation of Campylobacter (Bolton et al., 1983). It was reported that Preston medium preceded by enrichment on modified Preston Enrichment Broth was found to be the most selective medium for Campylobacter while Butzler was the least effective. Campylobacter are very sensitive to superoxide anions (Goossens and Butzler, 1992; Corry et al., 1995; Blais and Phillippe, 1999), and it is believed that the chemical mixture (FBP) quenches superoxide anions generated in the medium which might improve the aerotolerance of Campylobacter (Smibert, 1978; Goossens and Butzler, 1992). According to Smibert (1978), pyruvate can destroy hydrogen peroxide whereas iron and bisulfite together act non-enzymatically to destroy superoxide radicals. High-energy radicals such as superoxide and peroxides are generated by photochemical reduction of medium components and inhibit the growth of Campylobacter, thus incorporation of FBP mix into media has special importance. It has been described that the addition of FBP to the medium can cause ten times reduction in the hydrogen peroxide toxicity (Smibert, 1978). Glutathione and pyruvate are believed to protect the cells against self-destruction by reducing the oxygen tension of the media. They also can stimulate the expression of genes associated with the stationary phase, which allows the cells to adapt to stress responses protecting them against denaturation (Dodd, 1997). Often glutathione is added to the Campylobacter media to assist in the recovery of stress-damaged bacteria. Moreover, both FBP and blood are also added to the medium to minimize toxic oxygen products and to promote growth. Enzymes such as catalase, peroxidase, and peroxide dismutase, are present in the blood and have the ability to decompose toxic oxygen derivatives (Goossens and Butzler, 1992). 
Incorporation of charcoal to the medium can be used as an alternative of blood and it has been reported that charcoal could effectively replace the blood in the media formulations (Bolton and Coates, 1983). Instead of the 5\% of blood in other Campylobacter media CCDA contains $4 \%$ charcoal. Although this media provides best selectivity and good recovery of Campylobacter (Stern et al., 1992), there are certain disadvantages using this medium, for example, the need for constant shaking of the medium during plate pouring to avoid precipitation of the charcoal, and the difficulties in the identification of the translucent colonies of Campylobacter on the dark opaque color of the medium. In short, there is no consensus on a single standard method for isolating Campylobacter from different food or environmental samples. However, several protocols have been published from different sources including the International Standards Organisation (ISO), Public Health Laboratory Services (PHLS) from the United Kingdom and the Food and Drug Administration of the United States of America. Recently, the UK Microbiological Safety of Food Funders Group (MSFFG) has commissioned publicly-funded research on Campylobacter. They recommended methods for highly contaminated samples as well as for food surveillance. In addition, MSFFG endorsed a WHO recommendation that there is a need for collaborative efforts on international level to develop techniques for isolation of Campylobacter from food and environment (MSFFG, 2001)

\subsubsection{Epidemiology of Campylobacter}

In developed countries, Campylobacter is one of the most frequently reported causes of acute bacterial gastroenteritis. Significant variations in incidence rates have been observed between different countries (Brieseman, 1990; O'Brien et al., 1999). Several factors, including differences in infection rates in food animals, food production system, or different patterns of food consumption can be responsible for these variations. These differences in incidence rates can also occur because of differences in diagnosis, reporting systems, or case definitions used in each country's surveillance systems (Brieseman et al., 1990). In the United States, it is estimated that 2.5 million cases of campylobacteriosis occur annually. Although accounting for only 5\% of estimated food-related deaths, Campylobacters are responsible for approximately $17 \%$ of hospitalizations resulting from foodborne infections (Mead et al., 1999). Annual economic cost of Camyplobacter 
associated illnesses is estimated up to $\$ 8$ billion in the United States alone (Buzby et al., 1997). In a recent study in the United Kingdom, it was found that for every isolate of Campylobacter reported to the National surveillance Scheme, 7.6 were unreported. By extrapolating, it was estimated that the total number of cases of C. jejuni in 1999 in the United Kingdom was 450,000. This figure agrees closely with other community-based studies in both, the United Kingdom and United States that estimate a population-based incidence of approximately 1\% (Kendall and Tanner, 1982; Tauxe et al., 1992).

The Campylobacter enteritis causes significant morbidity and mortality in developed countries. A report from the U.S. Centers for Disease Control and Prevention estimated that each year Campylobacter infection causes 124 deaths in the United States (Mead et al., 1999). In an epidemiological survey conducted in the European Union, it was reported that fifteen out of $18 \mathrm{EU}$ countries reported 134,971 Campylobacter infections in 1999 alone (Takkinen et al., 2003). This study showed great variation in the notifications/100,000 inhabitants of different EU countries which ranged from 2.9 to 166.8 during the year 1999 . In 1998, the mean number of notifications per100, 000 inhabitants in the EU was 61 and in 1999 it was 71. These results showed that the increase in the notifications was about $16 \%$ between 1998 and 1999. During the period from 1995 to 1999, 11 countries reported 154 outbreaks and the highest number of the reported outbreaks was in 1997. The reporting of outbreaks varied greatly by country however, these numbers reflect a rough estimate of the true situation. Forty-eight percent of the outbreaks were linked with food, which served as a vehicle for transmission. Use of unpasteurised milk was responsible for $15 \%$ and another $15 \%$ were water-borne. In every fifth outbreak (21\%), the cause was not clear and remained unknown (Takkinen et al., 2003). During the year 2005, the number of reported cases of Campylobacter in Germany was highest than ever before, surpassing the number of 60,000, which made Campylobacter a number one bacterial pathogen responsible for food poisoning in Germany. Total numbers of cases of campylobacteriosis during the year 2005 were higher than the total number of cases of salmonellosis reported in Germany (RKI, 2006). Campylobacter species occur in the animal food chain of humans from the most to the least economically developed cultures. Although, Campylobacter species are recognized as among the most common causes of diarrhea worldwide, the epidemiology of 
Campylobacter infections in the developing world differs markedly from that in the developed world.

\subsubsection{Antibiotic resistance and sensitivity}

Campylobacter jejuni and C. coli are susceptible to nalidixic acid, ciprofloxacin, norfloxacin, and ofloxacin (Taylor and Courvalin, 1988). Furazolidone is another drug that has been shown to be effective against Campylobacter species (Shane, 1997). All C. jejuni and C. coli isolates are intrinsically resistant to a number of antibiotics, including bacitracin, novobiocin, rifampin, streptogramin B, trimethoprim, vancomycin, and usually cephalothin. According to Taylor and Courvalin (1988), the Campylobacter genus, has apparently been able to acquire resistance determinants from both gram-positive and gram-negative organisms, although the former seem to be the more common source. Campylobacter spp. and Enterococcus spp. occupy a common niche (the human and animal gastrointestinal tracts) and DNA exchange between these two species within this environment is very likely to occur. Campylobacter spp. might acquire resistance against tetracycline, minocycline, kanamycin, chloramphenicol, streptomycin, spectinomycin, erythromycin, ampicillin and nalidixic acid. Erythromycin resistance is accompanied by cross-resistance to spiramycin, tylosin, and clindamycin (Blaser et al., 1982; Taylor and Courvalin, 1988; Shane, 1997).

\subsection{Pathogenesis}

\subsubsection{Campylobacter in the postgenomic era}

The virulence machinery of many enteric prokaryotic pathogens consists of adhesion, invasion, toxin production, and subversion of host cell processes. The role of these virulence processes is well described in other enteric pathogens but the exact mechanism of Campylobacter pathogenesis is yet to be elucidated. In the past decade, in-vitro assays have permitted the identification and characterization of a limited number of $C$. jejuni virulence determinants. Some of the corresponding genes have been mutated in order to assess the functional roles of these proteins in $C$. jejuni enteritis by using in-vivo infection models (Crushell et al, 2004). However, the complete analysis of Campylobacter pathogenesis is hampered by difficulties in genetic manipulations, lack of an effective animal model of 
human enteric infection and variability in virulence of different strains. In the year 2000, the completion of the $C$. jejuni NCTC11168 genome sequence was reported (Parkhill et al., 2000). The completion of the 1.6 megabase sequence and its deposition in the public domain has significant importance in Campylobacter research, and allows the identification of putative virulence factors. For example, it became evident that the only toxin genes present in Campylobacter are cytolethal distending toxin (CDTs) genes and there are no pilus structures encoded on the chromosome (Parkhill et al., 2000). Moreover, unique information from the completed C. jejuni genome sequence has prompted research endeavours into new directions. Especially, the identification of a substantial number of homopolymeric tracts indicated the potential importance of slipped-strand mispairing phenomena and consequently, lead to the idea of phase variation which plays a vital role in the virulence and survival of this organism (Bourke, 2002).

\subsubsection{Flagella.}

In C. jejuni, motility is achieved by a single flagellum at one or both ends of the bacteria, and it has an important role in virulence because it is required for the bacteria to reach the attachment sites and penetrate into the intestinal cells. It is also reported that the flagella of C. jejuni appeared to have an essential role in the causation of diarrheal disease. The importance of motility as a virulence factor is best demonstrated by true isogenic nonflagellated mutants, which are unable to colonize the intestine of experimental animals (Guerry et al., 1992). The role of flagella in the colonization of the mucous lining of the gastrointestinal tract has already been studied (Yao et al., 1994). Flagella are also important for invasion of host cells, as aflagellate organisms show markedly reduced internalization into host cells in-vitro (Wassenaar and Blaser, 1999). The flagella of C. jejuni are composed of proteins, encoded by two genes flaA and flaB sharing a high degree of sequence homology (Wassenaar and Blaser, 1999). It has been shown that defined mutations in the flaA gene results in truncated flagella and diminished motility which are unable to invade intestinal epithelial cells in-vitro (Wassenaar et al., 1991; Yao et al., 1994). Furthermore, a mutation in another gene encoding pyruvate formate lyase activating enzyme 1 (pflA) resulted in bacteria with paralyzed flagella that lead to a mutant which is still able to adhere, but is not capable of invasion in-vitro (Yao et al., 1994). Therefore, it 
was proven that FlaA is not the only determinant that is critical for invasion of this pathogen in-vitro. The genome sequence analysis of C. jejuni strain 11168 led to the prediction of the involvement of more than 50 genes in the assembly of the flagella. The regulation of the Campylobacter FlaA-regulon seems to be more complex because the respective genes are located in more than 32 individual loci, while in E. coli they are located in only six loci. Despite the fact that the phenotypes of many non-motile mutants are known, the exact mechanism of regulation of the flagellar genes in $C$. jejuni is still not understood. Recently, some flagellar transcription activators like RpoN, FliA and FlgR were identified, but how exactly these proteins are regulated and their role in the assembly of C. jejuni flagellum remains to be elucidated (Wösten et al., 2004).

\subsubsection{Chemotaxis}

Chemotaxisis defined as the movement of an organism towards or away from a chemical stimulus. Chemotaxis has been noted to be an important factor in the colonization of pathogenic bacteria including V. cholerae, S. typhimurium, and E. coli. Several studies demonstrated that chemotaxis is an important virulence determinant in $C$. jejuni and plays an important role in the colonization of mice. The cheY null mutant of $C$. jejuni was generated (Yao et al., 1997) and found to display a nonchemotactic but motile phenotype. A three-fold increase in the adherence and invasion of INT 407 cells was noticed as compared to the wild type with the cheY null mutant, which was unable to colonize mice or cause symptoms in infected ferrets. In the same study, it was shown that cheY diploid isolates (having two copies of cheY) showed a chemotactic behaviour and a decrease in their in-vitro adherence and invasion capabilities. Although, this isolate was able to colonize mice, it was unable to cause disease in the ferret model. It was suggested that these bacteria migrated towards the mucus within the crypts, but were unable to penetrate the mucus (Konkel et al., 2001).

\subsubsection{Adhesion and invasion}

There are several reports exploiting in-vitro adherence assays to characterize the interaction of C. jejuni with host cells. It has been reported that C. jejuni is capable to bind to several cell lines of human (INT 407, HEp-2, and HeLa) and non-human origin (Vero, CHO-K1, 
and MDCK) with equal efficiency. Human intestinal epithelial (INT407) and human colon (Caco-2) cell lines were thought to be good models to mimic those cells encountered by $C$. jejuni in-vivo and therefore, these cell lines were extensively used to study adhesion of $C$. jejuni. The concept that adhesion of $C$. jejuni to host cells is mediated by constitutively synthesized products is supported by the finding that metabolically inactive $C$. jejuni organisms can bind to cultured cells at levels equal to or greater than those at which metabolically active, untreated $C$. jejuni cells bind. A variety of putative adhesion factors of $C$. jejuni have been already identified which include the fibronectinbinding protein $\mathrm{CadF}$ (Konkel et al., 1997), a homologue of the gram-negative ABC transport system PEB1 (Pei and Blaser, 1993) and a major outer membrane protein (Moser et al., 1997). Recently, it has been suggested that a novel surface-exposed lipoprotein specific to $C$. jejuni plays a role in host cell adherence (Jin et al., 2001). The lack of a suitable and accessible animal model of infection is a major hindrance to determine the precise role of these potential virulence factors to human disease. A significant variation has been observed in the degree of invasiveness between different strains of C. jejuni (Newell et al., 1985; Konkel and Joens, 1989). Invasion of C. jejuni has been shown in colonic epithelial cells taken from infected humans and macaque monkeys (Woolridge and Ketley, 1997). Different experiments on a variety of cell lines including human intestine-derived Caco-2 and INT 407 cells showed invasiveness (Woolridge and Ketley, 1997; Kopecko et al., 2001). Some isolates of $C$. jejuni such as the well characterized strain 81-176 are proven to be highly invasive in these experimental models, however, many other isolates show low levels of host cell entry in-vitro (Kopecko et al., 2001). Recently, entry of C. jejuni in polarized epithelial cells via the basolateral membrane has been demonstrated as well as there is evidence for paracellular passage and M-cell transcytosis (cited by Woolridge and Ketley, 1997). Some studies demonstrated microtubule-dependent invasion of C. jejuni 81-176 and its reliance on microtubule motors for uptake and intracellular motility (Bourke, 2002; $\mathrm{Hu}$ and Kopecko, 1999). Likewise, most strains of C. jejuni showed microfilament or microtubule-dependent invasiveness (Biswas et al., 2000). 


\subsubsection{Toxin production}

Campylobacter jejuni-induced clinical symptoms, which often include a transient watery diarrhea that progress to a bloody diarrhea, are consistent with the idea that toxins play a role in this disease. Indeed, a variety of toxic activities has been reported in C. jejuni. However, cytolethal distending toxin (CDT) is the only verified Campylobacter toxin identified to date. CDT production by Campylobacter was first reported in 1988 (Johnson and lior, 1988). During the last few years, significant progress has been made to understand the cellular effect of CDT (Karlyshev and Wren, 2001; Hickey, 1999). In 1996, the isolation and characterization of the $c d t$ genes from $C$. jejuni 81-176 was reported and it is now well known that $\mathrm{CdtB}$ is the active moiety of the Cdt ABC complex (Pickett, et al 1996). It appears that $\mathrm{Cdt} A$ and $\mathrm{CdtC}$ interact with $\mathrm{CdtB}$ to form a tripartite CDT holotoxin necessary for the delivery of the enzymatically active subunit, CdtB (Lara-Tejero and Galan, 2001). It has also been shown by Whitehouse et al. (1998) that affected epithelial cells undergo cytodistension and cell cycle arrest in the G2/M phase. T lymphocytes exposed to CDT-mediating sonicates from $C$. upsaliensis showed cell cycle arrest. The role of CDT in C. jejuni pathogenesis has not been determined yet, however, it might play a role in modulation of immune response and invasiveness (Purdy et al., 2000).

Another increasingly recognized prokaryotic virulence mechanism is to subvert host cell processes by targeting bacterial products directly to the cytoplasm of the host. Konkel et al. (1999), reported a C. jejuni protein called CiaB that seems to enter host cells during the invasion process. It has been shown that isogenic $\mathrm{CiaB}$ mutants were deficient in secretion of a number of bacterial proteins. A flagellar export system encoded by the genome of $C$. jejuni 11168 has been reported, but there is no evidence for the presence of a typical type III secretory apparatus. Recently, Bacon et al identified homologues of a type IV secretory apparatus on a large plasmid of $C$. jejuni $81-176$. The $37 \mathrm{~kb}$ the $\mathrm{pVir}$ plasmid of $C$. jejuni harbours 54 predicted open reading frames (Bacon et al., 2002). In some studies, it has been shown that mutations in some of the plasmid-encoded genes might reduce invasion compared with the parental strain in-vitro. However, transfer of the plasmid to the sequenced strain, NCTC11168, did not show any difference in the invasiveness of this isolate (Bacon et al., 2000). 


\subsubsection{Responses to stress}

Compared to other food-borne bacterial pathogens, C. jejuni and C. coli have limited capacity for growth in the environment. Accordingly, the organisms are microaerophilic, have minimum growth temperatures between 32 and $36^{\circ} \mathrm{C}$, and have complex nutritional requirements. Campylobacter is unusually sensitive to different environmental stresses because unlike other enteric pathogens it lacks many adaptive responses. Genome analysis of Campylobacter proved that it does not possess the global regulator RpoS (Parkhill et al., 2000). In a number of gram-negative organisms, this global regulator is the basis for the survival of the bacterial cell during exposure to many types of environmental stresses. In some recent studies, it has been shown that Campylobacter can exhibit adaptive responses to both acidic and aerobic conditions (Murphy et al., 2003). It has also been recognized that Campylobacter is more resistant to stress than had previously been thought (MSFFG, 2001). Campylobacter can be inactivated by heat or normal pasteurization treatments. However it can exhibit a heat-shock response immediately after exposure to temperatures above the optimal range for growth (Konkel et al., 1998) and 24 proteins are preferentially synthesized by C. jejuni as heat-shock response. Some of these proteins such as GroELS, DnaJ, and Lon protease, have been characterized previously (Konkel, et al., 1998; Thies et al., 1999; Thies et al., 1998; Wu et al., 1994). In one study, it has been proven that mutants deficient in one of the heat-shock proteins have drastically reduced their growth at $46^{\circ} \mathrm{C}$ and are unable to colonize chickens. This finding suggests a role of heat-shock-proteins in both thermotolerance and colonization. There are potentially three regulatory systems that control the induction of the heat-shock response in C. jejuni. The RacRS regulation, previously characterized as a two-component regulatory system, is required for the differential expression of proteins at $37^{\circ} \mathrm{C}$ and $42^{\circ} \mathrm{C}$ and is therefore likely to play a role in the regulation of the heat shock response (Bras et al., 1999). The identification of CIRCElike consensus sequences upstream of the groES1 and dnaK operons of $C$. jejuni provides further support that the expression of these and maybe other heat shock genes is regulated by the HrcA homologue (Thies et al., 1999). Since Campylobacter can be isolated from a wide variety of aqueous environmental sources and refrigerated foods (Rollins et al., 1986), they must be able to survive exposure to low temperatures for considerable periods. 
From analysis of the $C$. jejuni genome sequence, it appears that Campylobacter does not seem to produce cold-shock proteins which may be a factor for no growth below $30^{\circ} \mathrm{C}$. Contrary to other bacteria, C. jejuni shows a rapid decline in its growth near its minimal growth temperature (Hazeleger et al., 1998). However, at temperatures as low as $4^{\circ} \mathrm{C}$, Campylobacter still can perform respiration, generate ATP, but is unable to replicate (Hazeleger et al., 1998). Although at lower temperature viability of the organism is lost rapidly, it can still be isolated from frozen meats and poultry products (Fernandez et al., 1996). Most of Campylobacter species are microaerophilic, including the important species directly linked to foodborne infections and are sensitive towards oxygen and its reduction products (Stead et al., 2000). Exposure to oxygen, while inevitable for most bacterial pathogens, leads to the formation of reactive oxygen intermediates as harmful byproducts that are capable of damaging nucleic acids, proteins and membranes. Many bacteria utilize their osmoregulatory mechanism to cope with osmotic stress but in Campylobacter such system is known to be absent (Parkhill et al., 2000).

\subsubsection{Bile tolerance}

In comparison to gram-positive bacteria, gram-negative bacteria express lipopolysaccharide (LPS) which confers resistance against hydrophobic compounds such as bile salts. Bile salts can act as detergents by solublizing the membrane proteins and lead to the destruction of the cell. Although LPS can provide advantage to bacterial cells during their passage through the small intestine of warm-blooded animals, they can be destroyed in the presence of high concentration of bile. According to Rhoades and Tanner (1995), a normal human liver secretes 600 to $1,200 \mathrm{ml}$ of bile per day into the duodenum. Bile is composed of bile salts, bile pigments, cholesterol, phospholipids and proteins and it is synthesized in the liver from cholesterol and bile acids. There are several reports on bacterial tolerance to the bile salts including adaptation to lethal concentrations of bile salts leading to a significant cross-protection towards heat shock (Christopher et al., 1982; Flahaut et al., 1996). Flahaut et al. (1996) described that pretreatment with bile salts can result in the induction of a subset of heat-shock proteins. These proteins may have a role in the observed crossprotection effect. Heat and bile salt shock can lead to the formation of proteins that help to protect the bacterial cell against external stress factors. Pace et al. (1997) described that low 
levels of bile might be important in regulating bacterial physiology and it may facilitate the host-pathogen interaction. It has been shown that bile can expedite growth of nutrientdeprived Vibrio parahaemolyticus and enhance its virulence, size of capsule and adherence to epithelial cells. Culturing of Campylobacter with bile may increase its capability to adhere and invade epithelial cells (Pace et al., 1997). Comparing the incidence of $C$. jejuni in the viscera, gallbladder and bile of broiler chickens, the liver was the organ of choice for Campylobacter infection (Carvalho et al. 1997). Although, the frequency of C. jejuni in the bile was low (6.9\%), it may indicate that Campylobacter can survive and maybe multiply in high concentrations of bile. In line with this suggestion is the fact that $21 \%$ of the bile samples from chickens contained Campylobacter spp. (cited by Carvalho et al., 1997).

\subsection{Animal models}

The mechanisms by which Campylobacter jejuni induces disease in human beings remain unknown. Therefore, there is a need of an appropriate animal model to identify virulence factors of Campylobacter jejuni. Laboratory mice are not naturally colonized with $C$. jejuni. This may be due to competition with enteropathogenic Helicobacter species, which have been recognized as murine commensals and pathogens (Fox et al., 1997). However, mice and rats have been used in various experiments involving C. jejuni, because of their defined microbial flora, and prescribed genetic traits (Migaki and Capen, 1984). Also, genetically manipulated mice offer a unique opportunity to study the influence of host genotype on the expression of the disease (Kaufmann, 1994; Kaufmann and Ladel, 1994). With a few exceptions, oral infection of mice with $C$. jejuni results in intestinal colonization and in some cases bacteremia, but usually does not cause clinical diarrhea (Abimiku and Dolby. 1988; Abimiku and Borriello, 1989; Blaser et al., 1983; Field et al., 1981). Pretreatment with oral antibiotics can prolong colonization. The mouse model also has highlighted the essential role of the bacterial flagella for colonization of the intestinal mucosa (Morooka and amako, 1985; Newwell et al., 1985). More recently, mutation in the C. jejuni cell-binding factor, PEB1a, was shown to significantly reduce the rate and duration of colonization of mice by C. jejuni 81-176. Since most of the strains of mice can be experimentally colonized by C. jejuni, they have been used in a number of studies (Abimiku and Dolby, 1988, Abimiko et al., 1989). Identification of bacterial factors 
important for the colonization of chickens may lead to the development of targeted intervention strategies to reduce contamination of the food chain by this pathogen. However, so far, the value of models of avian colonization to investigate human infection is not established. Comparison of animal models of the two related pathogens C. jejuni and Helicobacter pylori has been quite informative. Although faced with similar problems, acceptable animal models of several disease manifestations of $H$. pylori infection are now available. This experience suggests that appropriate models of campylobacteriosis can in principle be developed in the future.

\subsection{Genetics of $C$. jejuni and gene manipulation.}

It has been recently reported that $C$. jejuni has a circular chromosome of 1,641,481 base pairs $(30.6 \% \mathrm{G}+\mathrm{C})$ which is predicted to encode 1,654 proteins and 54 stable RNA species. The genome of $C$. jejuni was found to be unusual because there are virtually no insertional sequences and very few repeated sequences with an additional surprising feature of harbouring hypervariable sequences. These short homopolymeric runs of nucleotides are present in genes which are responsible for encoding the biosynthesis or modification of surface structures or in closely linked genes of unknown function. Availability of sequence data of the Campylobacter jejuni NCTC11168 genome now offer enormous opportunities to understand the molecular basis of virulence of this important pathogen. Post-genome analysis proposes that 24 hypervariable sequences mostly found in genes encoding surface structures may play a key role in enabling $C$. jejuni to evade the host immune response. Additionally three sialylation pathways were identified which may have a significant role in pathogenesis (Taylor, 1992).

Conjugative plasmids encoding $\mathrm{Cm}^{\mathrm{r}}, \mathrm{Km}^{\mathrm{r}}$, and/or $\mathrm{Tc}^{\mathrm{r}}$ are found more frequently in C. coli strains than in C. jejuni strains. These plasmids usually range in size from 45 to $50 \mathrm{~kb}$ with a $\mathrm{G}+\mathrm{C}$ content of $31-33 \mathrm{~mol} \%$, or being approximately equivalent to those of the host species. Some of these plasmids were sequenced and analysed for their role in virulence but in most of the cases only restriction maps of $\mathrm{Tc}^{\mathrm{r}}$ and $\mathrm{Km}^{\mathrm{r}}$ plasmids have been constructed. It has been described that their host range was strictly restricted to closely related Campylobacter species and that plasmid transfer frequencies can range from about $1 \times 10^{-5}$ to $1 \times 10^{-3}$ transconjugants per recipient cell in a $24 \mathrm{~h}$ mating period. Wang and Taylor 
(1990) observed that both C. coli and C. jejuni strains could take up DNA without any special treatment. Previously reported natural transformation frequencies were approximately $1 \times 10^{-3}$ transformants per recipient cell for C. coli and $1 \times 10^{-4}$ transformants per recipient cell for C. jejuni (Konkel et al., 2001). The incubation of DNA with DNaseI prevents transformation. However, no corelation between extracellular DNase production by Campylobacter recipient strains and its capacity to take-up foreign DNA has been found. Reported data suggest that cross-species transformation can occur between $C$. jejuni and C. coli. However, transformation of Campylobacter with plasmid DNA is much less efficient than with chromosomal DNA. There is evidence that small plasmids transform C. coli UA585 at a frequency 1,000-fold lower than that of chromosomal DNA markers (Wang and Taylor, 1990). Campylobacter spp. appears to tolerate exposure to high-voltage electric fields without any difficulty. Although C. jejuni NCTC1168 and other strains have been successfully electro-transformed, some other strains of $C$. jejuni and $C$. coli are not proven to be efficient strains in electroporation studies (Yan et al., 1990).

The first shuttle vector to be constructed for E. coli to Campylobacter transfer was pILL550, which conferred resistance to kanamycin in both Campylobacter and E. coli (Labigne-Roussel, 1987). The vector pILL550 contains an origin of replication derived from the C. coli plasmid piP445 that functions in both Campylobacter species and in E. coli. The presence of an oriT sequence from the IncPa plasmid RK2 facilitates the vector to be mobilized by a transfer-competent P-group plasmid into Campylobacter species. After pILL550 several more shuttle vectors were constructed and the similar strategy devised by Labigne-Roussel has been used (Vieira and Messing, 1982).

Various antibiotic resistance determinants, $\mathrm{Cm}^{\mathrm{r}}, \mathrm{Km}^{\mathrm{r}}$, and $\mathrm{Tc}^{\mathrm{r}}$ which consist of the cat, $a p h A-3$, and $\operatorname{tet}(\mathrm{O})$ genes, respectively, are used as plasmid selection markers in Campylobacter. Previously, C. jejuni were inactivated by shuttle transposon mutagenesis (Labigne-Roussel et al., 1988; Wang et al., 1991). The same strategy has been used to inactivate flagellar genes in both C. jejuni and C. coli (Guerry et al., 1991; Wassenaar et al., 1991). Some plasmids that replicate only in Campylobacter have also been constructed (Wang and Taylor, 1990). 


\section{Aims of the study}

Despite its well known importance as a human pathogen and the recent completion of its genome sequence, the pathogenesis of campylobacteriosis is poorly understood. This relative paucity of the understanding of Campylobacter pathogenesis is partly due to the fact that systems of experimental genetics are still in the phase of development for Campylobacter jejuni and C. coli. Standard genetic techniques developed for the Enterobacteriaceae have faced considerable obstacles to be successfully adapted for campylobacters. E. coli plasmids, even from broad-host range compatibility groups, fail to replicate in Campylobacter. Another problem is the unavailability of established high throughput methods for the efficient generation of random mutants. Signature-tagged mutagenesis (STM) is a high throughput method and has been used to identify genes involved in pathogenicity of different bacteria (Hensel and Holden, 1996). However, the lack of an in-vivo transposon mutagenesis method for the efficient generation of random mutants of Campylobacter spp. has restricted molecular genetic studies. Previous efforts to generate mutants have mainly relied on shuttle mutagenesis and homologous recombination (Bleumink-Pluym et al., 1999; Labigne-Roussel et al., 1988; Yao et al., 1994). An in-vivo transposition system based on the Himar1 transposable element has also been reported (Golden et al., 2000). However, the weakness of this system is unavoidable restriction of the suicide vector, which severely affects its efficiency and raises questions about its use as a high throughput method to generate random mutants of $C$. jejuni.

Considering the limitations of previously described methods for the identification of the putative virulence factors of Campylobacter jejuni, we sought to develop an efficient system for the in-vivo transposition of the C. jejuni genome, using an aphA-3 gene as an antibiotic marker. The Tn5 transposon has been used for the insertion mutagenesis of a variety of gram-negative bacteria and $\mathrm{Tn} 5$ is one of the intensively studied transposons. Therefore, the EZ::TN transposase, a well characterized bacterial transposase for transposon delivery, was applied in this study as a tool to generate mutants of $C$. jejuni. The structure and mechanism of action for this enzyme have been well elaborated for both wild and mutant types. It is known that in contrast to the wild-type transposases, hyperactive Tn5 mutant transposase (Tn5p) exhibits high transposition efficiency in-vitro. The production of DNA: transposase complexes with the transposase protein that is able to bind 
to both ends of transposon DNA has already been reported (Goryshin et al., 2003). Such complexes are known as transposomes and are formed by the protein binding to specific 19-bp recognition Mosaic End (ME) sequences of the transposon in the absence of $\mathrm{Mg}^{2+}$ ions. The activity of the transposome is dependent on $\mathrm{Mg}^{2+}$, therefore, after the electroporation, the transposase becomes activated in the presence of cellular $\mathrm{Mg}^{2+}$ levels and ultimately integrates the transposon DNA into a random position in the bacterial chromosomes (Goryshin et al., 2003). We therefore, sought to develop a transposon mutagenesis system based on Tn5 transposons to generate randomly knocked-out mutants of Campylobacter jejuni. In addition, we evaluated the principle feasibility and effectiveness of this method to design a signature- tagged mutagenesis study for the identification of putative virulence genes of $C$. jejuni. Furthermore, for the in-vivo screening of mutants, we ought to optimize BALB/c mice as a screening model.

Taken together, the prime objective of this study was to develop an efficient method to generate random mutants of $C$. jejuni and to optimize an in-vivo screening model to initiate a signature tagged mutagenesis study for the identification of putative virulence genes of $C$. jejuni. 


\section{Materials and Methods}

\subsection{Materials}

\subsubsection{Equipment}

\section{Equipment}

Agarose gel electrophoresis chambers

Balances

Bio safety cabin

Centrifuges

Electro Cell Manipulator

Zeiss energy filtering Cryo-elecron

microscope

Gel documentation system

Homogenizer with glass pestle

Hybridization oven

Light microscope

Magnet bars

$\mathrm{pH}-$ Meter

Photometer

Pipet-aid

Pipettes

Power supply

Semi-Dry blotter

Shaking incubator

Thermocycler

Thermomixer

UV-Crosslinker

UV-Table

Water bath

\section{Model and manufacturer}

Keutz Labortechnik, Reiskirchen

BP 221 S, Sartorius, Göttingen

LP6200 S, Sartorius, Göttingen

BDK und Luft Reinraumtechnik, GmbH

Megafuge 2.0 RS, Heraeus, Hanau

Modell 5417 R, Eppendorf, Hamburg

Modell 5417 C, Eppendorf, Hamburg

BTX ECM600, San Diego, California

Zeiss EM 902 Göttingen

BioDoc II, Biometra, Göttingen

Schütt Labortechnik GmbH, Göttingen

Modell OV5, Biometra, Göttingen

Olympus BH-2, Japan

RCT basic, IKA Labortechnik, Staufen

Modell 766 Calimatic, Knick, Berlin

Ultraspec 1000, Pharmacia Biotech, Freiburg

Hirschmann Laborgeräte, Eberstadt

Modell Research, Eppendorf, Hamburg

EPS 600, Pharmacia Biotech, Freiburg

Standard Power Pack P25, Biometra, Göttingen

Sartorius, Göttingen

SM-30 Control, Johanna Otto GmbH, Hechingen

Modell T3, Biometra, Göttingen

Modell Compact, Eppendorf, Hamburg

UVC-500, Hoefer, San Francisco, CA, USA

TFX-20M, Gibco BRL, Eggenstein

Rottberg, Laborgeräte Glasapparatebau

Göttingen 
2.1.2 Bacterial cell culture media and additives

\subsubsection{Bacterial cell culture media}

Name

Mueller Hinton Agar

Columbia Agar base

Brain Heart Infusion

Sheep blood

Luria Bertani Broth (LB)

$1 \%$ Bacto-Trypton

$0.5 \%$ Bacto-yeast extract

$0.5 \% \mathrm{NaCl}$

\subsubsection{Antibiotics (Dics)}

Antibiotic

Ampicillin

Tetracycline

Kanamycin

Ciprofloxacin

Gentamicin

Chloramphenicol

\subsubsection{Antibiotics (powder)}

Antibiotic

Chloramphenicol

Kanamycin

Tetracycline
Source

Oxoid

Merck

Bacto $^{\mathrm{TM}}$

Oxoid

\author{
LB-Plates \\ $0.5 \%$ Bacto-yeast extract \\ 0.1\% Bacto-Trypton \\ $1 \% \mathrm{NaCl}$ \\ 1.5\% Agar (Difco, Detroit, USA)
}

\section{Source}

Oxoid

Oxoid

Oxoid

Oxoid

Oxoid

Oxoid
Source

Sigma

Sigma

Sigma 


\subsubsection{Chemicals and reagents}

Unless otherwise specified, chemicals and solutions were purchased from Boehringer (Mannheim), Calbiochem (Bad Soden), Merck (Darmstadt), Roth (Karlsruhe), or Sigma

(Deisenhofen). In routine, all solutions were prepared by using double distilled water.

\section{Kits and reagents}

DNA Cloning Kits

TOPO TA Cloning Kit

Invitrogen, Karlsruhe

QIAGEN PCR Cloning Kit

Qiagen, Hilden

\section{Plasmid-DNA Isolation Kits}

GenElute Plasmid Mini Prep Kit

Sigma-Aldrich, Deisenhofen

GeneElute Plasmid Maxi Prep Kit

Sigma-Aldrich, Deisenhofen

DNA Isolation from Agarose Gels

QIAEX II Gel Extraction Kit

Qiagen, Hilden

DNA Purification

QIAquick PCR Purification Kit

Qiagen, Hilden

\section{Genomic DNA Isolation}

Qiagen genomic DNA isolation Kit

Qiagen, Hilden

\subsubsection{DNA Standards}

100 bp-DNA Ladder

MBI Fermentas, St. Leon-Rot

1031, 900, 800, 700, 600, 500, 400, 300,

200, 100, $80 \mathrm{bp}$

$1 \mathrm{~kb}$ Ladder

MBI MBI Fermentas, St. Leon-Rot

10000, 8000, 6000, 5000, 4000, 3500, 3000,

2500, 2000, 1500, 1000, 750, 500, 250 bp 


\subsubsection{Membranes and filters}

Nitrocellulose membrane

Hybond P (Amersham Biosciences)

Nylon membrane

Hybond P (Amersham Biosciences)

\subsubsection{Enzymes}

Quick T4 DNA Ligase

Proteinase K

KOD DNA-polymerase

Taq DNA-Polymerase

Restriction endonucleases

Shrimp Alkaline Posphatase

RNase A

\subsubsection{Bacterial strains}

\section{Bacterial Strains \\ Campylobacter jejuni}

E. coli

E. coli

\section{Specification}

NCTC11168

NCTC 11828

81-176

480

B2

DH5 $\alpha$

DH10B

DH10BpACYC184
New England Biolabs, Schwalbach

Roth, Karlsruhe

Novagen, Darmstadt

Roche, Mannheim

New England Biolabs, Schwalbach

Boehringer Mannheim

Sigma-Aldrich, Deisenhofen

\section{Source}

Dr. A. Karlyshev

Prof. M. Kist, Freiburg

Prof. M. Kist, Freiburg

Prof. M. Kist, Freiburg

University Hospital, Göttingen

Invitrogen

Invitrogen

Prof. Jorge E. Galan, USA 


\subsubsection{Vectors}

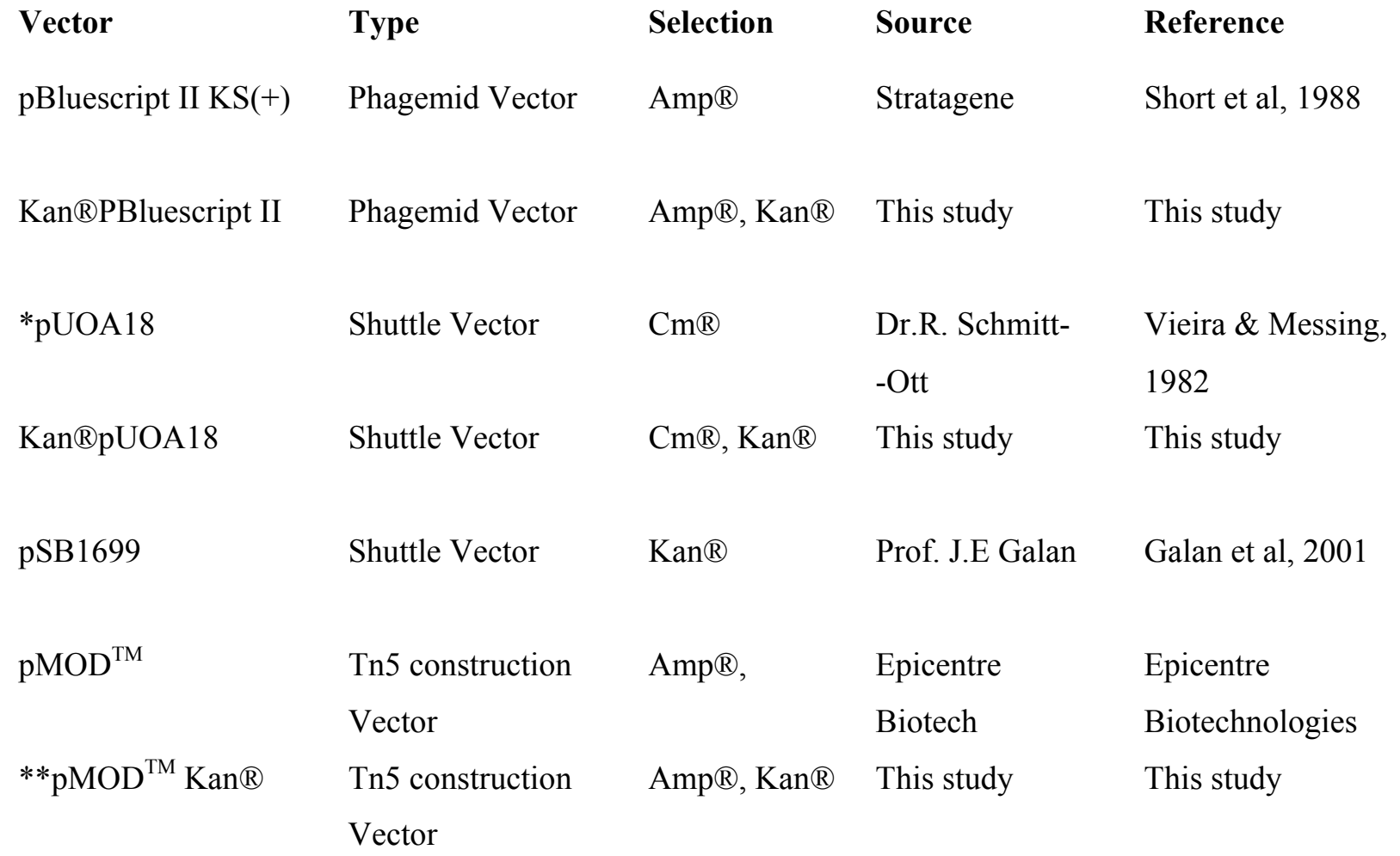

* This plasmid contains an origin of replication derived from the C. coli plasmid piP445 and functions both in Campylobacter species and E. coli.

** Transposon Construction Vectors $\mathrm{pMOD}^{\mathrm{TM}}-3<\mathrm{MCS}>$ replicates in standard E. coli strains using a colE1 origin of replication for rescue cloning applications. Transposons made with the pMOD ${ }^{\mathrm{TM}}$ $3<\mathrm{R} 6 \mathrm{~K}$ yori/MCS $>$ vector also have an R6Kyori within the transposon. After cloning of aphA-3gene in this vector it was named as $\mathrm{pMOD}^{\mathrm{TM}} \mathrm{Kan}{ }^{\circledR}$. 


\subsubsection{Oligonucleotide Primers}

Table 2.1: $\underline{\text { Oligonucleotide } K a n \circledR ~ p r i m e r s}$ were used as reverse primers to amplify a DNA fragment sized $1.8 \mathrm{~kb}$ including the kanamycin resistance gene ( $a p h A-3)$ tagged with 20 to $25 \mathrm{bp}$ variable DNA sequences (underlined in the table) and at the 5'site of each tag, a restriction digestion site GGGGTAC for KpnI restriction endonuclease was added to facilitate cloning into the $\mathrm{pMOD}^{\mathrm{TM}}$ vector. Primer Kan®FT3 (5'AGGGGAGAGAGAGAGGAAGG-3') was used as a forward primer and PBS_Kan® vector as a template for the polymerase chain reaction.

\begin{tabular}{|c|c|}
\hline 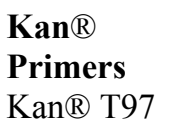 & GGGGTACCAGCGTACGCGGCGTCATGGGAACCCAGCGAACCATTTGAG \\
\hline Kan ${ }^{\circ} \mathrm{T} 106$ & GGGGTACCGTCGCACGTTCTGCTGGTATGAACCCAGCGAACCATTTGAG \\
\hline 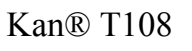 & GGGGTACCTCGCATCTTGTCATATAGGCAACCCAGCGAACCATTTGAGG \\
\hline Kan® T111 & GGGGTACCGATAGGCTTATATGCGTGCTAACCCAGCGAACCATTTGAGG \\
\hline $\operatorname{Kan}{ }^{\circledR} \mathrm{T} 112$ & GGGGTACCTACGGATCTCTGTGAAGTTAGTGCAACCCAGCGAACCATTTGAGG \\
\hline $\operatorname{Kan} \circledast \mathrm{T} 113$ & GGGGTACCTACGGCCAGATTCGAGAGGTCTATAACCCAGCGAACCATTTGAGG \\
\hline Kan® T116 & GGGGTACCTACGGTCGCCTATTCTCATGTCAGAACCCAGCGAACCATTTGAGG \\
\hline $\mathrm{Kan} 囚 \mathrm{~T} 117$ & GGGGTACCTACGGATAACGATGGGTGCAATCTAACCCAGCGAACCATTTGAGG \\
\hline Kan ${ }^{\circledR} \mathrm{T} 119$ & GGGGTACCTACGGCCTGTAATGGTGGATCTCAAACCCAGCGAACCATTTGAGG \\
\hline Kan $\mathbb{R} 124$ & GGGGTACCGTACGCTGTCAACTGTACTGTCATCACCCAGCGAACCATTTGAGG \\
\hline $\operatorname{Kan}{ }^{\circledR} \mathrm{T} 126$ & GGGGTACCGTACGGTGCCGTATGTGTTAATGCAACCCAGCGAACCATTTGAGG \\
\hline $\operatorname{Kan}{ }^{\circledR} \mathrm{T} 127$ & GGGGTACCGTACGCGGATCTATGGCATCTACTGACCCAGCGAACCATTTGAGG \\
\hline Kan® T129 & GGGGTACCGTACGTCGTGCAATTTAGAGGTGTCACCCAGCGAACCATTTGAGG \\
\hline Kan ${ }^{\circledR} \mathrm{T} 133$ & GGGGTACCTACGCCAATAGGTGCTCACGTCATAACCCAGCGAACCATTTGAGG \\
\hline Kan® T135 & GGGGTACCTACGTAGCAGTCTTGGCATACATGAACCCAGCGAACCATTTGAGG \\
\hline $\operatorname{Kan}{ }^{\circledR} \mathrm{T} 136$ & GGGGTACCTACGCTGTGACTGACTGTAGCTCTAACCCAGCGAACCATTTGAGG \\
\hline Kan ${ }^{\circledR} \mathrm{T} 139$ & GGGGTACCTACGGATATGCGTTACGTGAGTCTAACCCAGCGAACCATTTGAGG \\
\hline $\operatorname{Kan}(\mathrm{T} 141$ & GGGGTACCTACGTCCCAGAATTGTCAGCGATTAACCCAGCGAACCATTTGAGG \\
\hline $\operatorname{Kan}{ }^{\circledR} \mathrm{T} 142$ & GGGGTACCTACGCCAATAGTGATGAGTCGCCTAACCCAGCGAACCATTTGAGG \\
\hline Kan ${ }^{\circledR} \mathrm{T} 143$ & GGGGTACCTACGGATCTCGATTATGCTCAAGGAACCCAGCGAACCATTTGAGG \\
\hline $\operatorname{Kan}{ }^{\circledR} \mathrm{T} 144$ & GGGGTACCTACGCTGTCAGATTAGTGAGCATGAACCCAGCGAACCATTTGAGG \\
\hline Kan $® 145$ & GGGGTACCTACGCTGGCTCTGGATCTAGTCTCAACCCAGCGAACCATTTGAGG \\
\hline $\operatorname{Kan}{ }^{\circledR} \mathrm{T} 147$ & GGGGTACCTACGTTGGCAGATTTGGTATGCACAACCCAGCGAACCATTTGAGG \\
\hline Kan® T150 & GGGGTACCTACGATCCAGCATCTCGGGTACTGAACCCAGCGAACCATTTGAGG \\
\hline $\operatorname{Kan}{ }^{\circledR} \mathrm{T} 152$ & GGGGTACCTACGCATGAGAGTGCGGCTAACTAAACCCAGCGAACCATTTGAGG \\
\hline 155 & ACCTCAACCCAGCGAACCATTTGAGG \\
\hline
\end{tabular}


Kan® T156 GGGGTACCTACGTATAGCAATTCGGTATGCGGAACCCAGCGAACCATTTGAGG

Kan® T165 GGGGTACCTACGCACACGGCTGGAGAGCATATAACCCAGCGAACCATTTGAGG

Kan® T167 GGGGTACCTACGCGCATACGTGTGGACTGATAAACCCAGCGAACCATTTGAGG

Kan® T169 GGGGTACCTACGATCTGGCACTGACTCTCAATAACCCAGCGAACCATTTGAGG

Kan® T171 GGGGTACCTACGTGCCAGAGTTTCAGCTTCTCAACCCAGCGAACCATTTGAGG

Kan® T175 GGGGTACCTACGGTGCGTCCTTCTGCAATCTGAACCCAGCGAACCATTTGAGG

Kan ${ }^{\circledR}$ T181 GGGGTACCTACGAAGAGAGCTGAATCACGTCTAACCCAGCGAACCATTTGAGG

Kan® T182 GGGGTACCTACGATCATGTCAAGATCAGTGGGAACCCAGCGAACCATTTGAGG

Kan® T183 GGGGTACCTACGGAAACACTTATCAGATCGCGAACCCAGCGAACCATTTGAGG

Kan ${ }^{\circledR}$ T184 GGGGTACCTACGGCTGCATATTCGTAACCATGAACCCAGCGAACCATTTGAGG

Kan® T186 GGGGTACCTACGATCTCCACTGCATCAGGTGAAACCCAGCGAACCATTTGAGG

Kan® T189 GGGGTACCTACGTATATTAAGTGCTGTGGCGCAACCCAGCGAACCATTTGAGG

Kan® T190 GGGGTACCTACGCAGACGTATCTCTTGTTGCAAACCCAGCGAACCATTTGAGG

Kan®T192 GGGGTACCTACGCTGTCATCTCTGTCAATGGAAACCCAGCGAACCATTTGAGG

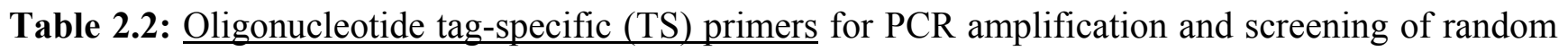
mutants of $C$. jejuni in the pool. Each primer sequence written in the table corresponds to a specific variable tag attached with the kanamycin resistance gene aphA-3.

\begin{tabular}{|c|c|}
\hline Primer & Sequence $5^{\prime}$ to $3^{\prime}$ \\
\hline Kan ${ }^{\circledR T S 97}$ & AGCGTACGCGGCGTCATGGGCAT \\
\hline $\operatorname{Kan}{ }^{\circledR} \mathrm{TS} 106$ & GTCGCACGTTCTGCTGGTATGCAT \\
\hline $\operatorname{Kan}{ }^{\circledR} \mathrm{TS} 108$ & TCGCATCTTGTCATATAGGC \\
\hline $\operatorname{Kan}{ }^{\circledR} \mathrm{TS} 111$ & GATAGGCTTATATGCGTGCT \\
\hline $\operatorname{Kan}{ }^{\circledR} \mathrm{TS} 112$ & TACGGATCTCTGTGAAGTTAGTGC \\
\hline $\operatorname{Kan}{ }^{\circledR T S} 113$ & TACGGCCAGATTCGAGAGGTCTAT \\
\hline $\operatorname{Kan}{ }^{\circledR} \mathrm{TS} 116$ & TACGGTCGCCTATTCTCATGTCAG \\
\hline $\operatorname{Kan}{ }^{\circledR} \mathrm{TS} 117$ & TACGGATAACGATGGGTGCAATCT \\
\hline $\operatorname{Kan}{ }^{\circledR} \mathrm{TS} 119$ & TACGGCCTGTAATGGTGGATCTCA \\
\hline $\operatorname{Kan}{ }^{\circledR T S} 124$ & GTACGCTGTCAACTGTACTGTCATC \\
\hline $\operatorname{Kan}{ }^{\circledR T S} 126$ & GTACGGTGCCGTATGTGTTAATGCA \\
\hline $\operatorname{Kan}{ }^{\circledR} \mathrm{TS} 127$ & GTACGCGGATCTATGGCATCTACTG \\
\hline $\operatorname{Kan} \circledast \mathrm{TS} 129$ & GTACGTCGTGCAATTTAGAGGTGTC \\
\hline $\operatorname{Kan}{ }^{\circledR T S} 133$ & TACGCCAATAGGTGCTCACGTCAT \\
\hline $\operatorname{Kan}{ }^{\circledR} \mathrm{TS} 135$ & TACGTAGCAGTCTTGGCATACATG \\
\hline Kan®TS137 & TACGCTGTGACTGACTGTAGCTCT \\
\hline
\end{tabular}




\begin{tabular}{|c|c|}
\hline Kan ${ }^{\circledR T S 139}$ & TACGGATATGCGTTACGTGAGTCT \\
\hline Kan $\circledast \mathrm{TS} 141$ & TACGTCCCAGAATTGTCAGCGATT \\
\hline Kan ${ } \mathrm{TS} 142$ & TACGCCAATAGTGATGAGTCGCCT \\
\hline Kan $® \mathrm{TS} 143$ & TACGGATCTCGATTATGCTCAAGG \\
\hline Kan $® T S 144$ & TACGCTGTCAGATTAGTGAGCATG \\
\hline $\operatorname{Kan}{ } \mathrm{TS} 145$ & TACGCTGGCTCTGGATCTAGTCTC \\
\hline Kan ${ }^{\circledR T S} 147$ & TACGTTGGCAGATTTGGTATGCAC \\
\hline Kan ${ }^{2} \mathrm{TS} 150$ & TACGATCCAGCATCTCGGGTACTG \\
\hline Kan $® \mathrm{TS} 152$ & TACGCATGAGAGTGCGGCTAACTA \\
\hline $\operatorname{Kan}{ }^{\circledR T S} 155$ & TACGAGCAGAGATGGACAGACCTC \\
\hline Kan $® \mathrm{TS} 156$ & TACGTATAGCAATTCGGTATGCGG \\
\hline Kan $® T S 165$ & TACGCACACGGCTGGAGAGCATAT \\
\hline Kan ${ }^{\circledR T S} 167$ & TACGCGCATACGTGTGGACTGATA \\
\hline Kan ${ }^{2}$ TS169 & TACGATCTGGCACTGACTCTCAAT \\
\hline $\operatorname{Kan}{ }^{\circledR T S} 171$ & TACGTGCCAGAGTTTCAGCTTCTC \\
\hline Kan $® \mathrm{TS} 175$ & TACGGTGCGTCCTTCTGCAATCTG \\
\hline $\operatorname{Kan} \circledast \mathrm{TS} 181$ & TACGAAGAGAGCTGAATCACGTCT \\
\hline $\operatorname{Kan}{ }^{\circledR} T S 182$ & TACGATCATGTCAAGATCAGTGGG \\
\hline $\operatorname{Kan}{ }^{\circledR} T S 183$ & TACGGAAACACTTATCAGATCGCG \\
\hline Kan®TS184 & TACGGCTGCATATTCGTAACCATG \\
\hline $\operatorname{Kan} \circledast \mathrm{TS} 186$ & TACGATCTCCACTGCATCAGGTGA \\
\hline $\operatorname{Kan}{ }^{\circledR} \mathrm{TS} 189$ & TACGTATATTAAGTGCTGTGGCGC \\
\hline $\operatorname{Kan}{ }^{\circledR} \mathrm{TS} 190$ & TACGCAGACGTATCTCTTGTTGCA \\
\hline $\operatorname{Kan}{ }^{\circledR} \mathrm{TS} 192$ & TACGCTGTCATCTCTGTCAATGGA \\
\hline
\end{tabular}

Table 2.3: Oligonucleotide primers used for the amplification and sequencing of particular genes mentioned in the table.

$\begin{array}{ll}\text { Name } & \text { Location } \\ \text { SBF } & \text { Tn55 in pBS1699 plasmid } \\ \text { SBR } & \text { Tn55 in pBS1699 plasmid } \\ \text { JA4 } & \text { aphA-3 Kan }{ }^{\circ} \text { gene } \\ \text { JA5 } & \text { aphA-3 Kan }{ }^{\circledR} \text { gene } \\ \text { TetF } & \text { tetO gene } \\ \text { TetR } & \text { tetO gene } \\ \text { HIPF } & \text { hipO gene of } C \text {. jejuni }\end{array}$

$\begin{array}{ll}\text { Sequence } \mathbf{5}^{\prime} \text { to } \mathbf{3} & \text { Size } \\ \text { ACCGAGGTATGAAAACGAG } & 1.7 \mathrm{~kb} \\ \text { TATATCAAGTAAAGTAACAAA } & 1.7 \mathrm{~kb} \\ \text { TAATAAATGGCTAAAATGAGAATA } & 574 \mathrm{bp} \\ \text { TCGCCGTGGGAAAAGACAA } & 574 \mathrm{bp} \\ \text { TTGCCAATGGTATATCGGGAA } & 530 \mathrm{bp} \\ \text { TGCGGGGGTACTTACACGACT } & 530 \mathrm{bp} \\ \text { GAA GAG GGT TTG GGTGGT } & 735 \mathrm{bp}\end{array}$




$\begin{array}{ll}\text { HIPR } & \text { hipO gene of } C \text {. jejuni } \\ \text { CCF } & \text { aspA gene of } C \text {. jejuni } \\ \text { CCR } & \text { aspA gene of } C \text {. jejuni } \\ \text { SekanF } & a p h A-3 \mathrm{Kan} \AA \text { gene } \\ \text { SekanR } & a p h A-3 \mathrm{Kan}{ }^{\circledR} \text { gene }\end{array}$

$\begin{array}{ll}\text { AGC TAGCTTCGCATAATAACTTG } & 735 \mathrm{bp} \\ \text { GGT ATG ATT TCT ACAAAGCGA } & 583 \mathrm{bp} \\ \text { ATA AAA GAC TAT CGT CGC GTG } & 583 \mathrm{bp} \\ \text { TATCACCTCAAATGGTTCGCTGGG } & 200 \mathrm{bp} \\ \text { GGGGATCAAGCCTGATTGGGAGA } & 200 \mathrm{bp}\end{array}$

Table 2.4 Oligonucleotide primers used to confirm a recovered pool of mutants during the in-vivo screen in BALB/c mice. Each primer sequence can bind specifically with a variable DNA tag present in the transposon.

\begin{tabular}{|c|c|}
\hline Primer Name & Sequence $5^{\prime}$ to $3^{\prime}$ \\
\hline $\operatorname{Kan}{ }^{\circledR T S} 106$ & GTCGCACGTTCTGCTGGTATGCAT \\
\hline Kan ${ }^{\circledR T S 108}$ & TCGCATCTTGTCATATAGGC \\
\hline $\operatorname{Kan}{ }^{\circledR T S} 111$ & GATAGGCTTATATGCGTGCT \\
\hline $\operatorname{Kan}{ }^{\circledR T S} 112$ & TACGGATCTCTGTGAAGTTAGTGC \\
\hline Kan ${ }^{\circledR T S} 113$ & TACGGCCAGATTCGAGAGGTCTAT \\
\hline Kan ${ }^{\circledR T S} 116$ & TACGGTCGCCTATTCTCATGTCAG \\
\hline Kan ${ }^{\circledR T S} 117$ & TACGGATAACGATGGGTGCAATCT \\
\hline $\operatorname{Kan}{ }^{\circledR T S} 141$ & TACGTCCCAGAATTGTCAGCGATT \\
\hline Kan ${ }^{\circledR T S 142}$ & TACGCCAATAGTGATGAGTCGCCT \\
\hline $\operatorname{Kan}{ }^{\circledR T S} 144$ & TACGCTGTCAGATTAGTGAGCATG \\
\hline $\operatorname{Kan}{ }^{\circledR} \mathrm{TS} 145$ & TACGCTGGCTCTGGATCTAGTCTC \\
\hline $\operatorname{Kan}{ }^{\circledR} \mathrm{TS} 150$ & TACGATCCAGCATCTCGGGTACTG \\
\hline
\end{tabular}




\subsection{Methods}

\subsubsection{Media and growth conditions}

Campylobacter strains were cultured on Columbia agar base (Merck) supplemented with $5 \%$ sheep blood (BA), polymyxin B $(2.5 \mathrm{IU} / \mathrm{ml})$, trimethoprim $(5 \mu \mathrm{g} / \mathrm{ml})$, and vancomycin $10 \mu \mathrm{g} / \mathrm{ml}$ and incubated at $42^{\circ} \mathrm{C}$ under microaerophilic conditions $\left(5 \% \mathrm{O}_{2}, 10 \% \mathrm{CO}_{2}, 85 \%\right.$ $\mathrm{N}_{2}$ ) for 48 hours. For broth culturing of C. jejuni, Mueller Hinton $(\mathrm{MH})$ and Brain heart infusion (BHI) broth have been used throughout this study. Microaerophilic conditions were generated using the BBL CampyPak Plus (Becton Dickinson), gas pack in an enclosed chamber or by inflating plastic sealed bags with a gas mixture containing $85 \% \mathrm{~N}_{2}$, $10 \% \mathrm{CO}_{2}$ and $5 \% \mathrm{O}_{2}$. For the selection of $C$. jejuni mutants, antibiotics were used in the following concentrations: kanamycin, $50 \mu \mathrm{g} / \mathrm{ml}$; chloramphenicol, $20 \mu \mathrm{g} / \mathrm{ml}$. All C. jejuni strains were stored at $-80^{\circ} \mathrm{C}$ in $\mathrm{MH}$ broth containing $15 \%$ glycerol. E. coli $\mathrm{DH} 5 \alpha$ was grown in Luria-Bertani (LB) agar or broth. For E. coli, antibiotics were used in the following concentrations: ampicillin, $100 \mu \mathrm{g} / \mathrm{ml}$; kanamycin, $50 \mu \mathrm{g} / \mathrm{ml}$; and chloramphenicol, $30 \mu \mathrm{g} / \mathrm{ml}$. All E. coli strains were stored at $-80^{\circ} \mathrm{C}$ in LB containing $20 \%$ glycerol. Mueller Hinton agar supplemented with 5\% sheep blood (BA) with different tetracycline concentrations was used for determination of MICs.

\subsubsection{Biochemical and molecular characterization of strains}

\subsubsection{Biochemical characterization}

All Campylobacter strains used in this study were biochemically differentiated at species level by gram stain, oxidase and catalase activities, hippurate hydrolysis, hydrogen sulfide production and susceptibility to nalidixic acid by using a commercially available species differentiation kit (API CAMPY, bioMérieux, Marcy-l'Etoile, France).

\subsubsection{Genomic and plasmid DNA preparation}

Small-scale genomic DNA preparation was done by the CTAB (hexadecyltrimethyl ammonium bromide) genomic DNA isolation method. A lawn culture on Columbia blood agar plates was flooded with $3 \mathrm{ml}$ of physiological $0.9 \% \mathrm{NaCl}$ and $1.5 \mathrm{ml}$ of cells was centrifuged for $2.5 \mathrm{~min}$ at 14,000 g (Eppendorf 5417R) at room temperature. The pellet was resuspended by vortexing in $567 \mu$ l of TE buffer ( $\mathrm{pH} 7.4$ ), with $30 \mu 1$ of $10 \%$ SDS and $6 \mu 1$ 
of $10 \mathrm{mg} / \mathrm{ml}$ proteinase $\mathrm{K}$ (QIAGEN), mixed, and incubated for an hour at $37^{\circ} \mathrm{C}$. Subsequently, $100 \mu 1$ of $5 \mathrm{M} \mathrm{NaCl}$ and $80 \mu \mathrm{CTAB} / \mathrm{NaCl}$ solution were added and mixed thoroughly by vortexing, and incubated for an hour at $65^{\circ} \mathrm{C}$. DNA was extracted with chloroform, isoamylalcohol (24:1). DNA precipitation was done by an equal volume of ice cold isopropanol and pelleted by centrifugation for $10 \mathrm{~min}$ at $14,000 \mathrm{~g}$ at room temperature. DNA pellets were washed with $1 \mathrm{ml} 70 \%$ ethanol and resuspended in $50 \mu 1$ of sterile water and stored at $-20^{\circ} \mathrm{C}$. Plasmid DNA from Campylobacter isolates was purified from an overnight culture on blood agar by using mini-Qiagen columns (Qiagen, Hilden, Germany) as proposed by the manufacturer.

\subsubsection{Quantification of DNA}

DNA concentrations were determined by measuring the absorbance at $260 \mathrm{~nm}\left(\mathrm{~A}_{260}\right)$ in an Eppendorf spectrophotometer. DNA concentrations were quantified based on the formula that an absorbance of 1 unit at $260 \mathrm{~nm}$ corresponds to $50 \mu \mathrm{g}$ DNA per ml. To confirm the concentration of the DNA, $5 \mu 1$ of each sample was migrated on agarose gel with $10 \mu 1$ of 1 $\mathrm{kb}$ DNA ladder, the concentration of the DNA was estimated by comparing intensities of the bands on agarose between the sample and the bands of the ladder.

\subsubsection{PCR and Southern blot analysis of the hipO gene}

Campylobacter lab strains and clinical isolates were analyzed for the presence of the hipO gene. The primer pair used for detection of the hipO gene consisted of HIP400F and HIP1134R (Table 2.3). The expected amplified product size was 735bp. The PCR reaction mixture consisted of 1x PCR buffer for Taq polymerase (Roche Diagnostics, Mannheim, Germany); 1ng of C. jejuni genomic DNA, $200 \mu \mathrm{M}$ each of dATP, dCTP, dGTP and dTTP; $0.4 \mu \mathrm{M}$ each primer and $1 \mathrm{U}$ of Taq polymerase. PCR parameters were initial denaturation at $94^{\circ} \mathrm{C}$ for $30 \mathrm{~s}$, annealing at $58^{\circ} \mathrm{C}$ for $1 \mathrm{~min}$ and extension at $72^{\circ} \mathrm{C}$ for $2 \mathrm{~min}$ for 40 cycles. Final extension was done at $72^{\circ} \mathrm{C}$ for $10 \mathrm{~min}$. The presence of the hipO gene in isolates lacking biochemical hippurate hydrolase activity was confirmed by Southern blot analysis. By using the above mentioned primer pair, an amplified PCR product was labelled with digoxigenin 11-UTP (Roche Diagnostics, Mannheim, Germany) and was used as a probe to hybridize with BglII-digested genomic DNA of Campylobacter isolates. DNA was blotted onto a nitrocellulose membrane (Optitran BA-S 85, Schleicher and Schuell, Dassel, 
Germany). Solutions and conditions were used according to the standard protocol (Sambrook and Russell, 2001). Hybridization was performed at $42^{\circ} \mathrm{C}$ for $18 \mathrm{~h}$. Washings for membranes were carried out at $65^{\circ} \mathrm{C}$ twice in $2 \mathrm{x} \mathrm{SSC}, 0.5 \% \mathrm{SDS}$ for $15 \mathrm{~min}$ at $37^{\circ} \mathrm{C}$ and in $0.1 \mathrm{x} \mathrm{SSC}, 0.5 \% \mathrm{SDS}$ for $30 \mathrm{~min}$. Digoxigenin was detected with specific peroxidase-labelled antibodies using the ECL ${ }^{\mathrm{TM}}$ analysis system (Amersham Pharmacia Biotech, Freiburg, Germany) according to the recommendations of the supplier. Hippurate hydrolase negative isolates were confirmed as Campylobacter coli by a PCR method (data not shown). Genomic DNA was isolated by the CTAB (hexadecyltrimethyl ammonium bromide) method and a set of a previously reported primer pair was used to amplify a 583 bp fragment of the aspartokinase gene (Linton et al., 1997).

\subsubsection{Drug resistance of Campylobacter isolates}

\subsubsection{Antibiotic resistance and tetracycline MICs determination.}

For the drug resistance study, Campylobacter strains were initially tested for resistance to ampicillin, ciprofloxacin, erythromycin, gentamicin and tetracycline by a disc-diffusion method. A slightly turbid bacterial suspension by emulsifying colonial growth in $5 \mathrm{ml}$ sterile water was prepeared. A swab was charged with the water suspension and this was dispersed over the surface of a blood agar plate to produce a lawn of confluent bacteria. Sterile tweezers were used to place a disc on the surface of the agar plate after ensuring that the discs were widely spaced. The plates were incubated in a microaerophilic atmosphere at $37^{\circ} \mathrm{C}$ for $24-48 \mathrm{~h}$. The bacterial growth zones of inhibition were examined around the antibiotic discs. A zone of inhibition indicated either sensitivity (S) or resistance (R) of the isolate to a particular antibiotic (Gaudreau and Gilbert, 1997). The minimal inhibitory concentration of tetracycline was subsequently determined by an agar dilution method according to the recommendations of the Clinical and Laboratory Standards Institute (CLSI, formerly NCCLS) guidelines (NCCLS, 1997; CLSI, 2006). Mueller-Hinton blood agar supplemented with tetracycline concentrations of $4,8,16,32,64,128$ and $256 \mu \mathrm{g} / \mathrm{ml}$

were inoculated with $1 \mu \mathrm{l}$ of $(\mathrm{BHI})$ containing $1-2 \times 10^{7}$ bacteria and incubated at $37^{\circ} \mathrm{C}$ under microaerophilic conditions for 40-48h. Two C. jejuni tetracycline resistant and one C. jejuni strain known to be tetracycline susceptible (MIC $4 \mu \mathrm{g} / \mathrm{ml}$ ) were used as controls. 
Each experiment was conducted in triplicate. The lowest concentration of the antimicrobial agent that produced no visible growth was considered as MIC for the relative isolate.

\subsubsection{Detection and localisation of the $\operatorname{tet}(\mathrm{O})$ gene in $C$. coli isolates}

The presence of the tet $(\mathrm{O})$ gene in tetracycline-resistant $C$. coli isolates was confirmed by a tet $(\mathrm{O})$-specific $\mathrm{PCR}$. The primer pair used for amplification of the tet $(\mathrm{O})$ gene was $\mathrm{TetF}$ and TetR (Table 2.3). The PCR conditions were as follows: an initial melting temperature $94{ }^{\circ} \mathrm{C}$ for $1 \mathrm{~min}$, annealing at $55^{\circ} \mathrm{C}$ for $30 \mathrm{~s}$, extension at $72{ }^{\circ} \mathrm{C}$ for $2 \mathrm{~min}$, and a final extension at $72{ }^{\circ} \mathrm{C}$ for $10 \mathrm{~min}$. Southern blot analysis was performed to determine the tet(O) localisation. DNA probes were generated and labelled with digoxigenin-11-dUTP (Roche Diagnostics, Mannheim, Germany) by PCR using the same primer pair. Plasmid pCjA13 carrying the tet $(\mathrm{O})$ gene was used as a template for this PCR reaction The generated probes were hybridised with the HindIII-digested C. coli plasmids. DNA was then blotted onto nitrocellulose membranes (Optitran BA-S 85, Schleicher and Schuell, Dassel, Germany) and detection of the tet(O) gene was performed with a specific peroxidase-labelled antibody using the ECL ${ }^{\mathrm{TM}}$ analysis system (Amersham Pharmacia Biotech, Freiburg, Germany). Hybridization was performed at $42^{\circ} \mathrm{C}$ for $18 \mathrm{~h}$. Washings of the membranes were carried out at $65^{\circ} \mathrm{C}$ twice in $2 \mathrm{x} \mathrm{SSC}, 0.5 \% \mathrm{SDS}$ for $15 \mathrm{~min}$ at $37^{\circ} \mathrm{C}$ and in $0.1 \mathrm{xSC}, 0.5 \% \mathrm{SDS}$ for $30 \mathrm{~min}$.

\subsection{Genetic modification of Campylobacter jejuni}

\subsubsection{Construction of EZ::TN transposon elements}

The kanamycin resistance gene aphA-3 originated from Campylobacter coli is able to confer the respective resistance in C. jejuni. The EZ::TN transposon construction system (Epicenter) was used to construct a EZ::TNkan ${ }^{\circledR}$ transposon element. The plasmid PSB1699, bearing kanamycin resistance gene aphA-3, was kindly provided by Jorge E. Galan from Yale University. The aphA-3 gene was sub-cloned into BamHI digested pBluescript SKII plasmid (Stratagene), which resulted in the pBSK_Kan plasmid (Fig. 2.1). 

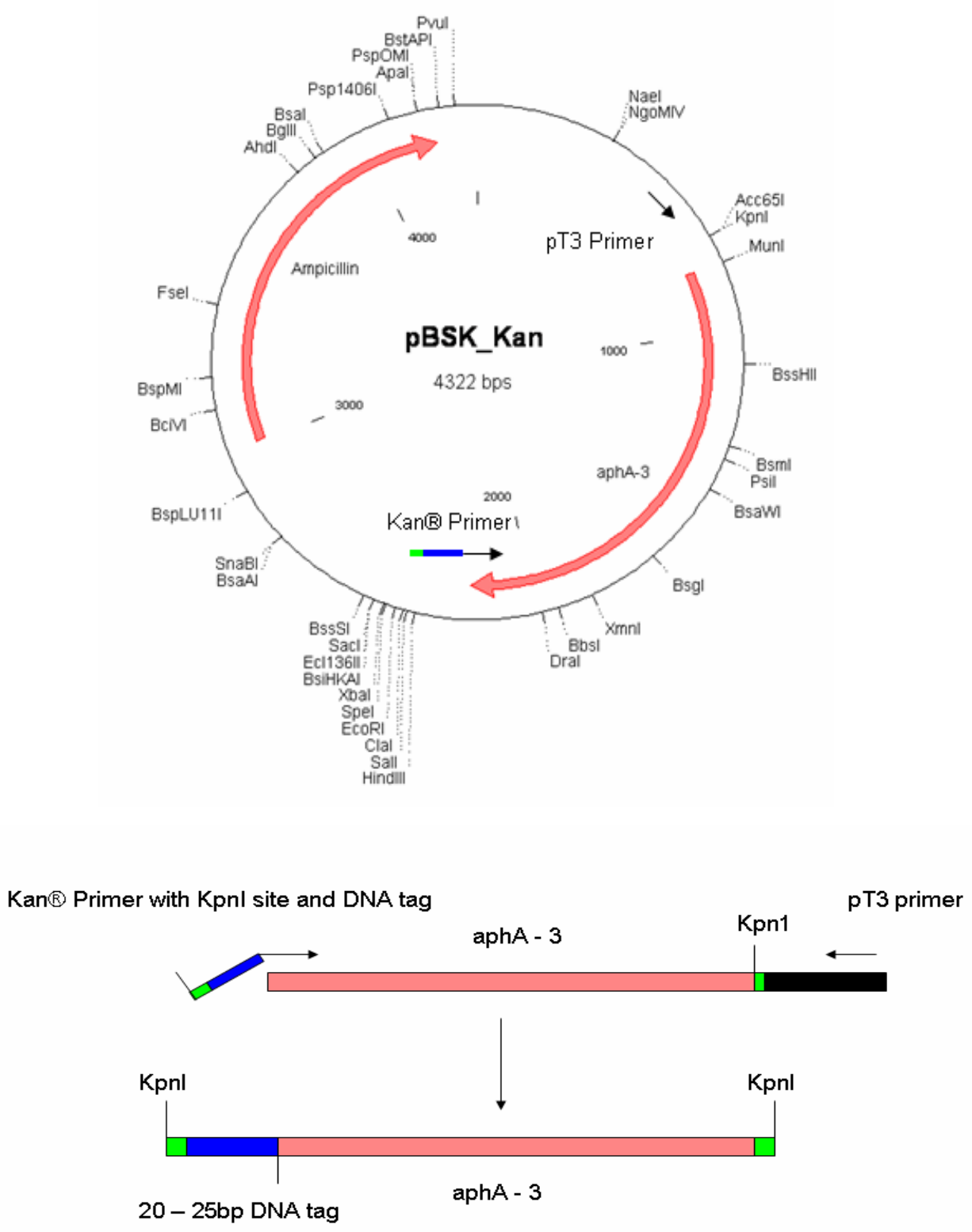

Figure 2.1: pBSK_Kan contains the T3 and T7 bacteriophage promoters. Kanamycin resistance cassette aphA-3 was subcloned into a BamHI restriction site of the vector and pT3 and $\mathrm{Kan}{ }^{\circledR}$ primers were used to amplify a $1.8 \mathrm{~kb}$ tagged aphA-3 gene.

The plasmid pBSK_kan served as a template for a PCR reaction designed to tag the aphA-3 gene by using $\mathrm{Kan}{ }^{\circledR}$ primers (Table. 2.1). Each $\mathrm{Kan}{ }^{\circledR}$ primer contained a 20 to $25 \mathrm{bp}$ variable DNA tag named "signature tag", a primer binding site for the $a p h A-3$ gene and a 
Kpn1 restriction. The tag sequences were chosen from those previously reported to work well in similar experiments (http://www.lshtm.ac.uk/itd/units/pmbbu/karlyshev/tags.htm accessed on October 21, 2003). By using the plasmid pBSK_Kan as a template, a PCR was carried out to amplify a $1.8 \mathrm{~kb}$ DNA fragment by using the T7 primer of pBluescript SKII plasmid and a $\mathrm{Kan}{ }^{\circledR}$ primer (Fig. 2.1). The PCR conditions were as follows: an initial melting temperature of $95^{\circ} \mathrm{C}$ for $1 \mathrm{~min}$, annealing at $58{ }^{\circ} \mathrm{C}$ for $30 \mathrm{~s}$, extension at $72^{\circ} \mathrm{C}$ for 2 min and a final extension at $72^{\circ} \mathrm{C}$ for $10 \mathrm{~min}$ for 40 cycles.

The kanamycin resistance gene (aphA-3) was tagged with 40 variable DNA signatures and the DNA fragments of the aphA-3 gene were subcloned into KpnI-digested transposon construction vector EZ::TN pMOD ${ }^{\mathrm{TM}}$. Prior to ligation, EZ::TN pMOD ${ }^{\mathrm{TM}}$ was dephosphorylated by using shrimp alkaline phosphatase and gel-purified with the QIAGEN Gel purification kit. DNA concentrations were estimated by measuring the absorbance at $260 \mathrm{~nm}\left(\mathrm{~A}_{260}\right)$ in an eppendorf spectrophotometer and also verified by loading $5 \mu 1$ from each sample DNA on agarose gel. The concentrations and sizes of DNAs were estimated by comparing intensities of bands of known DNA concentrations and sizes, DNA fragments were ligated into EZ::TN pMOD ${ }^{\mathrm{TM}}$ vector which resulted inEZ::TN pMOD ${ }^{\mathrm{TM}}$ Kan ${ }^{\circledR}$ (Fig. 2.2). 


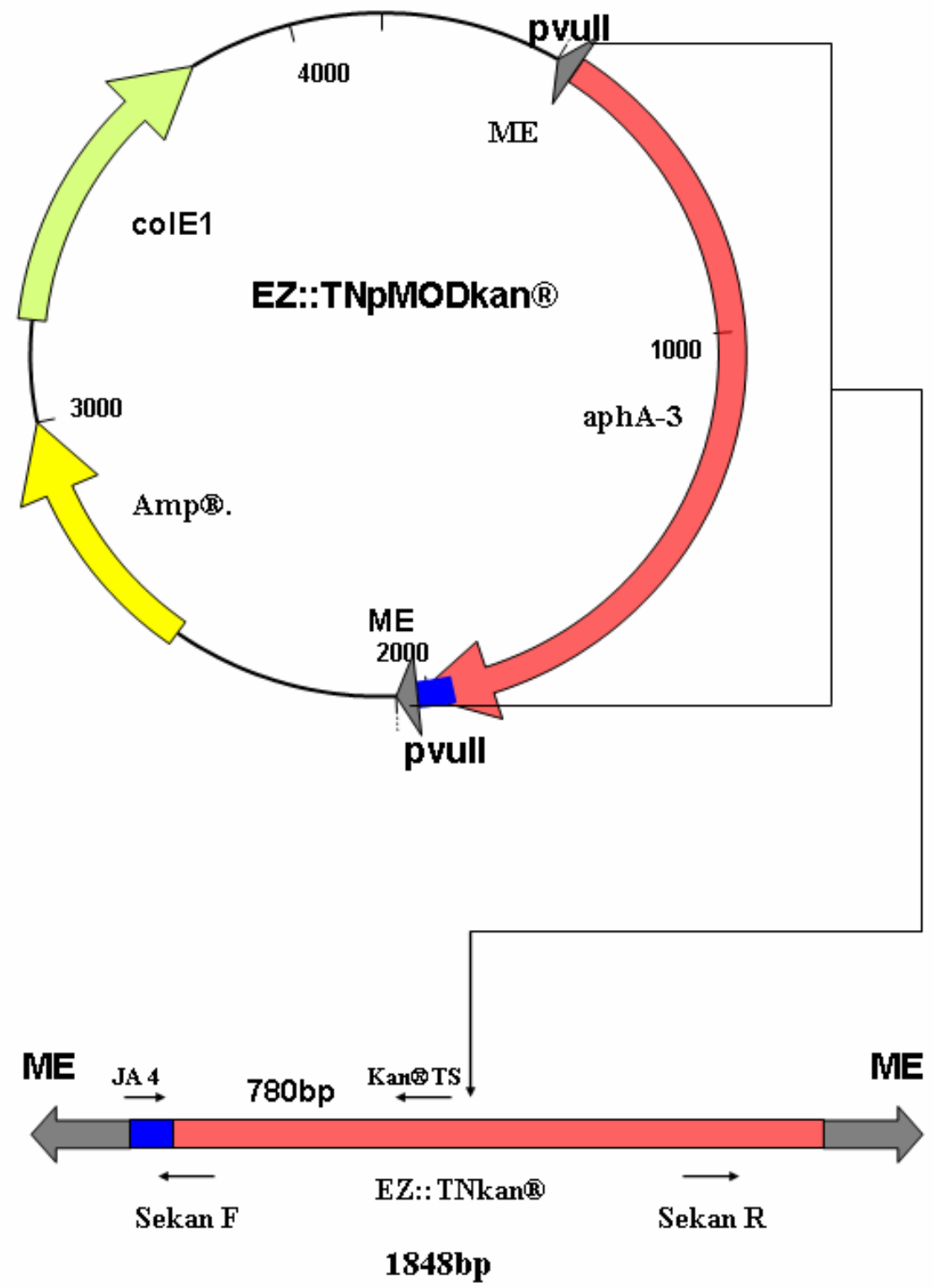

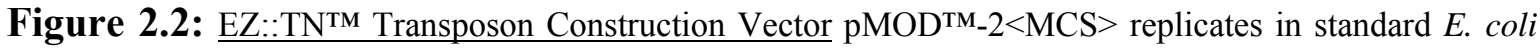
strains using a colE1 origin of replication. EZ::TNkan ${ }^{\circledR}$ transposons were constructed by subcloning the tagged aphA-3 gene (shown in red) in pMOD $^{\mathrm{TM}}-2$. Also shown are the primers used for tag-specific PCR (JA4 and kan ${ }^{\circledR T S}$ see table 2.2) and those used for sequencing of the regions flanking transposon insertion sites (SekanF and SekanR). ME represent mosaic ends of the transposon. 


\subsubsection{Competent cells of $E$. coli and $C$. jejuni for electro-transformation}

A single fresh colony of E. coli DH5 $\alpha$ was inoculated into $20 \mathrm{ml} \mathrm{LB}$ medium and placed at $37^{\circ} \mathrm{C}$ with a shaking speed $250 \mathrm{rpm}$. Then, $10 \mathrm{ml}$ of the culture was diluted in one liter of pre-warmed LB medium and was left on the shaker at $37^{\circ} \mathrm{C}$ until O.D. $600=0.5-0.8$ was reached. The culture was transferred into $50 \mathrm{ml}$ Falcon centrifuge tubes and was chilled for 15 minutes. After chilling, the tubes were centrifuged for 15 minutes at $4000 \times \mathrm{g}$ at $4^{\circ} \mathrm{C}$ in a pre-cooled centrifuge (Megafuge 2.0 RS, Heraeus, Hanau). Cell pellets were gently resuspended in ice-cooled water and centrifuged for 15 minutes. The same step was repeated twice. Cell pellets were again gently resuspended in $20 \mathrm{ml} \mathrm{10 \%} \mathrm{glycerol} \mathrm{and}$ centrifuged as in previous steps. Finally, all pellets were carefully resuspended to a final volume of $2-3 \mathrm{ml}$ in $10 \%$ glycerol. Cells were stored as aliquots $(50 \mu \mathrm{l} /$ tube $)$ at $-80^{\circ} \mathrm{C}$. For the production of competent cells of C. jejuni, a lawn culture on Columbia blood agar plates was flooded with $1 \mathrm{ml} \mathrm{MH}$ broth per plate. Subsequently, this was centrifuged for $5 \mathrm{~min}$ at $>10,000 \times \mathrm{g}$ at $4^{\circ} \mathrm{C}$ in a tabletop centrifuge (Eppendorf 5417R). Pellets were gently resuspended in $1 \mathrm{ml}$ of ice cold wash buffer (272mM Sucrose, 15\% Glycerol) and washed thrice by centrifuging at $>10,000 \times \mathrm{g}$ at $4^{\circ} \mathrm{C}$. After the last washing, the pellet was resuspended in $500 \mu 1$ of ice cold washing buffer and $50 \mu 1$ aliquots of cells were stored at $80^{\circ} \mathrm{C}$. All the steps of this procedure were performed on ice.

\subsubsection{Electroporation}

Freshly made competent cells were used for all electroporations. Forty microliter of competent cells were pipetted into ice cold sterile $0.5 \mathrm{ml}$ microfuge tubes. An appropriate number of bacterial electroporation cuvettes were kept with the cells on ice. 10pg to 20ng of the DNA needed to be electroporated was added in a volume of $1-2 \mu 1$ to each microfuge tube and the tube was incubated on ice for 30-60 seconds. All appropriate positive and negative controls were included. The electroporation apparatus was set to deliver an electrical pulse of $25 \mathrm{uF}$ capacitance, $2.5 \mathrm{KV}$ and $200 \mathrm{Ohm}$ resistance. The DNA cell mixture was pipetted into a cold electroporation cuvette and the cuvette was placed in the electroporation device. A pulse of electricity was delivered to the cells at the setting described above. A time constant of 4-5 milliseconds was registered each time. After the pulse, the electroporation cuvette was immediately removed and $1 \mathrm{ml}$ of SOC medium was 
added. The cells were transferred to a $17 \times 150 \mathrm{~mm}$ polypropylene tube and were incubated with gentle rotation for 1 hour at $37^{\circ} \mathrm{C}$. Then, different volumes (up to $200 \mu$ ) of the electroporated cells were plated onto LB agar containing kanamycin $(50 \mu \mathrm{g} / \mathrm{ml})$. Finally, the plates were incubated at $37^{\circ} \mathrm{C}$ in inverted positions. After 16 hours, transformed colonies were observed.

\subsubsection{Amplification of the transposons}

For screening purpose, a single colony was picked from each plate by using a sterile pipette tip. All picked colonies were inoculated into $5 \mathrm{ml} \mathrm{LB}$ broth with $50 \mu \mathrm{g} / \mathrm{ml}$ kanamycin in a 15 $\mathrm{ml}$ tube. The cultures were kept on a shaker for overnight at $37^{\circ} \mathrm{C}$ and were used for plasmid preparation by using mini-Qiagen columns (Qiagen, Hilden, Germany). The isolated plasmids (EZ::TN pMODkan $\left.{ }^{\circledR}\right)$ were checked for purity and DNA concentrations. Subsequently, restriction digestions were carried out to liberate the transposons by exploiting PvuII restriction sites of the plasmids (EZ::TN pMODkan $\left.{ }^{\circledR}\right)$. Digested plasmids were analyzed for correct sizes of the transposons by visualizing on agarose gel. Five $\mu 1$ of the digested DNA from each reaction were loaded on $0.9 \%$ agarose gel including a positive control and $1 \mathrm{~Kb}$ ladder. One $\mu \mathrm{l}$ of the DNA (EZ::TN pMODkan $\left.{ }^{\circledR}\right)$ from each plasmid preparation was diluted and 5pg of the DNA was used as a template for PCR by using the primer pair FP1 and RP1 provided from epicentre with plasmid EZ::TN pMOD ${ }^{\mathrm{TM}}$. The PCR conditions used for this reaction were an initial melting temperature of $95^{\circ} \mathrm{C}$ for 1 min, annealing at $62^{\circ} \mathrm{C}$ for $30 \mathrm{~s}$, extension at $72^{\circ} \mathrm{C}$ for $2 \mathrm{~min}$ and a final extension at $72^{\circ} \mathrm{C}$ for $10 \mathrm{~min}$. Finally, the transposons were amplified by KOD DNA polymerase under the PCR conditions mentioned above. The PCR products were digested with PvuII restriction endonuclease to liberate $\mathrm{EZ}:: \mathrm{TNkan}{ }^{\circledR}$ transposons from the over hanging DNA sequence of the EZ::TN pMOD ${ }^{\mathrm{TM}}$ vector. All PCR products were analyzed for their sizes on $0.9 \%$ agarose gels by loading $2 \mu \mathrm{l}$ of each sample DNA. The rest of the DNA was loaded on the $0.9 \%$ agarose gel in the absence of ethidium bromide and transposons were gel purified. DNA concentrations of transposon DNAs were quantified and stored at $-20^{\circ} \mathrm{C}$. 


\subsubsection{Cross hybridization of tags}

The presence of 40 "signature tags" in the transposons was verified by a PCR method. Tagspecific primers named as "TS primers" were used to amplify a 780bp DNA fragment. The PCR assay was performed by using a mixture of 39 templates that was prepeared by mixing $1 \mu 1$ (100ng) of each plasmid preparation (EZ::TNpMODKan $\left.{ }^{\circledR}\right)$. Forty different mixtures of templates were prepared and in each mix a template corresponding to a particular tag to be verified for cross hybridization was excluded (Fig. 2.3). The final concentration of the DNA in each mix was adjusted as $1 \mathrm{ng} / \mu 1$. In principle, each template mix could be used for the amplification of one particular signature tag. One micro-litre of each mix was used as a DNA template and forty different PCRs were set to verify cross-hybridization of the "signature tags". This PCR assay provided a chance to every tag-specific primer "TS" to bind with any DNA template but excluded the possibility for binding to its original corresponding DNA template. All the tag-specific primers were designed to have the same annealing temperatures. Therefore, PCR conditions given below were possible for all reactions: 35 cycles of an initial melting temperature of $95^{\circ} \mathrm{C}$ for $1 \mathrm{~min}$, annealing at $58^{\circ} \mathrm{C}$ for $30 \mathrm{~s}$, extension at $72^{\circ} \mathrm{C}$ for $2 \mathrm{~min}$ and a final extension at $72^{\circ} \mathrm{C}$ for $10 \mathrm{~min}$. No cross hybridization of 'signature tags' was detected in this experiment. 


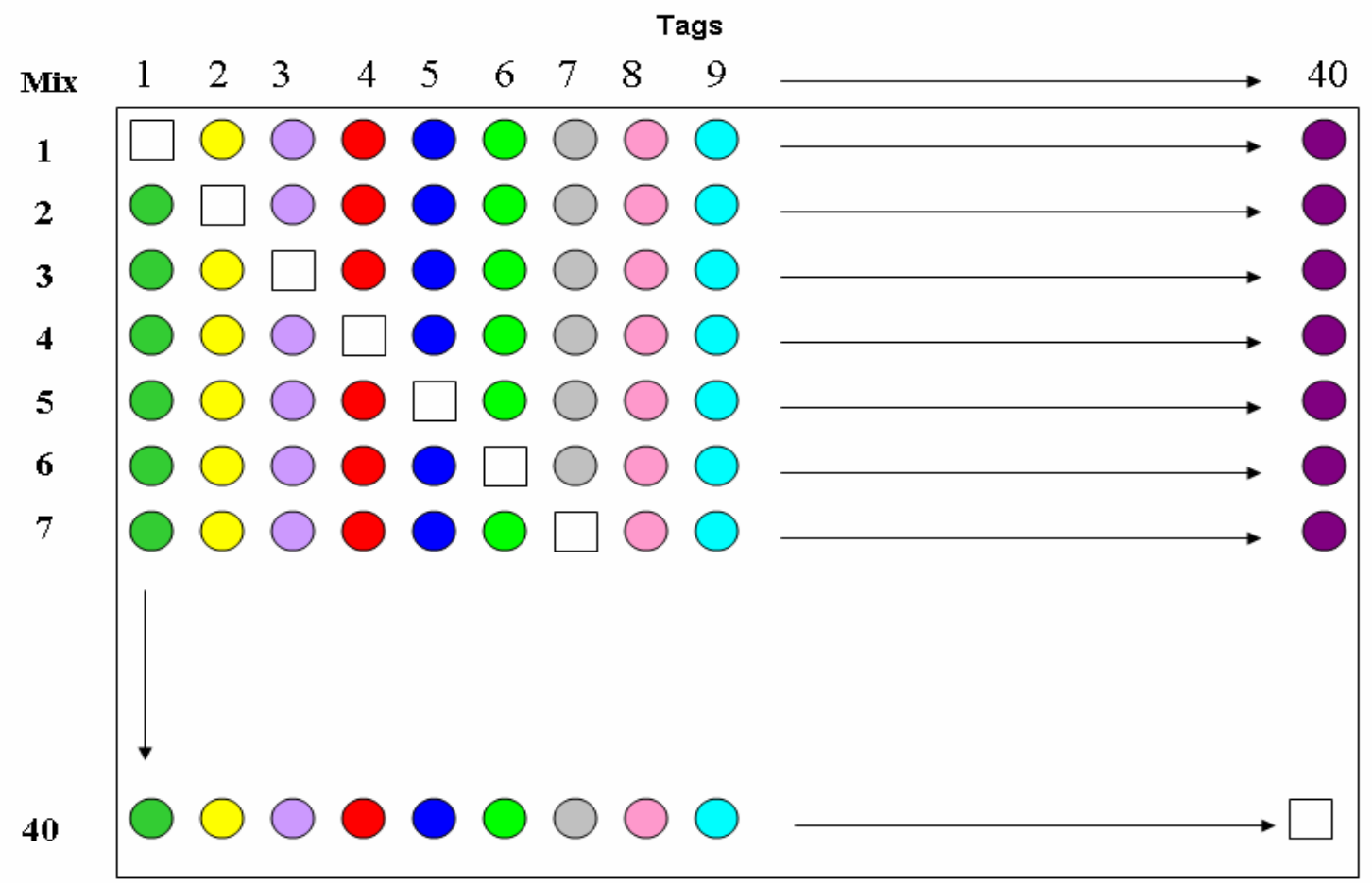

Figure 2.3: Each coloured circle denotes a unique DNA tag, whereas, an entire row represents one DNA template mix used for PCR analysis. Each DNA tag was checked for cross-hybridization by excluding one particular tag in each mix that is represented as white box in the diagram.

\subsubsection{In-vivo transposition}

The transposition reaction was carried out by mixing 100ng agarose gel-purified EZ::TNKan ${ }^{\circledR}$ transposon DNA, $2 \mu 1$ of EZ::TN transposase, $2 \mu 1$ of $100 \%$ glycerol and subsequent incubation for $30 \mathrm{~min}$ at room temperature. The reaction mixture was electroporated into E. coli DH5 $\alpha$ and transposon insertional mutants were selected by plating the transformants on LB agar plates containing $50 \mu \mathrm{g} / \mathrm{ml}$ of kanamycin. For generating random insertion mutants of $C$. jejuni, the transposition reaction was carried out as described above. The reaction mixture was electroporated into C. jejuni B2 strain as previously described and kanamycin-resistant colonies were selected on Columbia blood

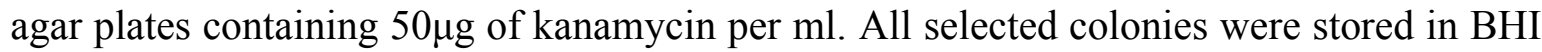
broth with $15 \%$ glycerol in $-80^{\circ} \mathrm{C}$ 


\subsubsection{Verification of randomness of transposon insertions}

The random insertion of transposon $\operatorname{Tn} 5 \mathrm{Kan} \AA$ throughout the $C$. jejuni genome was confirmed by Southern blot analysis of 18 randomly chosen kanamycin insertion mutants. Genomic DNA was prepeared by the CTAB (hexadecyltrimethyl ammonium bromide) genomic DNA isolation method and digested with Bsph1 restriction endonuclease. Then, DNA was blotted onto a nitrocellulose membrane (Optitran BA-S 85, Schleicher and Schuell, Dassel, Germany). Solutions and conditions were used according to the standard protocol (Sambrook and Russell, 2001) and were as mentioned before (2.2.2.4).

\subsection{Screening of $C$. jejuni mutants}

\subsubsection{Sensitivity to sodium chloride and sodium deoxycholate}

Minimum inhibitory concentration of $\mathrm{NaCl}$ for the $C$. jejuni $\mathrm{B} 2$ strain was determined by using the agar dilution method. Bacteria of the B2 and NCTC11168 strains were cultured in Mueller Hinton Broth $(0.5 \% \mathrm{NaCl})$ for 24 hours. OD was set as 1.0 at 550nm wavelengths. After serial dilutions, $100 \mu \mathrm{l}$ of each cell suspension was plated on Columbia blood agar

plates that supplemented with $0,0.5,1.0,1.5,2.0,4.0$, or $6.0 \%(\mathrm{wt} / \mathrm{vol}) \mathrm{NaCl}$. The plates were incubated at $42^{\circ} \mathrm{C}$ in a microaerophilic atmosphere. Duplicate determinations were done for each treatment studied. The same procedure was adopted to determine the MICs and to test the sensitivity of $C$. jejuni mutants for sodium deoxycholate.

\subsubsection{Motility assay}

Transposon mutants were screened for motility by measuring swarming on motility agar plates. Transformants were grown in Mueller Hinton broth and then diluted to an optical density at $600 \mathrm{~nm}\left(\mathrm{OD}_{600}\right)$ of 0.025 . Approximately $1 \mu \mathrm{l}$ of this suspension was stabbed into a $0.4 \% \mathrm{MH}$ agar plate. Plates were incubated in micro-aerobic conditions at $37^{\circ} \mathrm{C}$ for approximately eighteen hours. Control strain NCTC11168 was grown on each plate to monitor plate-to-plate variation. 


\subsubsection{Transmission Electron Microscopy}

Staining with a $3 \%(\mathrm{wt} / \mathrm{vol})$ aqueous solution of phosphotungstic acid $(\mathrm{pH} 7.0)$ or a $4 \%$ $(\mathrm{wt} / \mathrm{vol})$ aqueous solution of uranyl acetate $(\mathrm{pH} 4.5)$ was performed according to the method of Valentine et al (Valentine et al., 1968). Electron micrographs were taken, at calibrated magnifications, with a Zeiss energy filtering Cryo-elecron microscope (Zeiss EM 902) (Zeiss, Germany), equipped with a TRS $1 \mathrm{~K}$ camera and was operated in the conventional bright-field mode. Digital images were acquired by scanning photographs or petri dishes (UMAX Power Look). Image processing, which was limited to cropping, conversion to grayscale, and adjustment of brightness and/or contrast, was done with Photoshop (Adobe, Inc.) software. Image enhancement of flagella was performed by translational analysis (Hoppert and Holzenburg, 1999).

\subsection{In-vivo screening of $C$. jejuni mutants}

\subsubsection{Mice infection assay}

Campylobacter jejuni strains NCTC11168, 81-176, NCTC11828 and the clinical isolate B2 were cultured on Columbia blood agar plates. After 24 hours, the bacteria were harvested in separate culture tubes by using $5 \mathrm{ml}$ of sterile saline and diluted to an OD at $550 \mathrm{~nm}$ $\left(\mathrm{OD}_{500}\right)$ of 0.05 . Subsequently, the suspensions were serially diluted ten-fold and plated onto Columbia blood agar plates. The number of cfu was counted after 24 hours of incubation at $42^{\circ} \mathrm{C}$ in a micro-areophilic atmosphere. Group of three 5 to 6 weeks old female $\mathrm{BALB} / \mathrm{c}$ mice were infected intra-peritoneally with a bacterial suspension containing approximately, $1 \times 10^{8}, 1 \times 10^{9}$ and $1 \times 10^{10} \mathrm{cfu} / 0.2 \mathrm{ml}$. Mice were sacrificed after 7 days post infection. The liver was put into in a $50 \mathrm{ml}$ sterile Falcon tube that contained $5 \mathrm{ml}$ of saline. All tubes containing tissues and saline were weighed and registered. The tissue was homogenized and the mixtures were shifted to a $50 \mathrm{ml}$ sterile Falcon tube and kept on ice for five minutes. From each homogenized mixtures, 1ml was carefully transferred to another sterile tube and centrifuged for 2 minutes at 10,000 rpm. The pellets were resuspended in $1 \mathrm{ml}$ of sterile distilled water. Dilution series were made in sterile distilled water and $100 \mu \mathrm{l}$ of each dilution was plated on Columbia blood agar plates that were kept under microaerophilic conditions. A few colonies were picked and sub- 
cultured on a fresh blood agar plate to perform biochemical and molecular identification for the particular mutant strain. For in-vivo screening of the signature-tagged transposon mutagenized and pooled bacteria, the same procedure was followed. However, in this case, mutants recovered from the liver were plated on Columbia blood agar plates that contained $50 \mu \mathrm{g} / \mathrm{ml}$ of kanamycin. For histopathological examination, fixed liver tissue samples from mice were processed, embedded in paraffin, and sectioned at 5-6 $\mathrm{mm}$ for hematoxylin and eosin (HE) staining. Replicate sections from spleen and liver were Giemsa stained to identify bacteria.

\subsection{Analysis of $\operatorname{Tn} 5$ Kan ${ }^{\circledR}-C a m p y$ insertions}

To determine the precise sites of insertion of selected mutants, genomic DNA from the different $C$. jejuni insertion mutants were prepared by using a genomic DNA preparation kit. Genomic DNA from the mutants was then used as a template in a inverse PCR. Two primers, SekanF and SekanR, that are directed outwards within the aphA-3 cassette, were used to determine the point of insertion of the EZ::TNKan ${ }^{\circledR}$. 


\section{Results}

\subsection{Species identification of thermophilic Campylobacter strains}

Infections caused by $C$. jejuni are highly prevalent in humans and the mechanisms of pathogenesis of the disease are poorly understood. In addition, it is not clear whether certain types of $C$. jejuni strains show a specific preference for particular hosts. Therefore, before initiating a study to explore virulence factor of $C$. jejuni, strain variation was taken into consideration and proper characterization of strains used in the study was carried out. Hippurate hydrolase is an important biochemical test used to differentiate between C. jejuni and other Campylobacter species. We collected eighty-three thermophilic Campylobacter isolates from patients of the University Hospital of Göttingen who suffered from gastroenteritis. The isolates were identified by testing for the presence of the hipO gene by using phenotypic and molecular methods. On the basis of their hippurate hydrolase activity, 67 isolates (81\%) were identified as C. jejuni (Table 3.1).

Table 3.1: Characterization of hippurate hydrolase positive $C$. jejuni isolates

\begin{tabular}{|c|c|c|c|c|c|c|c|c|}
\hline${ }^{\text {a Isolate }}$ & plasmid & tetO & olot & ERY & AMP & TET & CIP & GEN \\
\hline CjA5 & + & + & + & ${ }^{\mathbf{b}} \mathbf{S}$ & ${ }^{{ }^{\mathbf{c}} \mathbf{R}}$ & $\mathbf{R}$ & $\mathbf{R}$ & $\mathbf{S}$ \\
\hline CjB2 & + & + & + & $\mathbf{S}$ & $\mathbf{R}$ & $\mathbf{R}$ & $\mathbf{R}$ & $\mathbf{S}$ \\
\hline CjA9 & + & + & + & $\mathbf{S}$ & $\mathbf{R}$ & $\mathbf{R}$ & $\mathbf{S}$ & $\mathbf{S}$ \\
\hline CjA13 & + & + & + & $\mathbf{S}$ & $\mathbf{R}$ & $\mathbf{R}$ & $\mathbf{S}$ & $\mathbf{S}$ \\
\hline CjA14 & + & + & + & $\mathbf{S}$ & $\mathbf{S}$ & $\mathbf{R}$ & $\mathbf{R}$ & $\mathbf{S}$ \\
\hline CjA6 & + & + & + & $\mathbf{S}$ & $\mathbf{S}$ & $\mathbf{R}$ & $\mathbf{S}$ & $\mathbf{S}$ \\
\hline CjA7 & + & + & + & $\mathbf{S}$ & $\mathbf{S}$ & $\mathbf{R}$ & $\mathbf{S}$ & $\mathbf{S}$ \\
\hline CјA8 & + & - & - & $\mathbf{S}$ & $\mathbf{R}$ & $\mathbf{S}$ & $\mathbf{S}$ & $\mathbf{S}$ \\
\hline CjB3 & + & - & - & $\mathbf{S}$ & $\mathbf{R}$ & $\mathbf{S}$ & $\mathbf{S}$ & $\mathbf{S}$ \\
\hline CjB5 & + & - & - & $\mathbf{S}$ & $\mathbf{R}$ & $\mathbf{S}$ & $\mathbf{S}$ & $\mathbf{S}$ \\
\hline CjB4 & + & - & - & $\mathbf{S}$ & $\mathbf{S}$ & $\mathbf{S}$ & $\mathbf{R}$ & $\mathbf{S}$ \\
\hline CjA4 & + & - & - & $\mathbf{S}$ & $\mathbf{R}$ & $\mathbf{S}$ & $\mathbf{S}$ & $\mathbf{S}$ \\
\hline $\mathrm{CjA22}$ & + & - & - & $\mathbf{S}$ & $\mathbf{S}$ & $\mathbf{S}$ & $\mathbf{R}$ & $\mathbf{S}$ \\
\hline CjB1 & + & - & - & $\mathbf{S}$ & $\mathbf{S}$ & $\mathbf{S}$ & $\mathbf{R}$ & $\mathbf{S}$ \\
\hline CjA15 & - & - & - & $\mathbf{S}$ & $\mathbf{S}$ & $\mathbf{R}$ & $\mathbf{R}$ & $\mathbf{S}$ \\
\hline CjA31 & - & - & - & $\mathbf{S}$ & $\mathbf{R}$ & $\mathbf{S}$ & $\mathbf{R}$ & $\mathbf{S}$ \\
\hline
\end{tabular}




\begin{tabular}{|c|c|c|c|c|c|c|c|}
\hline CjA34 & - & - & - & $\mathbf{S}$ & $\mathbf{R}$ & $\mathrm{S}$ & $\mathbf{R}$ \\
\hline CjB10 & - & - & - & $\mathbf{S}$ & $\mathbf{R}$ & $S$ & $\mathbf{R}$ \\
\hline $\mathrm{CjC} 1$ & - & - & - & $\mathbf{S}$ & $\mathbf{R}$ & 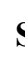 & $\mathbf{R}$ \\
\hline CjA33 & - & - & - & $\mathbf{S}$ & $\mathbf{R}$ & $S$ & $\mathbf{S}$ \\
\hline $\mathbf{C j A 3}$ & - & - & - & $\mathbf{S}$ & $\mathbf{R}$ & $S$ & $\mathbf{R}$ \\
\hline CjA11 & - & - & - & $\mathbf{S}$ & $\mathbf{R}$ & $s$ & $\mathbf{S}$ \\
\hline CjA18 & - & - & - & $\mathbf{S}$ & $\mathbf{R}$ & s & $\mathbf{S}$ \\
\hline $\mathrm{CjA25}$ & - & - & - & $\mathbf{S}$ & $\mathbf{R}$ & S & $\mathbf{S}$ \\
\hline CjA26 & - & - & - & $\mathbf{S}$ & $\mathbf{R}$ & s & $\mathbf{S}$ \\
\hline $\mathrm{CjA28}$ & - & - & - & $\mathbf{S}$ & $\mathbf{R}$ & S & $\mathbf{S}$ \\
\hline CjA29 & - & - & - & $\mathbf{S}$ & $\mathbf{R}$ & s & $\mathbf{S}$ \\
\hline $\mathrm{CjC8}$ & - & - & - & $\mathbf{S}$ & $\mathbf{R}$ & $S$ & $\mathbf{S}$ \\
\hline $\mathrm{CjA2}$ & - & - & - & $\mathbf{S}$ & $\mathbf{R}$ & s & $\mathbf{S}$ \\
\hline CjB6 & - & - & - & $\mathbf{S}$ & $\mathbf{R}$ & S & $\mathbf{S}$ \\
\hline CjB19 & - & - & - & $\mathbf{S}$ & $\mathbf{S}$ & F & $\mathbf{S}$ \\
\hline CjA27 & - & - & - & $\mathbf{S}$ & $\mathbf{S}$ & I & $\mathbf{S}$ \\
\hline CjB8 & - & - & - & $\mathbf{S}$ & $\mathbf{S}$ & F & $\mathbf{S}$ \\
\hline $\mathrm{CjC2}$ & - & - & - & $\mathbf{S}$ & $\mathbf{S}$ & $\mathbf{F}$ & $\mathbf{S}$ \\
\hline CjB9 & - & - & - & $\mathbf{S}$ & $\mathbf{S}$ & s & $\mathbf{R}$ \\
\hline $\mathrm{CjC4}$ & - & - & - & $\mathbf{S}$ & $\mathbf{S}$ & $s$ & $\mathbf{R}$ \\
\hline $\mathrm{CjC13}$ & - & - & - & $\mathbf{S}$ & $\mathbf{S}$ & s & $\mathbf{R}$ \\
\hline CjB20 & - & - & - & $\mathbf{S}$ & $\mathbf{S}$ & S & $\mathbf{R}$ \\
\hline CjA17 & - & - & - & $\mathbf{S}$ & $\mathbf{S}$ & $S$ & $\mathbf{R}$ \\
\hline CjA16 & - & - & - & $\mathbf{S}$ & $\mathbf{S}$ & $S$ & $\mathbf{S}$ \\
\hline CјA19 & - & - & - & $\mathbf{S}$ & $\mathbf{S}$ & $s$ & $\mathbf{S}$ \\
\hline $\mathrm{CjA20}$ & - & - & - & $\mathbf{S}$ & $\mathbf{S}$ & s & $\mathbf{S}$ \\
\hline $\mathrm{CjA21}$ & - & - & - & $\mathbf{S}$ & $\mathbf{S}$ & $S$ & $\mathbf{S}$ \\
\hline $\mathrm{CjA23}$ & - & - & - & $\mathbf{S}$ & $\mathbf{S}$ & $s$ & $\mathbf{S}$ \\
\hline $\mathrm{CjA24}$ & - & - & - & $\mathbf{S}$ & $\mathbf{S}$ & s & $\mathbf{S}$ \\
\hline CjA30 & - & - & - & $\mathbf{S}$ & $\mathbf{S}$ & $s$ & $\mathbf{S}$ \\
\hline CjA32 & - & - & - & $\mathbf{S}$ & $\mathbf{S}$ & s & $\mathbf{S}$ \\
\hline CjA35 & - & - & - & $\mathbf{S}$ & $\mathbf{S}$ & $s$ & $\mathbf{S}$ \\
\hline CjB11 & - & - & - & $\mathbf{S}$ & $\mathbf{S}$ & S & $\mathbf{S}$ \\
\hline CjB12 & - & - & - & $\mathbf{S}$ & $\mathbf{S}$ & $S$ & $\mathbf{S}$ \\
\hline CjB13 & - & - & - & $\mathbf{S}$ & $\mathbf{S}$ & $s$ & $\mathbf{S}$ \\
\hline CjB14 & - & - & - & $\mathbf{S}$ & $\mathbf{S}$ & s & $\mathbf{S}$ \\
\hline CjB15 & - & - & - & $\mathbf{S}$ & $\mathbf{S}$ & $s$ & $\mathbf{S}$ \\
\hline
\end{tabular}




\begin{tabular}{|c|c|c|c|c|c|c|c|}
\hline CjB16 & - & - & - & $\mathbf{S}$ & $\mathbf{S}$ & $\mathbf{S}$ & $\mathbf{S}$ \\
\hline CjB7 & - & - & - & $\mathbf{S}$ & $\mathbf{S}$ & $\mathbf{S}$ & $\mathbf{S}$ \\
\hline CjA10 & - & - & - & $\mathbf{S}$ & $\mathbf{S}$ & $\mathbf{S}$ & $\mathbf{S}$ \\
\hline $\mathrm{CjC3}$ & - & - & - & $\mathbf{S}$ & $\mathbf{S}$ & $\mathbf{S}$ & $\mathbf{S}$ \\
\hline CjC6 & - & - & - & $\mathbf{S}$ & $\mathbf{S}$ & $\mathbf{S}$ & $\mathbf{S}$ \\
\hline $\mathrm{CjC} 7$ & - & - & - & $\mathbf{S}$ & $\mathbf{S}$ & $\mathbf{S}$ & $\mathbf{S}$ \\
\hline CjC9 & - & - & - & $\mathbf{S}$ & $\mathbf{S}$ & $\mathbf{S}$ & $\mathbf{S}$ \\
\hline $\mathrm{CjC10}$ & - & - & - & $\mathbf{S}$ & $\mathbf{S}$ & $\mathbf{S}$ & $\mathbf{S}$ \\
\hline $\mathrm{CjC11}$ & - & - & - & $\mathbf{S}$ & $\mathbf{S}$ & $\mathbf{S}$ & $\mathbf{S}$ \\
\hline $\mathrm{CjC12}$ & - & - & - & $\mathbf{S}$ & $\mathbf{S}$ & $\mathbf{S}$ & $\mathbf{S}$ \\
\hline $\mathrm{CjC} 14$ & - & - & - & $\mathbf{S}$ & $\mathbf{S}$ & $\mathbf{S}$ & $\mathbf{S}$ \\
\hline $\mathrm{CjC} 15$ & - & - & - & $\mathbf{S}$ & $\mathbf{S}$ & $\mathbf{S}$ & $\mathbf{S}$ \\
\hline CjB18 & - & - & - & $\mathbf{S}$ & $\mathbf{S}$ & $\mathbf{S}$ & $\mathbf{S}$ \\
\hline CjB21 & - & - & - & $\mathbf{S}$ & $\mathbf{S}$ & $\mathbf{S}$ & $\mathbf{S}$ \\
\hline
\end{tabular}

Table 3.1: Presence of the tetracycline resistance gene tet $(\mathrm{O})$ was determined by PCR and Southern blot. Antibiotic resistance frequencies of clinical isolates of C. jejuni were determined by agar dilution test. ERY, erythromycin; GEN, gentamicin; AMP ampicillin; CIP, ciprofloxacin; TET, tetracycline. ${ }^{\mathrm{a}} \mathrm{Cj}=$ C. jejuni, ${ }^{\mathrm{b}} \mathrm{S},=$ sensitive ${ }^{\mathrm{c}} \mathrm{R},=$ resistant.

Our data showed that sixteen Campylobacter isolates (19\%) did not show any hippurate hydrolase activity. However, in seven of these hippurate hydrolase-negative isolates, the hipO gene was detected by probing genomic DNA with a digoxigenin-11-dUTP-labelled hipO-probe (Fig 3.1a); these isolates were identified as atypical C. jejuni. In addition, C. coli-specific PCR was used to confirm these isolates. The remaining nine hippurate hydrolase negative isolates were confirmed as C. coli, by a specific PCR (Fig. 3.1b). 
(a)

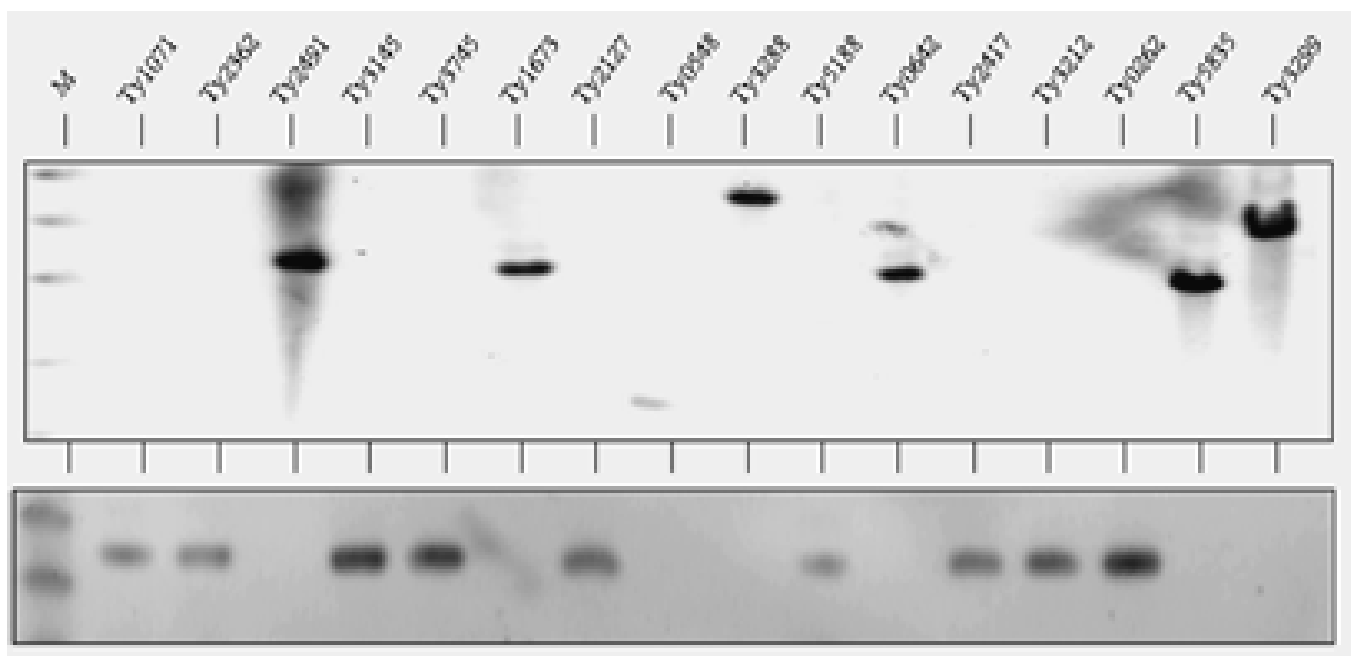

Figure 3.1: Genotypic species differentiation of hippurate hydrolase-negative thermophilic Campylobacter strains. (a) BglII-digested genomic DNA probed with digoxigenin-labelled hipO. (b) C. coli-specific PCR amplification of genomic DNA.

\subsection{Antibiotic resistance and the role of plasmids in $C$. jejuni and $C$. coli}

Tetracycline MICs were determined for those 19 Campylobacter clinical isolates that were initially identified to be tetracycline resistant by the disk diffusion test. Tetracycline MICs ranged from 16 to $256 \mathrm{mg} / \mathrm{L}$. In case of thirteen C. jejuni isolates, MIC was determined as $>256 \mathrm{mg} / \mathrm{L}$ and 6 C. coli isolates had MIC of $16 \mathrm{mg} / \mathrm{L}$ (Table 3.2).

Table 3.2: Characterization of tetracycline-resistant Campylobacter isolates

\begin{tabular}{|c|c|c|c|c|c|c|}
\hline \multirow[b]{2}{*}{ Isolate } & \multirow[b]{2}{*}{ hipO } & \multirow[b]{2}{*}{$\ddagger$ aspA } & \multirow[b]{2}{*}{$\begin{array}{c}{ }^{\dagger} \text { Detectable } \\
\text { plasmids }\end{array}$} & \multirow[b]{2}{*}{ TET ${ }^{\circledR}($ MIC) } & \multicolumn{2}{|c|}{$\operatorname{tet}(0)$} \\
\hline & & & & & PCR & Hybridization \\
\hline *CjA5 & + & $\S \mathrm{Nd}$ & + & $\mathrm{R}(>256 \mu \mathrm{g} / \mathrm{ml})$ & + & Plasmid \\
\hline $\mathrm{CjB2}$ & + & $\mathrm{Nd}$ & + & $\mathrm{R}(>256 \mu \mathrm{g} / \mathrm{ml})$ & + & Plasmid \\
\hline СјA9 & + & $\mathrm{Nd}$ & + & $\mathrm{R}(>256 \mu \mathrm{g} / \mathrm{ml})$ & + & Plasmid \\
\hline CjA13 & + & $\mathrm{Nd}$ & + & $\mathrm{R}(>256 \mu \mathrm{g} / \mathrm{ml})$ & + & Plasmid \\
\hline CjA14 & + & $\mathrm{Nd}$ & + & $\mathrm{R}(>256 \mu \mathrm{g} / \mathrm{ml})$ & + & Plasmid \\
\hline CjA6 & + & $\mathrm{Nd}$ & + & $\mathrm{R}(>256 \mu \mathrm{g} / \mathrm{ml})$ & + & Plasmid \\
\hline $\mathbf{C j A} 7$ & + & $\mathrm{Nd}$ & + & $\mathrm{R}(>256 \mu \mathrm{g} / \mathrm{ml})$ & + & Plasmid \\
\hline CjA15 & + & $\mathrm{Nd}$ & - & $\mathrm{R}(>256 \mu \mathrm{g} / \mathrm{ml})$ & + & Genomic \\
\hline
\end{tabular}




$\begin{array}{ccccccc}\text { CjB19 } & + & \mathrm{Nd} & - & \mathrm{R}(>256 \mu \mathrm{g} / \mathrm{ml}) & + & \text { Genomic } \\ \mathbf{C j A 2 7} & + & \mathrm{Nd} & - & \mathrm{R}(>256 \mu \mathrm{g} / \mathrm{ml}) & + & \text { Genomic } \\ \mathbf{C j B 8} & + & \mathrm{Nd} & - & \mathrm{R}(>256 \mu \mathrm{g} / \mathrm{ml}) & + & \text { Genomic } \\ \mathbf{C j C 2} & + & \mathrm{Nd} & - & \mathrm{R}(>256 \mu \mathrm{g} / \mathrm{ml}) & + & \text { Genomic } \\ \mathbf{C j 3 2 8 8} & + & - & - & \mathrm{R}(>256 \mu \mathrm{g} / \mathrm{ml}) & + & \text { Genomic } \\ \# \mathbf{C c 1 0 7 1} & - & + & + & \mathrm{R}(16 \mu \mathrm{g} / \mathrm{ml}) & + & \text { Genomic } \\ \mathbf{C c 3 7 4 5} & - & + & + & \mathrm{R}(16 \mu \mathrm{g} / \mathrm{ml}) & + & \text { Genomic } \\ \mathbf{C c 2 1 2 7} & - & + & + & \mathrm{R}(16 \mu \mathrm{g} / \mathrm{ml}) & + & \text { Genomic } \\ \mathbf{C c 3 1 4 5} & - & + & - & \mathrm{R}(16 \mu \mathrm{g} / \mathrm{ml}) & + & \text { Genomic } \\ \mathbf{C c 3 2 1 2} & - & + & - & \mathrm{R}(16 \mu \mathrm{g} / \mathrm{ml}) & + & \text { Genomic } \\ \mathbf{C c 0 2 6 2} & - & + & - & \mathrm{R}(16 \mu \mathrm{g} / \mathrm{ml}) & + & \text { Genomic }\end{array}$

${ }^{\dagger}$ The method applied in this study allowed the detection of plasmid sized $1-66 \mathrm{~kb} .{ }^{*} \mathrm{Cj}=C$. jejuni, $\# \mathrm{Cc}=C$. Coli, $\S N d .=$ Data not available, $\$$ Aspartokinase gene of C. coli

The frequency of tetracycline resistance was significantly higher $\left(\chi^{2}\right.$ test: $\left.p<0.001\right)$ in $C$. coli $(67 \%)$ than in C. jejuni (18\%). In both Campylobacter species, the tetracycline resistance was associated with the presence of the tet( $\mathrm{O})$ gene. Plasmids were detected in $23 \%(\mathrm{n}=19)$ of the all Campylobacter isolates.(Fig. 3.2, Fig. 3.4a).

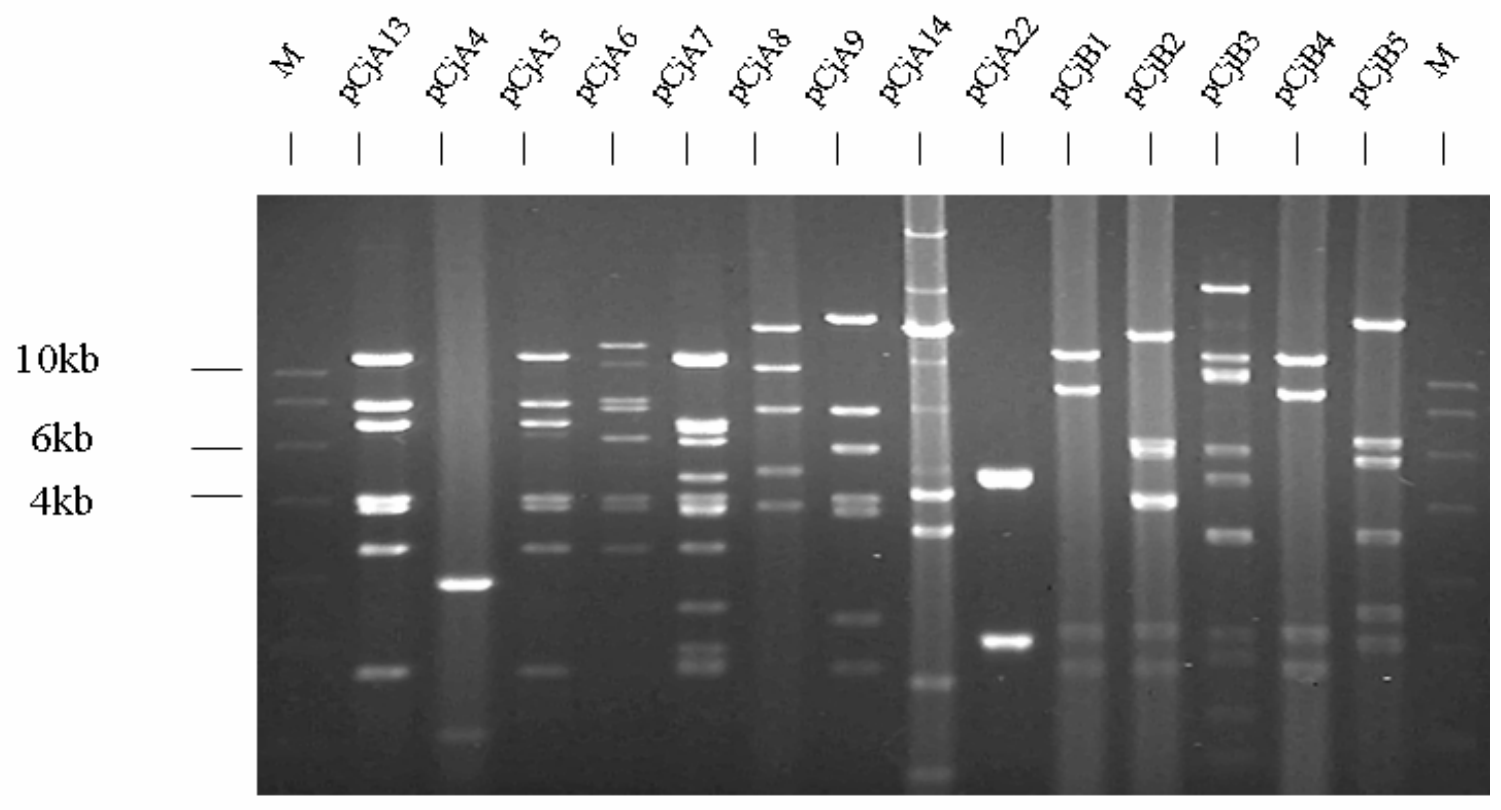

Figure 3.2: Figure shows diversity of C. jejuni strains. BglII-digested plasmid DNA of Campylobacter jejuni isolates 
On species level, 19\% $(\mathrm{n}=14)$ of the $C$. jejuni and $56 \%(\mathrm{n}=5)$ of the $C$. coli isolates harboured plasmids. The size of plasmids ranged between 6 and $66 \mathrm{~kb}$ for $C$. jejuni and between 5 and $9 \mathrm{~kb}$ for C. coli (Data not shown). Fifty percent $(\mathrm{n}=7)$ of $C$. jejuni and $60 \%$ $(\mathrm{n}=3)$ of the plasmid-positive C. coli isolates were resistant to tetracycline (Table 3.2). PCR amplification of the tet $(\mathrm{O})$ gene from total bacterial DNA revealed that high-level tetracycline resistance $(\mathrm{MIC}>256 \mu \mathrm{g} / \mathrm{ml}$ ) is associated in all cases with the presence of the tet $(\mathrm{O})$ gene in $C$. jejuni (Table 3.2). In C. coli isolates, tetracycline resistance is significantly lower (minimal inhibitory concentration $16 \mu \mathrm{g} / \mathrm{ml}$ ) than in C. jejuni. To determine the localization of the $\operatorname{tet}(\mathrm{O})$ gene, plasmid DNA from C. jejuni and C. coli strains was probed with the digoxigenin-11-dUTP labelled tet $(\mathrm{O})$ probe (Fig. 3.3 and Fig. $3.4 b)$.

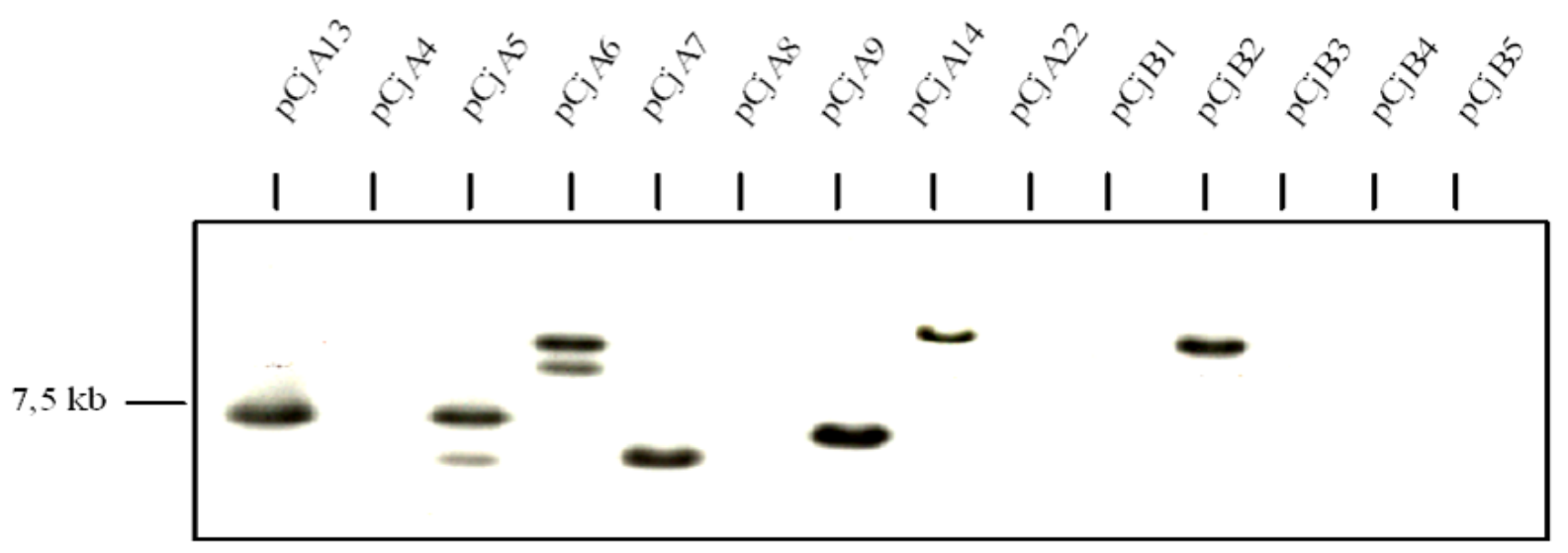

Figure 3.3: Correlation of tetracycline resistance of $C$. jejuni isolates and the presence of the tet $(\mathrm{O})$ gene. BglII-digested C. jejuni plasmid DNA was probed with the digoxigenin-labelled tet(O) gene. For pCjA5 and pCjA6, two bands are visible that most probably are due to incomplete digestion of plasmid DNA.

Our results revealed that $54 \%(n=7)$ of the tetracycline resistant $C$. jejuni isolates carried the tet $(\mathrm{O})$ gene on their plasmids (Fig. 3.3), whereas in C. coli, none of the isolates carried the tet $(\mathrm{O})$ gene on the plasmid (Fig. 3.4b). However, the presence of the tet $(\mathrm{O})$ gene in the chromosomal DNA was confirmed by PCR from genomic DNA of C. coli (data not shown). 


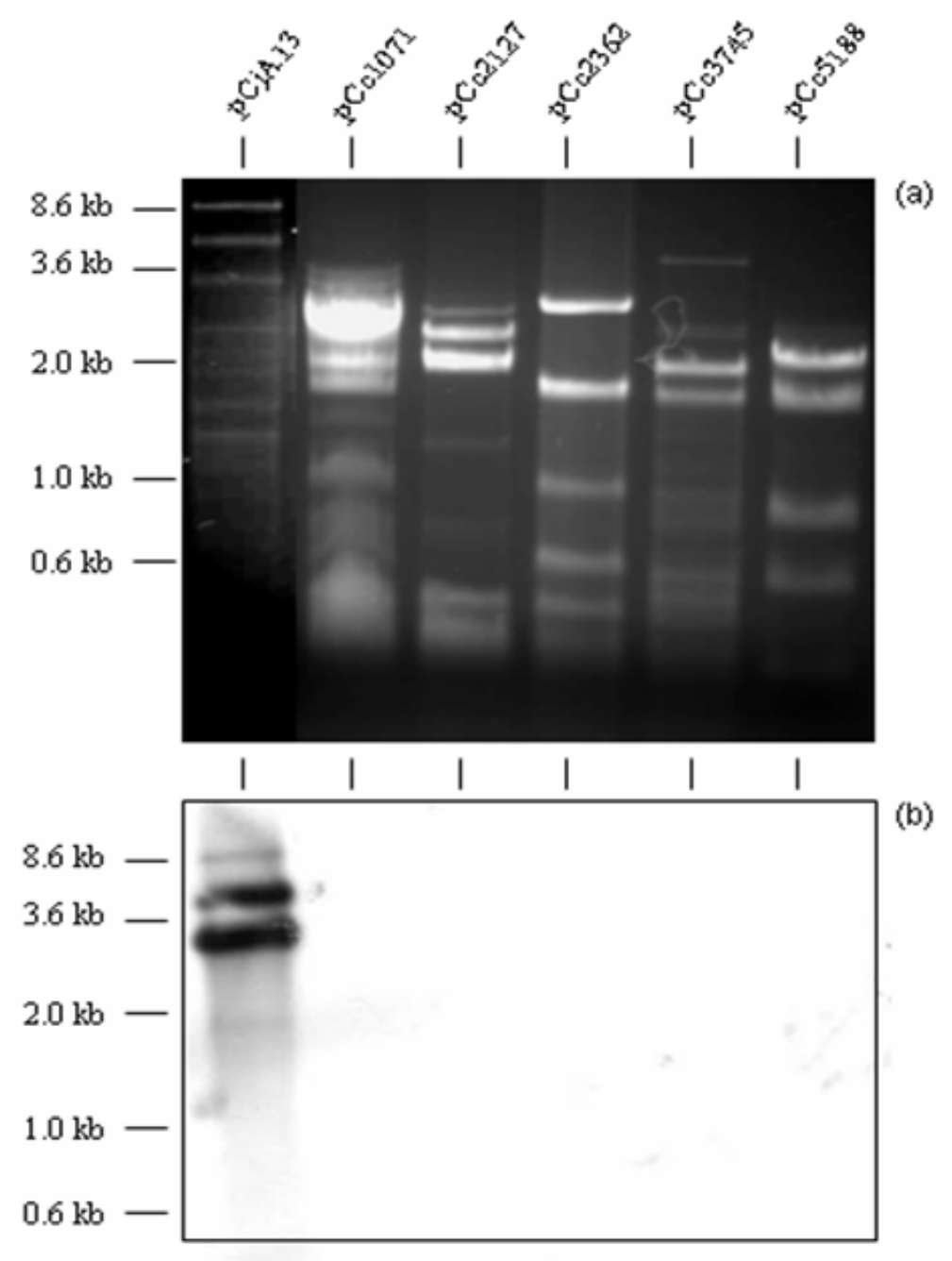

Figure 3.4: HindIII-digested C. coli plasmid DNA, (a) agarose gel electrophoresis of ethidium bromide stained plasmid DNA. (b) Probed with digoxigenin labelled tet(O).pCjA13 served as a positive control and two bands are visible that are most probably the result of incomplete digestion of plasmid DNA. 


\subsection{In-vivo transposition of $E$.coli and $C$. jejuni}

By using the scheme illustrated in chapter 2, the kanamycin resistance gene (aphA-3) was tagged with 40 variable DNA signatures (tags) which resulted into $1.8 \mathrm{~kb}$ DNA fragments (Fig. 3.5).

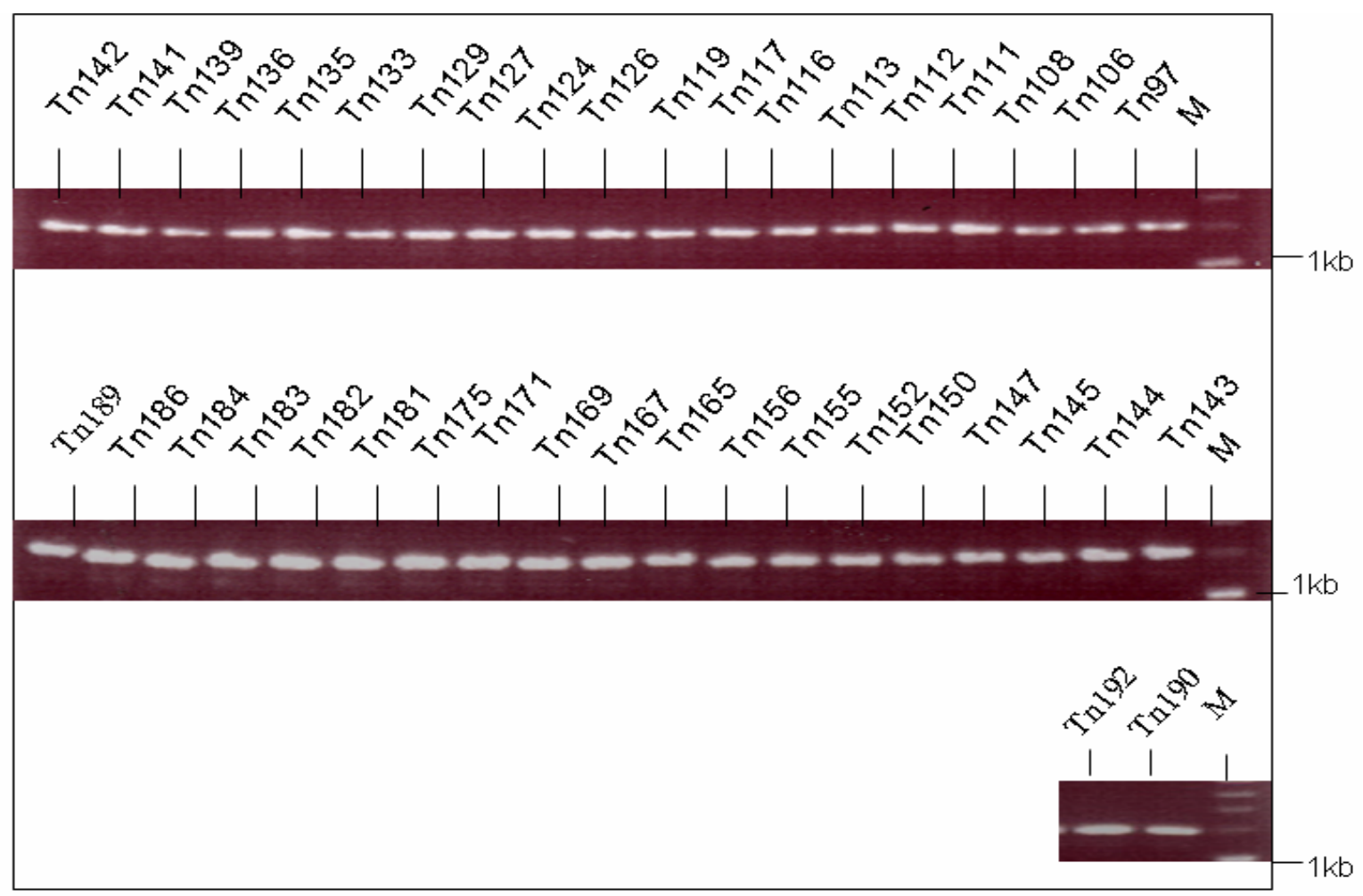

Figure 3.5 Each band labelled as "Tn" represents an EZ::TN5kan® transposon tagged with a unique DNA sequence of 20 to $25 \mathrm{bp}$. In the figure "M" represents $1 \mathrm{~kb}$ DNA ladder. The size of each fragment was estimated as $1.8 \mathrm{~kb}$.

Prior to the in-vivo transposition, all the tagged transposon fragments were analyzed for the cross hybridization by using a PCR strategy (See chapter 2). This analysis revealed no cross hybridization of the tags (data not shown). E. coli DH5o electrocompetent cells were used to test the efficiency of the EZ::TN5kan ${ }^{\circledR}$ transposon for in-vivo transposition. A total of $1 \times 10^{4}$ transformants/ $\mu \mathrm{g}$ of transposon DNA were obtained, indicating that EZ::Tnkan ${ }^{\circledR}$ can be successfully used for in-vivo transposition. Several repetitions of this experiment produced comparable number of transformants. In all cases, no antibiotic-resistant colonies were obtained in the absence of the EZ::TN transposase in the reaction mixture. 
To generate random insertional mutants of $C$. jejuni, EZ::TN transposons:transposase complexes were prepared according to the above mentioned procedure: one $\mu l$ of the transposons:transposase complex was electroporated into C. jejuni strain B2. Kanamycinresistant colonies were selected on Columbia blood agar plates containing $50 \mu \mathrm{g}$ of kanamycin per ml. One electroporation of C. jejuni strain B2 resulted in $3.5 \times 10^{2}$ to $5.8 \times 10^{3}$ transformants $/ \mu \mathrm{g}$ of transposon DNA. During all the electroporation experiments, $1 \mu 1$ of transposon DNA (in the absence of transposase), and glycerol mix was electroporated as a negative control which produced no visible colonies on blood agar plates. Our experiments confirmed the functionality of the constructed transposons and it was clearly demonstrated that they can be used to produce insertional mutagenesis in $C$. jejuni. Approximately 55 random mutants of $C$. jejuni were generated reaching a total number of 660 by utilizing 12 transposons each tagged with a unique DNA tag (Fig. 3.6).

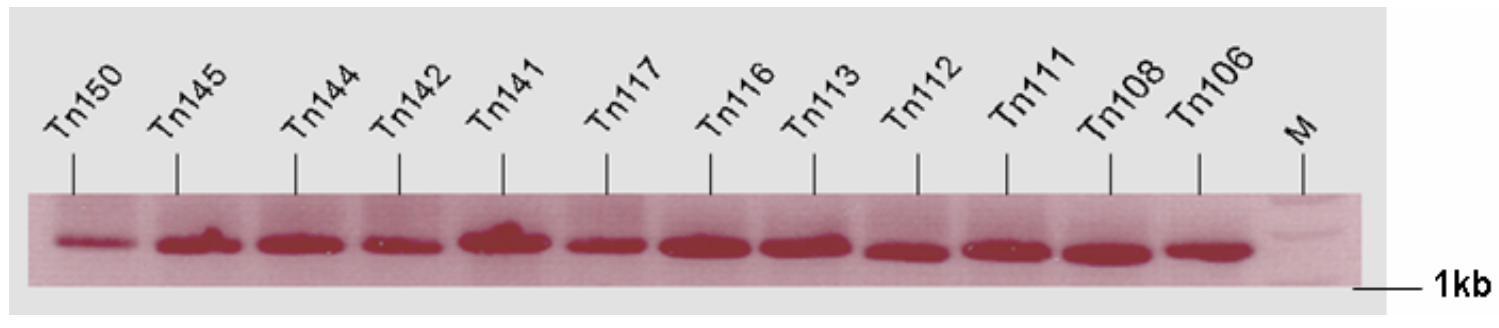

Figure 3.6 Transposons used to generate STM mutants. Each band represents $1.8 \mathrm{~kb}$ EZ::TN5kan ${ }^{\circledR}$ transposon used for the in-vivo transposition of $C$. jejuni chromosome. Transposons shown in the figure were used to generate a random library of the 660 mutants. "M" represents $1 \mathrm{~kb}$ DNA ladder

\subsection{Random insertions of EZ::TNkan ${ }^{\circledR}$ in the chromosome of $C$. jejuni.}

To determine whether EZ::TNkan ${ }^{\circledR}$ is inserted randomly in the $C$. jejuni genome, Southern blot analysis of 18 randomly chosen kanamycin insertion mutants was performed. Chromosomal DNAs were isolated from the different mutants of C. jejuni, subsequently digested with $\mathrm{BspHI}$ and separated on a $0.9 \%$ agarose gel. Restriction endonuclease $\mathrm{BspHI}$ was chosen because it cuts in the middle of the transposon. Therefore, when probed with digoxigenin-11-dUTP labelled EZ::TNkan ${ }^{\circledR}$ transposon DNA; two unique bands of different sizes were expected from digested chromosomes on single insertion of the 
transposon. However, as is shown in Figure 3.7, a few samples (lane 3, 9, 19) produced a single band. Strong labelling of these bands compared to other ones, however, indicate that they most likely are the result of an overlap of two fragments of similar sizes. In hybridization experiments, the BspHI-digested chromosomal DNA of wild-type C. jejuni did not show any hybridization signal (Lane 7). Taken together, this analysis demonstrated random insertion of EZ::TNkan ${ }^{\circledR}$ transposon which proofs the usefulness of this transposon in generating pools of random mutants of $C$. jejuni.

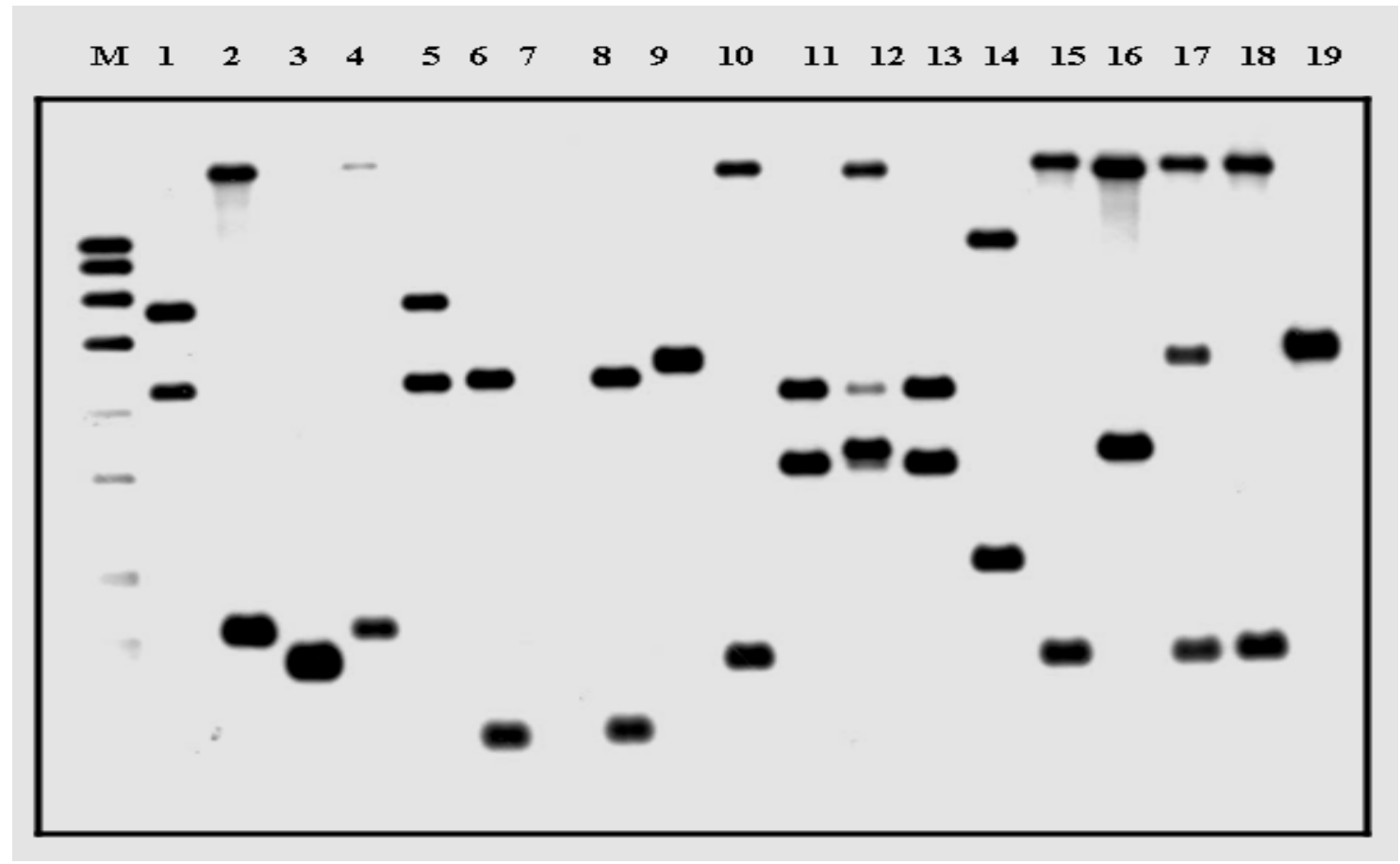

Figure 3.7: Southern blot analysis of randomly inserted Tn $5 \mathrm{kan}{ }^{\circledR}$ transposons in C. jejuni. Chromosomal DNAs from 18 randomly chosen insertion mutants (lane 1-6 to 8-19) and wild type B2 (Lane No.7) were digested with BspHI and probed with the digoxigenin labelled aphA-3 gene.

Randomness of these mutants was also confirmed by DNA sequencing results of insertional mutants with defined phenotypes. 


\subsection{Isolation of non-motile mutants of $C$. jejuni}

The flagellar motility is known as one of the important virulence factors and colonization determinants of $C$. jejuni. Therefore, to test the usefulness of our transposition system, we chose to screen 660 of the obtained mutants for motility defects on MH motility agar. Three mutants were found as completely non-motile or displayed reduced or altered motility phenotypes (Fig. 3.8).

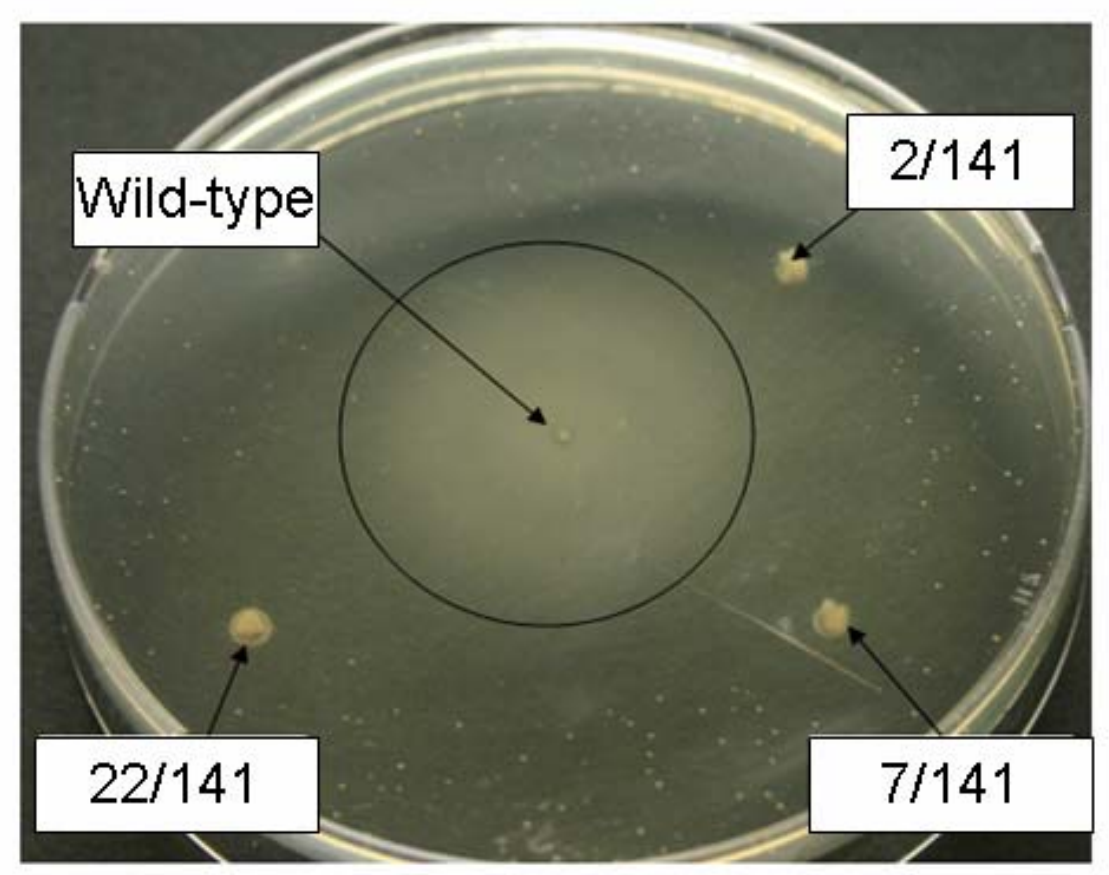

Figure 3.8: Non motile mutants of $C$. jejuni. Transposon mutagenesis produced three $(2 / 141,7 / 141$, and 22/141) completely non-motile isolates. WT, wild type B2 strain of $C$. jejuni showed a swarming phenotype indicating full motility (in circle).

The chromosomal DNA from the two mutants was isolated and used for DNA sequence analysis. This revealed insertion of EZ::TNkan ${ }^{\circledR}$ transposon in the genes $c j 0793$ (encoding 
the sensor recognition domain of FlgS) in mutant 2/141, and cj0955c (encoding probable phosphoribosylformylglycinamidine synthase subunit II) in mutant 7/141.

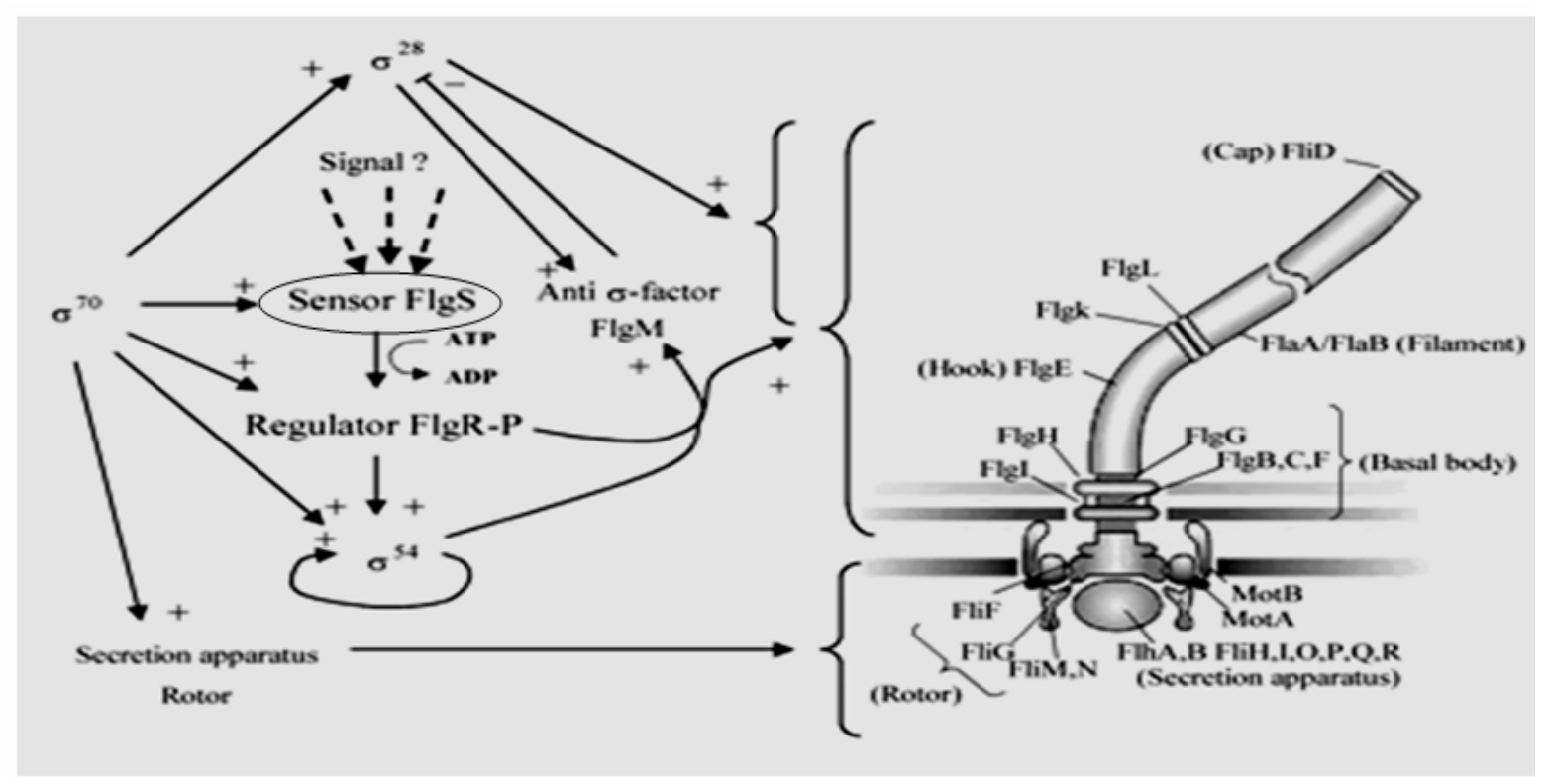

Figure 3.9: A model of the regulation of the flagellum of $C$. jejuni. In the presence of an unknown signal, sensor recognition domain of FlgS (encoded by cj0793), autophosphorylates which results in the transfer of the phosphate to the response regulator FlgR, and the alternative factor $\sigma^{54}$, stimulates the transcription of the genes needed for the activation of FliA (factor $\sigma^{28}$ ) which is required for the full assembly of the flagella. (Purposed by Wösten, 2004).

One of the insertion sites of these mutants was found in the two component sensor gene cj0793 (Fig. 3. 9), which appeared to be a central factor for flagellar motility (Wösten et al., 2004). This non-motile mutant, however, showed normal flagella (Fig.3.10). Another nonmotile mutant had the EZ::TNkan ${ }^{\circledR}$ insertion in a gene (cj0955c) of unknown function or not previously associated with motility or any other phenotype in C. jejuni. Electron microscopic analysis of the non-motile mutants revealed the absence of flagella in two mutants $22 / 141$ and $7 / 141$. 


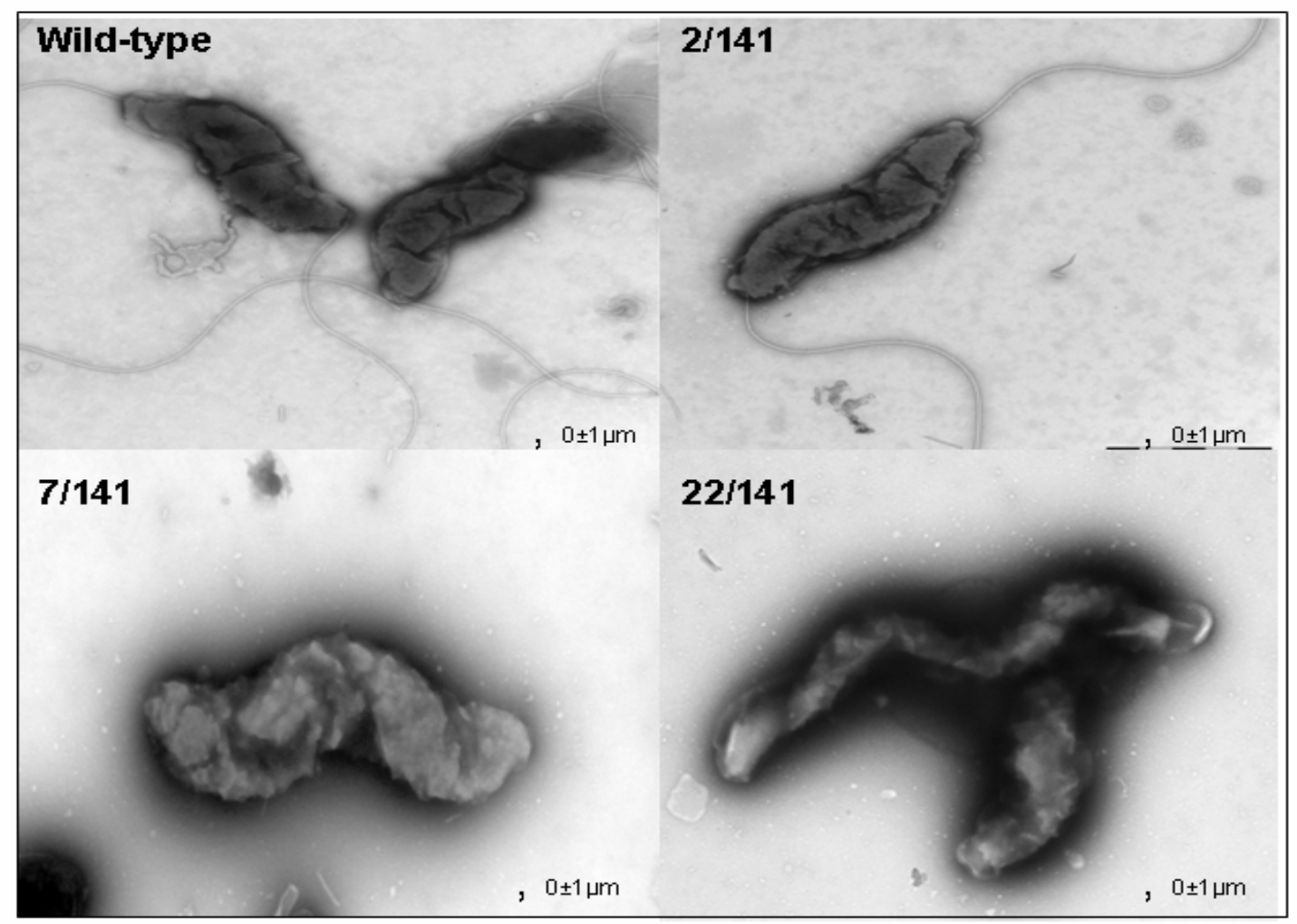

Figure 3.10 Electron micrographs of the C. jejuni strain B2 (wild-type) and non-motile mutants 2/141, 7/141and 22/141. Bars, $0 \pm 1 \mu \mathrm{m}$.

\subsection{Isolation of an osmo-sensitive mutant}

Sodium chloride is known as one of the most important food adjuncts in food preservation. Most strains of $C$. jejuni can grow well in the presence of $0.5 \% \mathrm{NaCl}$. By using an agar dilution method, we tested various concentrations $(0.5 \%$ to $4.5 \% \mathrm{wt} / \mathrm{vol})$ of $\mathrm{NaCl}$ to determine the minimal inhibitory concentration of $\mathrm{NaCl}$ for selected strains of $C$. jejuni. Our results showed that the growth of all tested C. jejuni strains (NCTC11168, NCTC11828 and B2) was completely inhibited in the presence of $2 \% \mathrm{NaCl}$. At $42^{\circ} \mathrm{C}$ however, in the presence of $1.5 \% \mathrm{NaCl}$, a normal growth of the $\mathrm{B} 2$ strain was observed. All 660 random mutants of $C$. jejuni were screened for their sensitivity towards $1.5 \%$ salt in comparison to $C$. jejuni wild type strain B2. Our screen revealed that one mutant that had insertion of EZ::TNkan ${ }^{\circledR}$ in gene cj0009 (gltD), encoding the NADPH-dependent glutamate synthase small subunit showed reduced growth in the presence of $1.5 \% \mathrm{NaCl}$. The NADPH-dependent (NADPH-GltS) is mostly found in bacteria and is a 
multicomponent ironsulfur flavoprotein belonging to the class of $\mathrm{N}$-terminal nucleophile amidotransferases. It catalyzes the conversion of L-glutamine and $\alpha$-ketoglutarate into two molecules of L-glutamate.

\subsection{Screening for sodium deoxycholate sensitivity}

Bile is primarily composed of bile salts and up to some extent of phospholipids and cholesterol (Crawford, 1999). It is reported that the average concentration of bile salts in the human intestine varies from 0.2 to $2 \%$. The primary bile salts are cholic acid, glycocholic acid, deoxycholic acid, and taurocholic acid (Elliot, 1985). In chickens, a natural host for $C$. jejuni, the concentration of bile salts ranges from $0.01 \%$ in the cecum to $0.7 \%$ in the jejunum (Lin et al., 2005). The bile salts facilitate the digestion of fats and they also serve as an effective antimicrobial agent (Gunn, 2000). In gram-negative bacteria, bile salts can pass directly across the outer membrane or pass through porins (Thanassi et al., 1997), which indicates that enteric pathogens have developed some mechanisms to overcome the damaging effects of bile salts. We therefore screened 660 random mutants of C. jejuni for their sensitivity towards 1\% (wt/vole) sodium deoxycholate known as bile salt. In this screen, no difference in growth of wild type and mutants was observed. These repetitive assays demonstrate that, in principle, the EZ::TNkan ${ }^{\circledR}$ transposon system is suitable for the random mutagenesis of $C$. jejuni.

\subsection{Optimization of the BALB/c mouse model for $C$. jejuni infection}

To determine the optimum infection dose and suitable strain for signature-tag mutagenesis (STM) experiments, we tested four different strains of C. jejuni (NCTC11168, NCTC11828, 81-176, B2) with infection doses, $1 \times 10^{8}, 1 \times 10^{9}$ and $1 \times 10^{10} \mathrm{cfu}$, respectively. Seven days after i.p. infection, all mice were sacrificed and analysed for the presence of bacteria within their livers. The infection dose of $1 \times 10^{8}$ and $1 \times 10^{9}$ bacteria resulted in low recovery of bacteria from the liver (Table 3.3). However, higher numbers of bacteria were recovered when mice were infected with $1 \times 10^{10}$ bacteria.

Table 3.3 Female BALB/c mice were infected intraperitoneally with $1 \times 10^{8}$ and $1 \times 10^{9}$ viable bacteria. The numbers of recovered $C$. jejuni from the livers after 7 days of infection are shown in the right column. Each 
value represents the number of colonies counted on blood agar recovered from the liver of the individual mouse ( $>3$ mice for each strain).

\begin{tabular}{|c|c|c|c|}
\hline C. jejuni strain & Infection dose & Mouse No & Recovered cfu/mg \\
\hline \multirow{3}{*}{ NCTC11168 } & \multirow{3}{*}{$1 \times 10^{8}$} & 1 & 0 \\
\hline & & 2 & 0 \\
\hline & & 3 & 0 \\
\hline \multirow{3}{*}{ NCTC11828 } & \multirow{3}{*}{$1 \times 10^{8}$} & 1 & 900 \\
\hline & & 2 & 0 \\
\hline & & 3 & 0 \\
\hline \multirow{3}{*}{ B2 } & \multirow{3}{*}{$1 \times 10^{8}$} & 1 & 0 \\
\hline & & 2 & 0 \\
\hline & & 3 & 0 \\
\hline \multirow{3}{*}{$81-176$} & \multirow{3}{*}{$1 \times 10^{8}$} & 1 & 0 \\
\hline & & 2 & 0 \\
\hline & & 3 & 0 \\
\hline \multirow{3}{*}{ NCTC11168 } & \multirow{3}{*}{$1 \times 10^{9}$} & 1 & 3 \\
\hline & & 2 & 10 \\
\hline & & 3 & 5 \\
\hline \multirow{3}{*}{ NCTC11828 } & \multirow{3}{*}{$1 \times 10^{9}$} & 1 & 1 \\
\hline & & 2 & 1 \\
\hline & & 3 & 0 \\
\hline \multirow{3}{*}{ B2 } & \multirow{3}{*}{$1 \times 10^{9}$} & 1 & $4 \times 10^{2}$ \\
\hline & & 2 & $1 \times 10^{3}$ \\
\hline & & 3 & $3 \times 10^{2}$ \\
\hline
\end{tabular}

Since, in preliminary experiments, infection with $1 \times 10^{9}$ bacteria of strain NCTC11168 and 81-176 showed lowest recovery of bacteria as compared to NCTC11828 and B2 in all experiments performed, these strains were excluded in further experiments. For the comparative analysis, three female BALB/c mice were tested for each infection dose $1 \times$ $10^{8}, 1 \times 10^{9}$ of each strain respectively as shown in table 3.3. Infection dose of $1 \times 10^{10}$ of strain B2 produced reproducible and higher numbers of recovered bacteria. In some of the 
experiments, the same infection dose of NCTC11828 also resulted in higher numbers of bacteria from the livers. However, a lack of reproducibility and high variation in the numbers of recovered bacteria was a major obstacle in the optimization of a suitable infection dose for this particular strain. A comparison of two groups of seven female $\mathrm{BALB} / \mathrm{c}$ mice with an infection dose of $1 \times 10^{10}$ and respective numbers of recovered bacteria are shown in Table 3.4

Table 3.4 Female BALB/c mice were infected intraperitoneally with $1 \times 10^{10}$ viable bacteria. The numbers of recovered C. jejuni from the livers after 7 days of infection are shown in the right column. Each value represents the number of colonies counted on blood agar recovered from the individual mouse $(>7$ mice for each strain).

\begin{tabular}{|c|c|c|c|}
\hline C. jejuni strain & Infection dose & Mouse No & Recovered cfu/mg \\
\hline \multirow{7}{*}{ B2 } & \multirow{7}{*}{$1 \times 10^{10}$} & 1 & $2 \times 10^{5}$ \\
\hline & & 2 & $1.5 \times 10^{4}$ \\
\hline & & 3 & $8.6 \times 10^{4}$ \\
\hline & & 4 & $1.3 \times 10^{4}$ \\
\hline & & 5 & $2 \times 10^{5}$ \\
\hline & & 6 & $1 \times 10^{3}$ \\
\hline & & 7 & $1 \times 10^{4}$ \\
\hline \multirow{7}{*}{ NCTC11828 } & \multirow{7}{*}{$1 \times 10^{10}$} & 1 & 3 \\
\hline & & 2 & 1 \\
\hline & & 3 & 1 \\
\hline & & 4 & $12.5 \times 10^{5}$ \\
\hline & & 5 & 1 \\
\hline & & 6 & 0 \\
\hline & & 7 & 0 \\
\hline
\end{tabular}

Pathohistological examinations showed both macroscopic and microscopic changes in the liver and spleen of infected animals. Primary infection generally resulted in hepatosplenomegaly with inflammation. Furthermore, on the liver surface nodules indicated abcess like appearences (Fig. 3.11) 


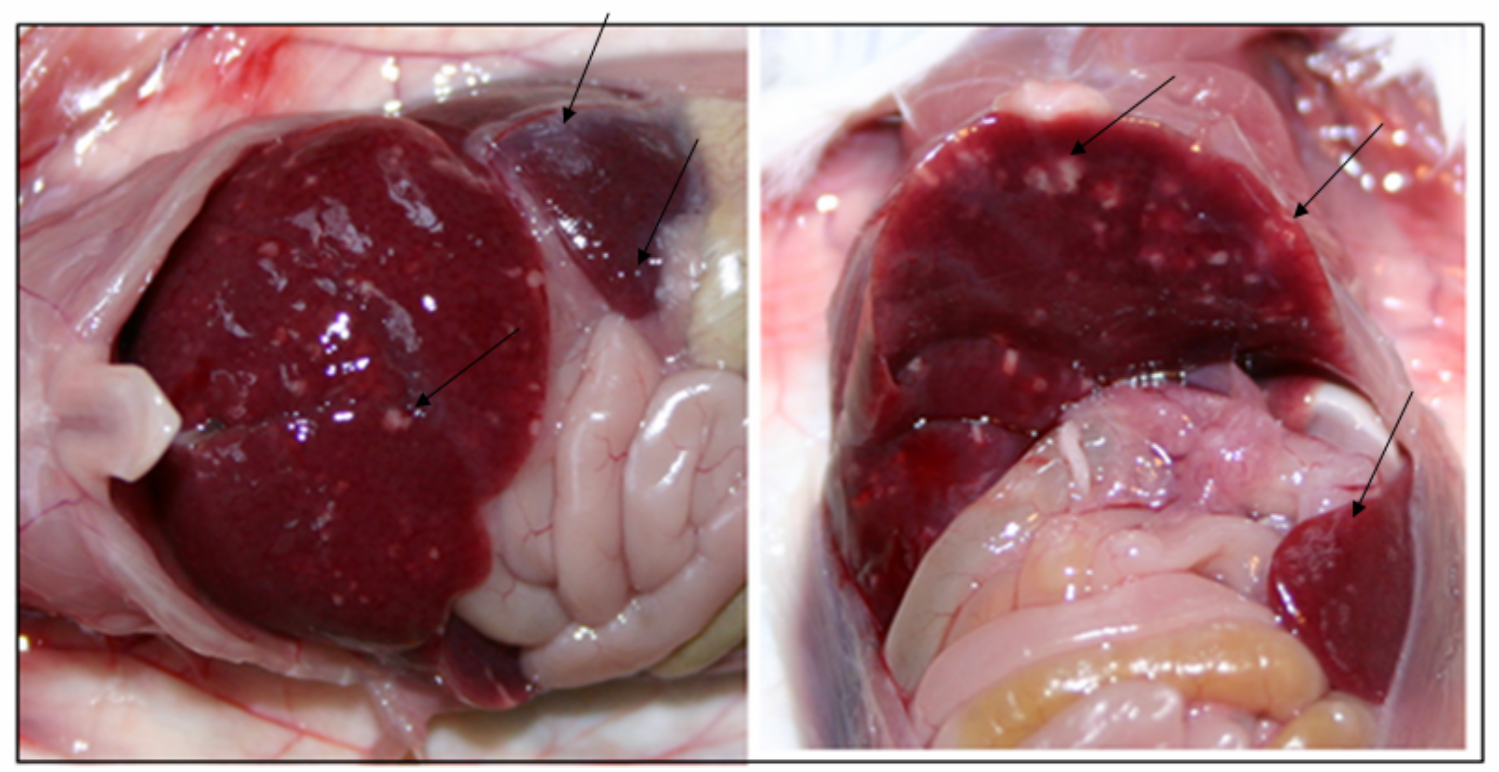

Fig 3.11 Gross pathology of C. jejuni infection in intraperitoneally infected female BALB/c mice at day 7 post infection. The livers were enlarged and contained numerous abcess-like nodes (accentuated by arrows). In addition, enlargement of the spleen is shown.

In histological sections, an inflammatory response could be seen, followed by tissue necrosis. The cell infiltrate consisted primarily of neutrophils and rarely lymphocytes (Fig 3.12). Although infection of mice with the C. jejuni strain $\mathrm{B} 2$ at an infection dose of 1 $\times 10^{10} \mathrm{cfu}$, resulted in a significantly higher number of recovered bacteria from the liver as compared to the other $C$. jejuni strains. A moderate variation in the number of recovered bacteria was observed within every single experiment. In repeated experiments, it was observed that $1 \times 10^{11} \mathrm{cfu}$ was a lethal infection dose for all mice tested in this study. Our data indicated that the optimum infection dose leading to reproducible results via the intraperitoneal infection route is $1 \times 10^{10} \mathrm{cfu}$ of $C$. jejuni strain B2. All other strains tested in this study showed lower and inconsistent recovery rates of bacteria from the livers of female BALB/c mice. 


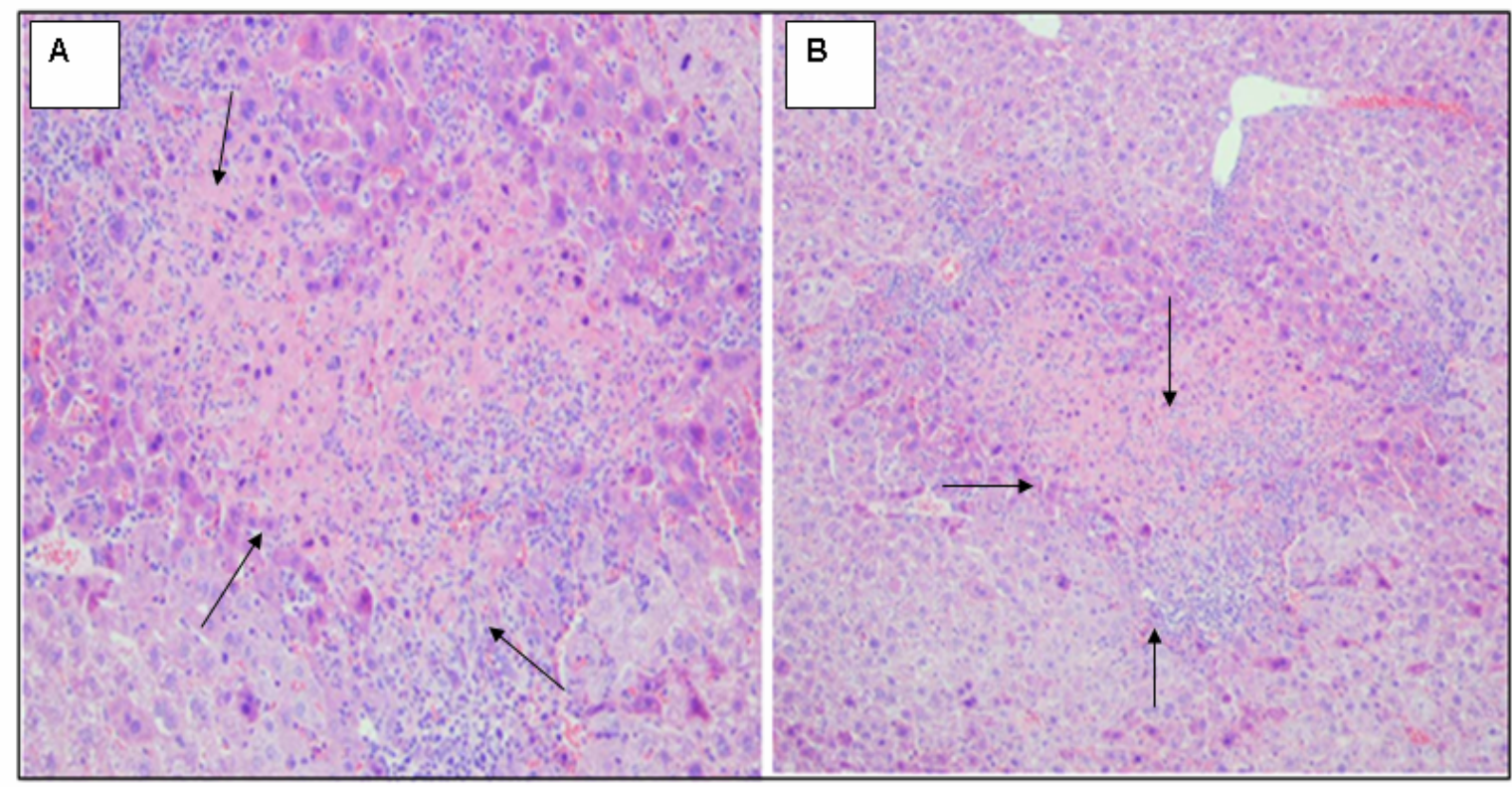

Figure 3.12 (A) Liver histology of a female BALB/c mouse 7 days after infection with $1 \times 10^{9}$ C. jejuni (B2 strain) showing lesions with infiltration of mononuclear cells. (B) Necrotic lesion (arrows) in the liver of a $\mathrm{BALB} / \mathrm{c}$ mouse day 7 post infection with an infection dose $1 \times 10^{9}$ C. jejuni. $A+B=$ Hematoxylin stained sections.

\subsection{Application of signature tagged mutagenesis of $C$. jejuni in vivo}

The in-vivo screening of signature tagged transposon mutants was done by using a pool of forty randomly selected mutants labelled with eight different signature tags. Mutants were subcultured on Columbia blood agar containing $50 \mu \mathrm{g} / \mathrm{ml}$ kanamycin. Eight different pools, each containing five different mutants were prepared and six weeks old female BALB/c mice were challenged with an infection dose of $1 \times 10^{10} \mathrm{cfu}$, respectively. Seven days post infection, the mutants were recovered from livers and plated on Columbia blood agar plates containing $50 \mu \mathrm{g} / \mathrm{ml}$ of kanamycin for further analysis. A variable recovery rate was observed ranging between $1 \times 10^{3}$ to $1 \times 10^{6} \mathrm{cfu}$ (Fig. 3.13). 


\section{In-vivo screen of STM mutants}

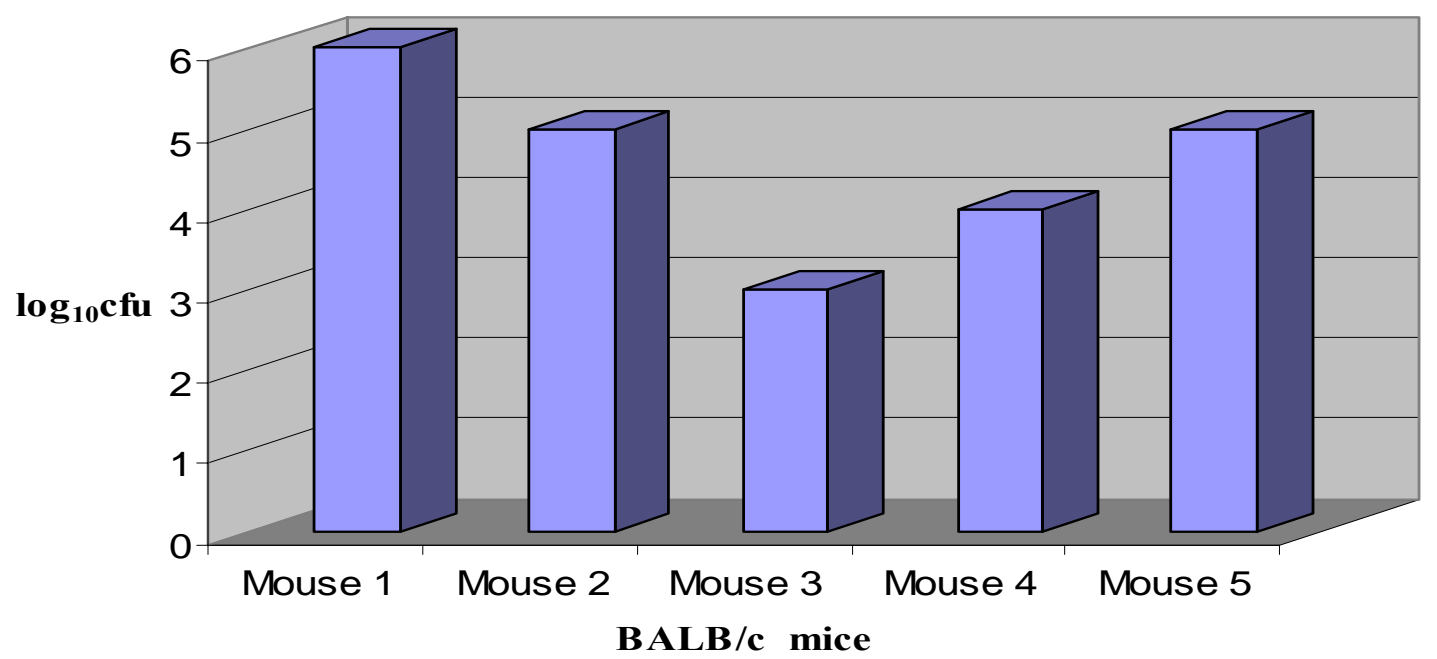

Figure 3.13: Numbers of $C$. jejuni mutants that were recovered from the liver of each female BALB/c mouse, 7 days after infection. Each BALB/c mouse was infected intraperitoneally with $1 \times 10^{10}$ viable STM mutants of C. jejuni. Data are described as $\log _{10}$ cfu recovered from each liver.

To confirm possible attenuated mutants, a PCR analysis by using tag-specific primers (Table 2.4) and a generic primer JA4 (Table 2.3) was carried out. Genomic DNA from the recovered mutants was used as a template. A pool of 40 signature-tagged mutants of $C$. jejuni was tested in six weeks old female BALB/c mice. The fundamental methodology of our STM system, following the production of a mutant library, is separated into two phases, an input and an output phase (Hensel et al 1995). The two phases of the experiment are essentially identical except that, prior to the out-put phase, a round of selection was performed. The presence or absence of the mutant is detected in both phases by extracting genomic DNA from the pool of mutants and PCR amplification of the transposon by using a primer pair based on regions of variable tags (Fig. 3.14). 


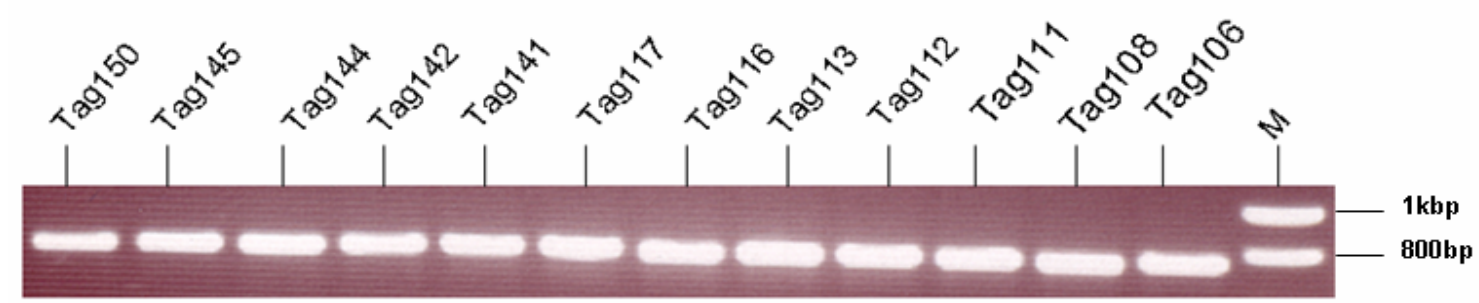

Figure 3.14. Using tag-specific primer (Table 2.4) and a generic primer (Table 2.3; JA4 primer), every single mutant can be distinguished from each other by amplifying a 780bp DNA fragment. "M" represents $1 \mathrm{~kb}$ DNA ladder

The comparison of the input pool and the out-put pool can reveal attenuated mutants. If the mutant is absent from the out-put pool but is present in the input pool, then the mutant is presumed to be attenuated which can be the result of random insertion of the transposon in the virulence associated gene. The scheme for the experiment is illustrated in Figure 3.15. All the tested mutants and their relative pools are shown in Table 3.5.

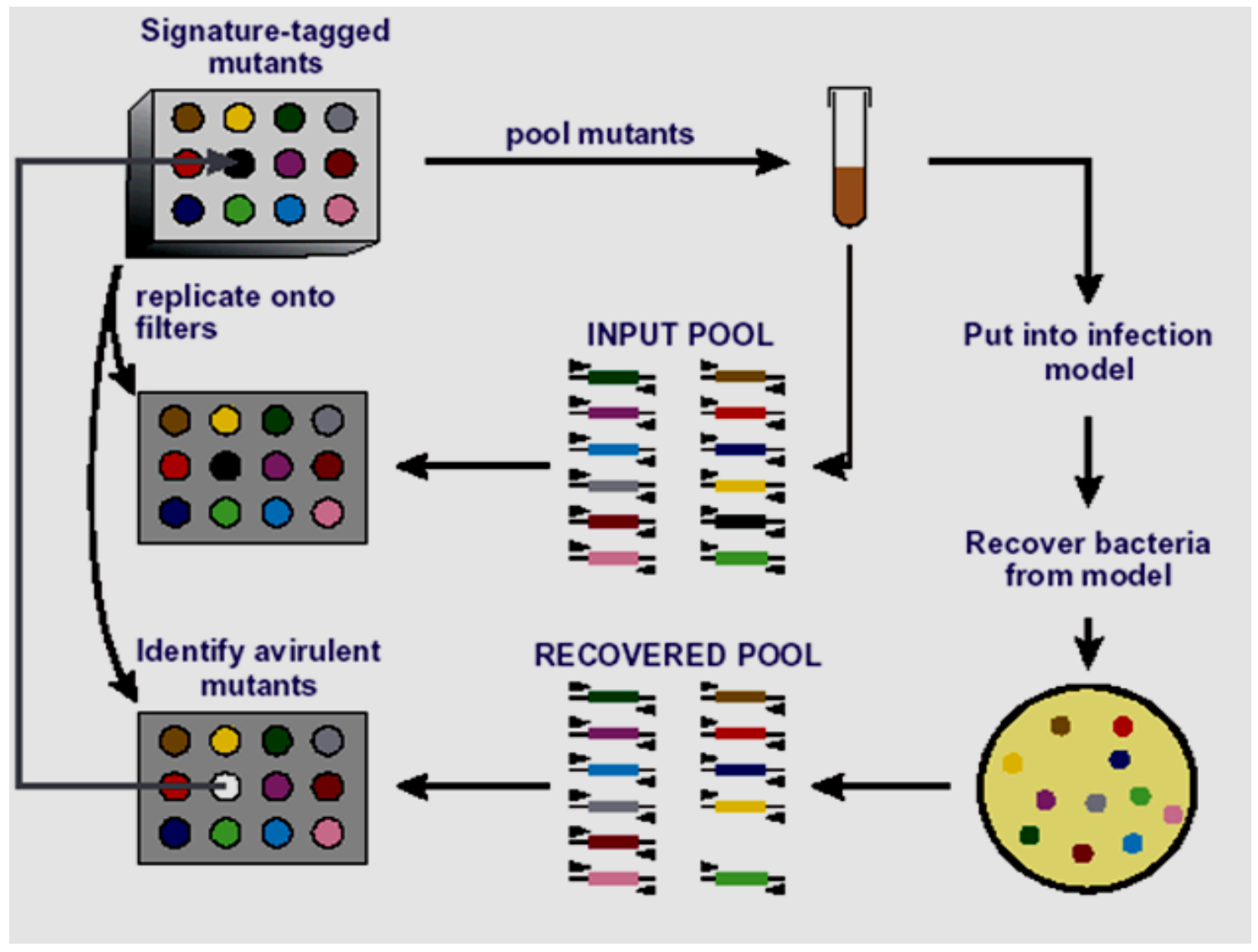

Figure 3.15: General scheme for the screening of a pool of STM mutants of $C$. jejuni 
by comparing the in-put pool and the out-put pool of mutants. Female BALB/c mice were used as a screening model in this study.

\begin{tabular}{|l|c|c|c|c|c|c|c|c|}
\hline Pool No & tag A & tag B & tag C & tag D & tag E & tag F & tag G & tag H \\
\hline Pool 1 & 1 & M & 1 & 1 & 1 & 1 & 1 & M \\
\hline Pool 2 & 2 & 2 & 2 & 2 & 2 & 2 & 2 & 2 \\
\hline Pool 3 & 3 & 3 & 3 & 3 & 3 & 3 & 3 & 3 \\
\hline Pool 4 & 4 & 4 & 4 & 4 & 4 & 4 & 4 & 4 \\
\hline Pool 5 & 5 & M & 5 & 5 & 5 & 5 & 5 & 5 \\
\hline
\end{tabular}

Table 3.5 Five different pools (in rows) prepeared by mixing five mutants from the each of the eight different tags A-H (in columns), were injected into six weeks old female BALB/c mice. In the Table boxes denoting "M" represent missing mutants from each recovered pool of the STM mutants.

Our results showed that 37 mutants were recovered and were verified by a tag-specific PCR. However, in repeated PCRs done by using total genomic DNA from the output pool as a template, three mutants were not detected (Table 3.5 denoted as "missing") during the first screening experiment. To verify their attenuation, we retested whether these mutants were reproducibly missing. Verification was done in three repeated experiments by following the same procedure. However, the missing mutants were recovered and confirmed by the tag-specific PCR. Therefore, the probability to achieve an avirulent mutant by screening a pool of small number of mutants is low. However, our results indicated that in principle female BALB/c mice can be utilized as a screening model for randomly generated signature- tagged mutants of $C$. jejuni. 


\section{Discussion}

\subsection{Genotypic and phenotypic diversity of Campylobacter spp.}

Over the last few decades, Campylobacter jejuni has emerged as an important food-borne pathogen and is a major public health concern. C. jejuni causes gastro-intestinal infections as well as post infection manifestations, e.g Guillain-Barré syndrome or reactive arthritis (Schmidt-Ott et al., 2006). Annually, approximately 60,000 cases of Campylobacter spp. enteritis are reported in Germany (RKI, 2006). Complications of C. jejuni infection vary from mild, noninflammatory, self-limiting diarrhoea to severe, inflammatory, bloody diarrhoea (Wassenaar and Blaser, 1999). Consequently, the importance of C. jejuni as a major public health problem is well recognized which makes it important to understand the pathogenesis of this disease. The genome sequence of $C$. jejuni has been recently reported (Parkhill et al., 2000), and little is known about the mechanisms, contributing to the genetic diversity of this pathogen. The sequenced strain NCT 11168 contains no transposons, phage remnants, or insertion sequences in its genome. Several reports have pointed out a relative intraspecies genotypic and phenotypic diversity in comparison to other enteropathogens.

There are two serotyping schemes detecting a wide variety of serotypes (Lior et al., 1982). In addition, the genotypic diversity of this pathogen has been reported by ribotyping, pulsed-field gel electrophoresis, and several PCR-based techniques. However, due to the limitations of these methodologies, further characterization of the genetic basis is hindered. Diversity in C. jejuni strains has also been reported at the phenotypic level, particularly for characteristics implicated in pathogenicity, including adherence, invasion of epithelial cell lines, toxin production, serum resistance, polysaccharide production, sialylation of LOS and the ability to colonize chickens. Due to the direct association of the clinical isolates with disease, they can provide a valuable source for the selection of highly pathogenic strains. As for example, strain 81-176 was isolated from a patient during an outbreak of campylobacteriosis, and proven to be highly pathogenic in monkeys and humans (Russell et al., 1989). Therefore, with the major objective to later identify putative virulence factors

of C. jejuni, we collected and characterized clinical isolates of $C$. jeuni to increase the overall probability for the selection of a suitable strain for further analysis. 
Due to the lack of reliable specific phenotypical markers for species identification, many clinical laboratories identify Campylobacter isolates only on the genus level. Hippurate hydrolysis has been suggested as a key phenotypical test for differentiation of C. coli and C. jejuni (Harvey et al., 1980). On the basis of amino acid homology of the hippurate hydrolase, it was classified as a non-peptidase homologue of the M40 peptidase family within the MH peptidase by the Merops Protease Database (Merops, 2002). Other members of this family of peptidases are also reported in plants, archaebacteria and eubacteria. The hippurate hydrolase of $C$. jejuni can cleave the benzoyl group from $N$-benzoylglycine, therefore, it may be considered as an amidohydrolase. It is reported that other M40 peptidases were also proven to be amidohydrolases, including a thermostable carboxypeptidase from Sulfolobus solfataricus, an $N$-acyl-L-amino acid amidohydrolase from Bacillus stearothermophilus, a family of indole-3-acetic acid (IAA) amino acid hydrolases from the plant Arabidopsis thaliana, an IAA-aspartic acid hydrolase from Enterobacter agglomerans and an $N$-carbamylase from Pseudomonas spp. (Watabe et al., 1992). The enzymatic properties of the hippurate hydrolase enzyme suggest that it would be active under normal physiological conditions. It is speculated that carboxypeptidase activity of this enzyme might play a role in the nutrient acquisition by the bacterium during infection. Such phenomena would directly contribute to the virulence of $C$. jejuni. However, the in-vivo function of the hippurate hydrolase of $C$. jejuni remains to be understood (Steel et al., 2006).

Using commercially available test systems, a hippurate hydrolysis test can be performed rapidly but major difficulties remain to correctly identify any hippurate hydrolase-negative isolate of $C$. jejuni. The gene hipO is highly conserved among the strains of $C$. jejuni and does not exhibit any significant polymorphism, which makes it a reliable marker for the identification of C. jejuni strains (Steinhauserova et al., 2001). However, some atypical C. jejuni strains fail to express this enzyme. These atypical strains of $C$. jejuni are frequently reported in the literature (Linton et al. 1997). We therefore combined reliable biochemical and molecular markers for species differentiation of eighty-three clinical isolates. On the basis of their hippurate hydrolase activity, 67 isolates (81\%) were identified as C. jejuni. Sixteen Campylobacter isolates (19\%) did not show any hippurate hydrolase activity and 
were further evaluated for the presence of hipO gene. In conclusion, in the present study, initially nine strains were biochemically typed as C. coli, but were proven to be $C$. jejuni after Southern blot analysis.

\subsection{Antibiotic resistance in $C$. jejuni and $C$. coli}

The current findings stress that empiric antimicrobial therapy of Campylobacter enteritis should relay on the locally assessed susceptibility profiles. Thus, a general knowledge of the expected susceptibility pattern of Campylobacter species causing infections in a given geographic region is a prerequisite to initiate the most appropriate antimicrobial treatment.

Furthermore, it is necessary to perform antimicrobial profiling of clinical strains, supposed to be used for further research involving genetic manipulation. Therefore, after precise identification at the species level, we analysed drug resistance in 83 clinical isolates of Campylobacter by using a disk diffusion method (Gaudreau and Gilbert, 1997).

Previously, a higher rate of ciprofloxacin resistance was observed in C. jejuni isolates collected from lifestock (45.8\%) and human individuals (45.1\%) in Germany (Luber et al., 2003). In our study, $25.3 \%$ of $C$. jejuni and $10 \%$ of C. coli isolates showed resistance to ciprofloxacin. Comparable findings have been observed in The Netherlands with 29\% (Talsma et al., 1999) and Greece with 30.6\% (Chatzipanagiotou et al., 2002). The resistance rate against ciprofloxacin in Germany is lower as compared to other countries like Spain with 82\% (Prats et al., 2000) and Thailand with 84\% (Hoge et al., 1998). However, since at least some of the isolates showed resistance, the use of ciprofloxacin as a first choice for treatment might be questionable.

Tetracyclines have been purposed as an alternative choice in the treatment of $C$. jejuni and C. coli enteritis. Large geographical variations in susceptibility pattern of $C$. jejuni and $C$. coli to tetracycline have been observed. The rate of resistance in Denmark ranges from 0 to $11 \%$ (Aarestrup et al., 1997), in Spain it is 25\% (Gomez-Garces et al., 1995), and in the United States 48\% (Nachamkin et al., 1994). In this study, tetracycline MICs were determined for 19 Campylobacter isolates that were identified to be tetracycline-resistant by the disk diffusion test. Tetracycline MICs ranged from 16 to $256 \mu \mathrm{g} / \mathrm{ml}$. High-level tetracycline resistance was found in C. jejuni, whereas in C. coli isolates, tetracycline resistance level was significantly lower. In case of 13 C. jejuni strains, MIC was 
determined as $>256 \mu \mathrm{g} / \mathrm{ml}$ whereas six C. coli isolates had a MIC of $16 \mu \mathrm{g} / \mathrm{ml}$. The frequency of tetracycline resistance was significantly higher $\left(\chi^{2}\right.$ test: $\left.p<0.001\right)$ in C. coli (67\%) than in C. jejuni (18\%).

C. coli is frequently found in pigs (Moore and Madden, 1998), and it is known that the regular use of antimicrobial agents for therapeutic and growth promotion can play a role in the prevalence of antimicrobial-resistant strains of C. coli in pigs (Payot et al, 2001). Therefore, a higher frequency of tetracycline resistance in clinical isolates of $C$. coli might be linked with the use of related antibiotics in the food chain. Bacterial resistance to tetracycline commonly arises through one of these four identified mechanisms: efflux of tetracycline, modification of tetracycline, ribosomal protection, or mutation of the $16 \mathrm{~s}$ rRNA (Burdett et al., 1991; Ross et al., 1998; Schnappinger and Hillen, 1996). Of these, the plasmid-mediated tet $(\mathrm{O})$-encoded tetracycline resistance is reported frequently in Campylobacter spp. (Lee et al., 1994; Manavathu et al., 1988). The plasmids bearing the tet $(\mathrm{O})$ determinant were also isolated from other bacteria, such as Enterococcus faecalis and Streptococcus spp. and the plasmids were shown to have similar sizes and restriction profiles compared to those isolated from C. jejuni and C. coli (Zilhao et al., 1988).

Previously, the isolation rate of plasmids from Campylobacter species has been reported variable with $44 \%$ to $91 \%$ for clinical and poultry isolates (Gaudreau and Gilbert, 1997). In this study, approximately $23 \%(\mathrm{n}=19)$ of Campylobacter isolates harboured plasmids, ranging in size from 5.0 to 66 kilobases $(\mathrm{kb})$. Significant differences between plasmids were detected in both species of Campylobacter; $19 \%(\mathrm{n}=14)$ of the C. jejuni isolates and $56 \%$ of C. coli $(n=5)$ isolates harboured plasmids. Instead of 33 to 66 kilobases sized plasmids found in C. jejuni, C. coli isolates harboured plasmids sized 5 to 9 kilobases.

Fifty percent $(\mathrm{n}=7)$ of plasmid-harbouring $C$. jejuni and $60 \%(\mathrm{n}=3)$ of the plasmidpositive $C$. coli isolates were resistant to tetracycline. To determine the localization of the tet $(\mathrm{O})$ gene, plasmid DNA from C. jejuni and C. coli isolates was probed with the digoxigenin-11-dUTP labelled tet $(\mathrm{O})$ gene. Our results reveal that $54 \%(\mathrm{n}=7)$ of the tetracycline-resistant C. jejuni isolates carried the tet $(\mathrm{O})$ gene on their plasmids. Surprisingly, in $C$. coli none of the plasmids carried the tet $(\mathrm{O})$ gene. Amplification of the tet $(\mathrm{O})$ gene from genomic DNA of tetracycline-resistant $C$. coli isolates indicated a chromosomal localization of the tet $(\mathrm{O})$ gene. However, considering the limitation of the 
alkaline lysis method for plasmid isolation, the presence of low-copy number plasmids larger than $70 \mathrm{~kb}$ can not be totally excluded. It has been suggested previously that recombination events between plasmids and the chromosome or integration of a plasmid might occur which could explain chromosomally mediated tetracycline resistance in these isolates (Boosinger et al., 1990). It is also known that illegitimate recombination can cause integration of a heterologous plasmid in C. coli (Richardson and Park, 1997) and this would ultimately lead to a higher frequency of chromosomally mediated tetracycline resistance in C. coli. Previously, conjugation in two isolates having plasmids sized $40.5 \mathrm{~kb}$ (pCjA9) and $41.9 \mathrm{~kb}$ (pCjA13) has been shown (Schmidt-Ott et al., 2005). In that study, Southern blot analysis showed that tetracycline resistance in these isolates was tet(O) encoded and plasmid mediated which ultimately confirms conjugation transfer of tet $(\mathrm{O})$ in these C. jejuni isolates.

In conclusion, resistance against tetracycline in $C$. jejuni and $C$. coli isolates was associated with the tet( $\mathrm{O})$ gene in all cases, and there was a strong correlation between tetracycline resistance and plasmid carriage in C. jejuni isolates. Although all plasmidcontaining isolates of $C$. coli were resistant to tetracycline, none of the $C$. coli isolates carried the tet $(\mathrm{O})$ gene on the plasmid. Instead, the tet $(\mathrm{O})$ gene seems to be chromosomally encoded in all tetracycline-resistant Campylobacter coli isolates.

\subsection{Construction of transposon for the in-vivo transposition of the $C$. jejuni}

During the last decade, the development of new genetic tools provided enormous opportunities to identify putative virulence factors of microbial pathogens. One of the most powerful genetic approaches used for the identification of virulence associated genes is signature-tagged mutagenesis (STM), which was initially developed by David Holden and colleagues in 1995. This approach led to the identification of hundreds of new genes related to the virulence in a broad range of bacterial pathogens. Despite the efforts made to understand, so far little is known about the virulence factors of $C$. jejuni. One of the reasons in this lack of understanding is the deficiency of high through-put strategies to generate random mutants that can be tested in different biological environments. Several approaches have been previously used to generate mutants which mostly relied on shuttle mutagenesis and homologous recombination. A different approach called in-vivo transposition based on 
the Himar1 transposable element and a suicide vector has been used recently (Colegio et al., 2001). However, the reported weakness of this system is that restriction of the suicide vector cannot be avoided which severely affects its efficiency. Although the utility of this approach cannot be completely denied for some applications, low-efficiency of these systems makes it difficult to use them when the isolation of a large pool of mutants is intended.

There are several factors contributing to the difficulties to generate a high-throughput mutagenesis system for C.jejuni which is primarily due to the existence of powerful restriction barriers and inefficient expression of the appropriate transposase enzymes invivo, or a combination of these and some other factors (Colegio et al., 2001). In previous STM studies, composite transposons such as Tn5 elements have been used. These transposons are capable to encode two proteins, the transposase and a related protein, the transposition inhibitor, whose relative abundance determines, in part, the frequency of the Tn5 transposition event. The synthesis of these proteins found to be programmed by a complex set of genetic regulatory elements. For example, the host DNA methylation function, dam, inhibits transposase promoter recognition and indirectly enhances the transposition inhibitor promoter. The inhibitor lacks the N-terminal 55 amino acids of the transposase, suggesting that this sequence plays a key role in the transposition process. However, an intact $\mathrm{N}$-terminal sequence is required for the transposase's recognition of the 19-bp end DNA sequences which is the first critical step in the transposition process for Tn5 elements. Transposase-end DNA interaction is itself regulated by an intricate series of reactions involving several host proteins: DnaA, Dam, and Fis. The unique function of this transposase is that it acts primarily in cis and inhibits its own activity in trans. Models to explain these properties are described and it is known that transposition occurs preferentially from newly replicated DNA, yet to be partitioned to progeny cells (SteinigerWhite et al., 2004). Recent elucidation of the X-ray co-crystal structure of Tn5 transposase complexed with a DNA recognition end sequence provided the first three-dimensional picture (Fig. 4.1) of an intermediate in a transposition/retroviral integration pathway (Goryshin et al., 2000). 

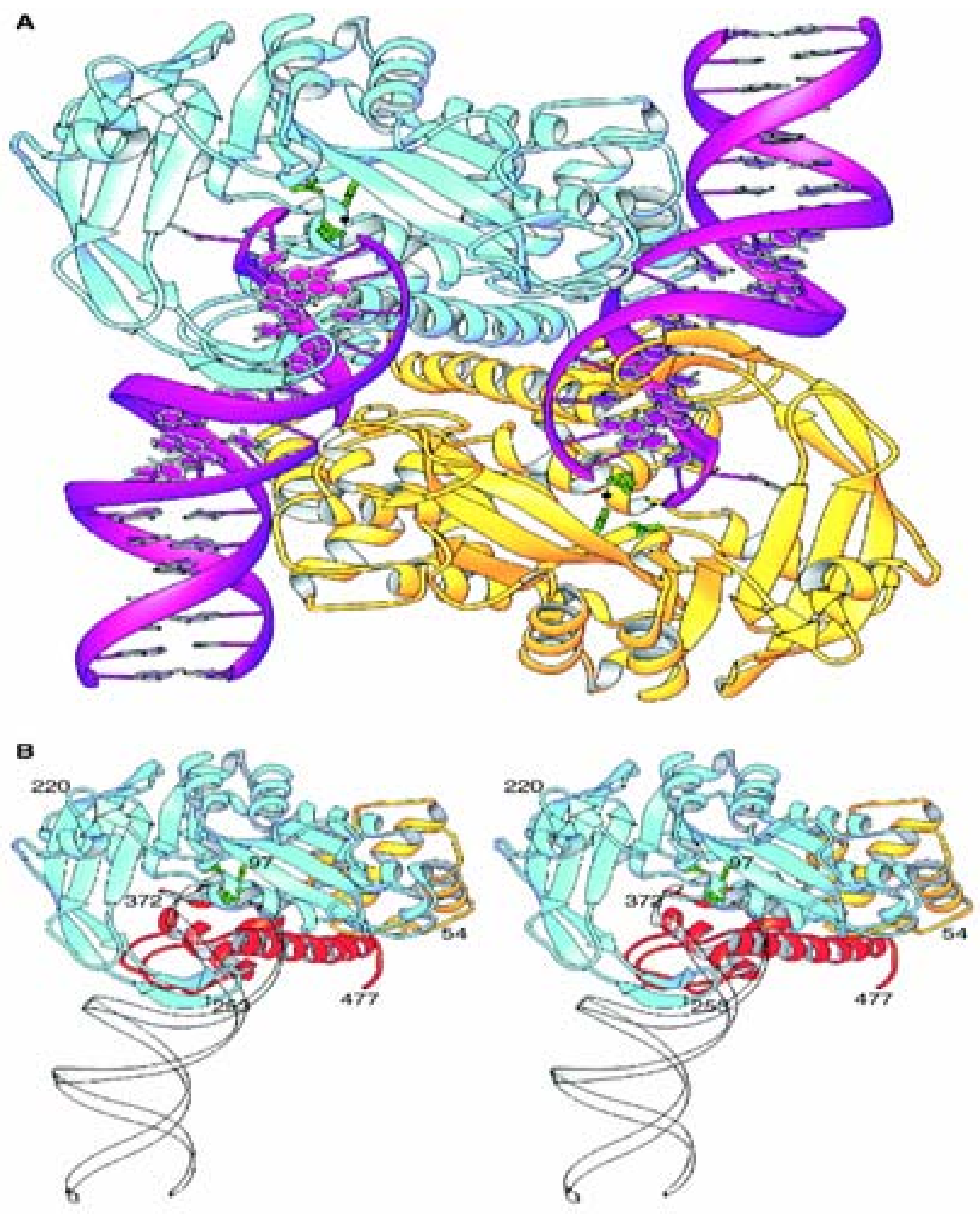

Figure 4.1: The structure of the Tn5 transposase/DNA complex. (A) Ribbon representation of the transposase/DNA dimer viewed along a crystallographic two-fold axis of symmetry. One protein subunit is colored yellow, the other is blue, and the two 19-bp DNA molecules are purple. The three catalytic residues are represented as green ball-and-stick structures, and the associated $\mathrm{Mn}^{2+}$ ion is black. (B) Stereoview of one monomer of transposase. The $\mathrm{NH}_{2}$-terminal domain is yellow, the catalytic domain is blue, and the $\mathrm{COOH}$ terminal domain is red. The active site residues $\mathrm{Asp}^{97}, \mathrm{Asp}^{188}$, and $\mathrm{Glu}^{326}$ and the associated $\mathrm{Mn}^{2+}$ ion are shown as green ball-and-stick structures. The backbone of a double-stranded DNA is represented by transparent ribbons. (from Goryshin et al, 2000). 
Therefore, prokaryotic transposon Tn5 is considered as a model system for studying the molecular mechanism of DNA transposition. There are several steps involved in the process of transposition: (a) binding of transposase monomers to the $19 \mathrm{bp}$ end sequences; (b) oligomerization of the end-bound transposase monomers, forming a transposition synaptic complex; (c) blunt end cleavage of the transposition synaptic complex from adjoining DNA, resulting in formation of a released transposition complex or transposome (d) binding to target DNA; and (e) strand transfer of the transposon 3' ends into a staggered target sequence (Goryshin, and Reznikoff, 1998). It is reported that forming of a functional Tn5 transposome complex is possible by incubating purified transposase with Tn5 DNA. No $\mathrm{Mg}^{++}$is necessary for the formation of these complexes. Upon addition of target DNA and $\mathrm{Mg}^{++}$, Tn5 transposomes can undergo efficient transposition in-vitro. Moreover Tn5 transposomes are reported to be stable for over a month when stored at $4{ }^{\circ} \mathrm{C}$ in the presence of $10 \%$ glycerol and for over a year at $-20^{\circ} \mathrm{C}$ or $-70^{\circ} \mathrm{C}$ without loss of activity. For in-vivo transposition, $1 \mu \mathrm{l}$ of transposome complex can be electroporated to the target cells and in the presence of $\mathrm{Mg}^{++}$of the target cells, an efficient transposition of Tn5 elements can be achieved (Goryshin et al., 2000).

Due to the well defined mechanism of these transposon elements, we chose to construct a Tn5 transposon using the transposon construction vector $\mathrm{pMOD}^{\mathrm{TM}}$. The $\mathrm{pMOD}^{\mathrm{TM}}$ transposon construction vector is a high-copy number, pUC-based vector for the preparation of transposons. The vector contains a multiple cloning site (MCS) between the hyperactive $19 \mathrm{bp}$ mosaic ends that are specifically recognized by Tn5 transposase. The kanamycin resistance gene aphA-3 originated from Campylobacter coli (Trieu-Cuot et al., 1985) and was labelled with 40 different variable tags of 20-25bp. All the tagged aphA-3 genes were subcloned into the $\mathrm{pMOD}^{\mathrm{TM}}$ transposon construction vector. Subsequent digestion with PvuII restriction endonuclease released the Tn5 transposons tagged with 40 variables DNA tags.

This transposome-based in-vivo transposition approach was then used to generate random mutants of C. jejuni strain B2. B2 strain is a clinical isolate and was tested repeatedly in $\mathrm{BALB} / \mathrm{c}$ mice for infection. In comparison to other strains, this isolate showed maximum numbers of bacterial recovery from the livers of BALB/c mice (up to $10^{6} \mathrm{cfu}$ ). In addition, electroporation efficiency of the B2 strain was tested by with the pUOA18 shuttle vector 
which produced $1 \times 10^{4}$ transformants. Due to these important features of B2, we chose this isolate of $C$. jejuni to generate random mutants by in-vivo transposition. The electroporation of the transposome complex generated up to $5.8 \times 10^{3}$ transformants indicating that EZ::TNkan ${ }^{\circledR}$ can undergo efficient transposition in-vivo. For each tag, we selected 55 transformants and by using 12 tags, 660 random mutants were generated. To confirm randomness of our transposon approach, Southern blot analysis of 18 random mutants was performed. In comparison to the total number of 660 mutants which are assumed as random, the sample size of 18 insertional mutants is relatively small. Nevertheless, the obtained data support the notion that EZ::TNkan ${ }^{\circledR}$ elements can be inserted randomly within their target DNA.

\subsection{Isolation of non-motile mutants of $C$. jejuni}

In some pathogenic bacterial species, flagella play a crucial role in the establishment of infection. The biogenesis of a flagellum is carefully regulated and depends on the timed gene expression and synthesis of several flagellum components. In case of C. jejuni, the importance of motility as a virulence factor is best demonstrated by true isogenic nonflagellated mutants. These mutants are unable to colonize the intestine of experimental animals (Guerry et al., 1992).

In order to test the feasibility of our transposition model, we screened 660 random mutants for their flagellar motility and identified three non-motile mutants. Sequence analysis of the DNA of the non-motile mutants revealed two insertions in the following genes; cj0793 (signal transduction histidine kinase), and cj0955c (probable phosphoribosylformylglycinamidine synthase subunit II). Transmission electron microscopic analysis showed normal flagella in the mutant having an insertion in the cj0793 gene. An insertion in the Cj 0955c gene resulted in an aflagellated mutant.

In a previous report, the regulation of the C. jejuni fla regulon was reported which showed that the FlgS/FlgR two-component signal transduction system is essential for the biosynthesis of flagella (Wösten et al., 2004). In this study, non-motile mutant showed an insertion in the gene $c j 0793$ better known as FlgS, which acts as a sensor kinase (Wösten et 
al., 2004). Due to an unidentified signal, the sensor kinase FlgS autophosphorylates and subsequently transfers its phosphate to its cognate response regulator FlgR. Phosphorylated FlgR and the sigma factor RpoN in turn trigger the expression of the genes needed for the assembly of the hook-basal body filament structure. This process is described as phase growth-dependent and very energy consuming. The autokinase activity, typical for twocomponent sensor kinase proteins, was confirmed by observing rapid phosphorylation of FlgS in the presence of ATP. Using a recombinant FlgS sensor protein, it was shown that FlgS was capable to maintain its phosphorylated status for several hours. However, phosphorylation of FlgR showed much less stability which appeared to be a characteristic shared with several other response regulators (Parkinson and Kofoid, 1992). In the absence of the putative signal recognition domain of the FlgS protein, phosphorylated FlgR was destabilized which indicated the dual function of complete FlgS sensor protein (i) to transfer its phosphate to FlgR and (ii) to stabilize the phosphorylated protein. FlgR is a member of the NtrC family of proteins and these proteins bind to enhancer-like sequences ( $>100 \mathrm{bp}$ ) upstream of sigma ${ }^{54}$-dependent promoters to activate the transcription of these promoters (Kustu et al., 1991).

The signals that initiate the FlgS/FlgR two-component system to turn on the fla regulon are not known. C. jejuni showed less tolerance to the environmental stress as is present in the upper gastrointestinal tract than other foodborne pathogens and it cannot survive at a $\mathrm{pH}$ lower than 4.9, and is sensitive to osmotic stress (Park, 2002). Thus, suboptimal environmental conditions may act as a signal. Thus far, activation of the early transcriptional flagellar genes has only been extensively studied for species that carry the master operon flhDC. In E. coli and Salmonella, a large number of global regulatory proteins such as cAMP-CRP, DnaK, DnaJ, GrpE, OmpR H-NS, and adenylate cyclase have been implicated in the activation of these genes, indicating a very complex regulated system (Chilcott, and Hughes, 2000). In species, in which some parts of the flagellar biosynthesis machinery are under the control of a two-component system and sigma ${ }^{54}$, like in $V$. cholera, C. crescentus, and $H$. pylori, the molecules that activate the sensors of these systems have not yet been identified (Wösten et al., 2004). In short, the role of the FlgS/FlgR two component systems in flagellar motility of C. jejuni is not fully elucidated. In our study, 
insertion of EZ::TNkan ${ }^{\circledR}$ transposon in the $c j 0793$ gene resulted in a non-motile mutant of C. jejuni and our findings support the notion that the FlgS/FlgR two component systems has a role in flagellar motility. The other non-motile mutants had an insertion in the gene cj0955c (probable phosphoribosylformylglycinamidine synthase subunit II). The respective protein has not previously been associated with motility of this organism and the function of this proetin in flagellar biosynthesis is unclear. For the complete understanding of the role of these genes in the motility of $C$. jejuni, further analysis would be necessary.

Nevertheless, our results show that our transposon system can in principle be successfully used for the in-vivo transposition to generate random mutants of $C$. jejuni and to knock-out genes relevant to the infection process.

\subsection{Isolation of an osmo-sensitive mutant of $C$. jejuni}

In our second genetic screen, the mutant $\Delta$ GltS showed reduced growth in the presence of $1.5 \%$ (wt/vol) $\mathrm{NaCl}$ when compared with wild-type B2 strain of $C$. jejuni. DNA sequence analysis showed of EZ::TNkan® insertion in the gene cj0009 (gltD) encoding NADPHdependent glutamate synthase small subunit). The NADPH-dependent GltS (NADPH-GltS) is mostly found in bacteria and the enzyme is composed of two tightly bound dissimilar subunits, which form the $a b$ holoenzyme containing one flavin adenine dinucleotide (FAD), one FMN cofactor, and three distinct iron-sulfur clusters: one $[3 \mathrm{Fe}-4 \mathrm{~S}] 0,+1$ center and two low potential [4Fe-4S]+1,+2 clusters. The larger $(a)$ subunit $(160 \mathrm{kDa})$ is known to catalyze the reductive synthesis of L-glutamate from L-glutamine and 2-oxoglutarate (Vanoni et al., 1998). The smaller (b) subunit (52 kDa) is a FAD-dependent NADPH oxidoreductase (Vanoni et al., 1996). Most of the information on this class of enzymes derives from work on the Azospirillum brasilense enzyme (Binda et al., 2000). Accumulation of glutamate in cells grown under osmotic stress is reported (Csonka, 1989, Csonka and Hanson, 1991). The response of bacteria to osmotic stress involves not only depression of functions to facilitate the adaptation of the cell to the environmental change but also influences the activity of cellular enzymes and regulatory proteins. In response to osmotic stress, the amount of unbound water decreases and the concentration of metabolic solutes increases (Cayley et al., 1992; Cayley et al., 1992b). The absolute amount of $\mathrm{K}^{+}$ increases in nearly all cells and normally, the activity of intracellular water is altered by 
these changes which affects the activity of many enzymes and regulatory proteins. Many bacteria accumulate organic compounds, including glutamate, in response to osmotic stress. Glutamate acts as an osmolyte to increase the intracellular concentration of solutes to reduce loss of water by osmosis (Imfoff et al., 1986). Glutamate also acts as a counter ion for $\mathrm{K}^{+}$that accumulates. It has been shown that $\mathrm{K}^{+}$glutamate stimulates protein-DNA interactions. Therefore, the accumulation of glutamate could be involved in regulation of the expression of many genes (Leirmo et al., 1987).

\subsection{In-vivo screening model}

The identification of putative virulence factors of $C$. jejuni has been been hampered by the lack of suitable genetic tools and subsequent in-vivo mutagensis system. Recently, several groups have developed methods for in-vivo and in-vitro transposon mutagenesis. Although being one of the most powerful tools used for in-vivo identification of virulence genes, the efficiency relies on several parameters, such as complexity of the infection dose, efficiency of hybridization, and variability in animal sensitivity to an infectious agent (Karlyshev et al., 2001).

In humans, C. jejuni is able to colonize the small and large intestines thereby causing inflammatory diarrhea with fever. Non-specific defense mechanisms such as gastric acidity and intestinal transit time are considered as important factors However, these mechanisms are not sufficient to prevent colonization and subsequent inflammation. It has been reported that $C$. jejuni is able to invade different host cells and can persist and multiply within intestinal epithelial cells and macrophages in-vitro. This prolonged intra-cellular survival might be one of the important reasons for the development of bacteremia during $C$. jejuni infection (Gerritsen and Veringa, 1993).

An experimental model of murine campylobacteriosis has been previously reported and proven to be a useful in-vivo model to demonstrate bacterial dissemination and tissue invasion. Different strains of mice were tested for the establishment of an in-vivo model and $\mathrm{BALB} / \mathrm{c}$ mice were the most sensitive and showed the most pronounced pathohistological changes in the examined organs. It has been clearly shown that intraperitoneal infection of $\mathrm{BALB} / \mathrm{c}$ mice leads to systemic $C$. jejuni spread and 
colonization of internal organs (Vuc 'kovic' et al., 1998). In this model, primary infection of the liver was found to be the most intense. We therefore, tried to optimize the BALB/c mice model for the screening of random transposon mutants of $C$. jejuni. First, four different wild type strains of C. jejuni (NCTC11168, NCTC11828, 81-176, B2) were with infection doses of $1 \times 10^{8}, 1 \times 10^{9}, 1 \times 10^{10} \mathrm{cfu}$, respectively. For determining the recovery rates of bacteria, all mice were sacrificed seven days after infection. In our experiments, all the strains tested showed only low recovery of bacteria from the livers of BALB/c mice (10-100 cfu), when infected with $1 \times 10^{8}$ cfu of viable $C$. jejuni bacteria.

Using an infection dose of up to $1 \times 10^{9} \mathrm{cfu}$ increased the numbers of bacteria that were recovered from the livers up to 100 fold. However, strains NCTC11168 and 81-176 showed consistent lower recovery rates of bacteria when compared to NCTC11828 and B2. Hepatosplenomegaly and inflammation were consistently found and abcess-like nodes were usually observed on the surface of the livers spleens were abnormally enlarged and inflammed. Histopathology of the tissues showed an inflammatory response with a massive cell infiltrate consisting primarily of neutrophils and rarely lymphocytes. Previously, a similar histological finding was made in infected BALB/c mice (Vuc `kovic' et al., 1998). However, we are not aware of any previous report suggesting the use of BALB/c mice as a screening model for randomly knocked-out mutants of $C$. jejuni. 


\section{References.}

Aarestrup, F.M., Nielsen, E.M., Madsen, M. and Engberg, J. (1997). Antimicrobial susceptibility patterns of thermophilic Campylobacter spp. from humans, pigs, cattle, and broilers in Denmark. Antimicrob Agents Chemother 41: 2244-2250.

Abimiku, A.G., and Dolby, J.M. (1988). Cross-protection of infant mice against intestinal colonisation by Campylobacter jejuni: importance of heat -labile serotyping (Lior) antigens. J. Med. Microbiol 26: 265-268.

Abimiku, A.G., Dolby, J.M., and Borriello. S.P. (1989). Comparison of different vaccines and induced immune response against Campylobacter jejuni colonization Epidemiol Infect 102: 271-80.

Bacon, D.J., Alm, R.A., Burr, D.H., Hu, L., Kopecko, D.J., Ewing, C.P., Trust, T.J. and Guerry, P. (2000). Involvement of a plasmid in virulence of Campylobacter jejuni 81-176. Infect Immun 68: 4384-4390

Bacon, D.J., Alm, R.A., Hu, L., Hickey, T.E., Ewing, C.P., Batchelor, R.A., Trust, T.J. and Guerry, P. (2002). DNA sequence and mutational analyses of the pVir plasmid of Campylobacter jejuni 81-176. Infect Immun 70: 6242-6250.

Biswas, D., Itoh, K., and Sasakawa, C. (2000). Uptake pathways of clinical and healthy animal isolates of Campylobacter jejuni into INT-407 cells. FEMS Immunol Med Microbiol 29: 203-211.

Binda, C., Bossi, R.T., Wakatsuki, S., Arzt, S., Coda, A., Curti, B., Vanoni, M.A. and Mattevi, A. (2000). Cross-talk and ammonia channeling between active centers in the unexpected domain arrangement of glutamate synthase. Structure 8: 1299-1308. 
Blais, B.W., and Phillippe, L.M. (1999). Growth of Campylobacter jejuni in various media under different atmospheric conditions. J. Rapid Methods Autom. Microbiol 7: 291300.

Blaser, M.J., Checko, P., Bopp, C., Bruce, A. and Hughes, J.M. (1982). Campylobacter enteritis associated with foodborne transmission. Am. J. Epidemiol 6: 886-894.

Blaser, M.J., LaForce, F.M., Wilson, N.A. and Wang. W.L. (1983). Experimental Campylobacter jejuni infection of adult mice. Infect Immun 39: 908-916.

Bleumink-Pluym, N. M., Verschoor, F. W., Gaastra, B. A., van der Zeijst, and Fry, B.N (1999). A novel approach for the construction of a Campylobacter mutant library. Microbiology 145: 2145-2151.

Bolton, F.J., and Coates, D. (1983). Development of a blood-free Campylobacter medium: screening tests on basal media and supplements, and the ability of selected supplements to facilitate aerotolerance. J. Appl. Bacteriol 54: 115-125.

Bolton, F.J., Coates, D., Hinchliffe, P.M. and Robertson, L. (1983). Comparison of selective media for isolation of Campylobacter jejuni/coli. J. Clin Pathol. 36:78-83.

Boosinger, T. R., Blevins, W.T., Heron, T.V. and Sunter. J. L. (1990). Plasmid profiles of six species of Campylobacter from human beings, swine and sheep. Ameri. J. Vet. Res 51: 718-22.

Bourke, B. (2002). Campylobacter infection: small bowel and colon. Curr Opin Gastroenterol 18: 4-9.

Bras, A.M., Chatterjee, S., Wren, B.W., Newell, D.G. and Ketley, J.M. (1999). A novel Campylobacter jejuni two-component regulatory system important for temperaturedependent growth and colonization. J. Bacteriol. 181: 3298-3302. 
Brieseman, M.A. (1990). A further study of the epidemiology of Campylobacter jejuni infection. N. Z. Med. J. 103: 207-209.

Buchanan, R.F., and Gibbons, N.F. (1974). Bergey's Manual of Determinative Bacteriology. 8th Edition. The Williams \& Wilkins Co., Baltimore.

Burdett, V. (1991). Purification and characterization of Tet(M), a protein that renders ribosomes resistant to tetracycline. J. Biol. Chem. 266: 2872-2877.

Butzler, J., (1984). Campylobacter Infection in Man and Animals. CRC Press, Inc. Boca Raton, FL.

Buzby J.C., Allos, B.M., and Roberts, T. (1997). The economic burden of Campylobacter associated Guillain-Barré syndrome. J Infect Dis 176: 192-197.

Cayley, S., Lewis, B. A., Guttman, H. J. and Record, Jr. M. T. (1992). Characterization of the cytoplasm of Escherichia coli $\mathrm{K}-12$ as a function of the external osmolarity: implications for protein-DNA interactions in vivo. J. Mol. Biol. 222: 281-300.

Cayley, S., Lewis, B. A. and Record. M. T. (1992). Origins of the osmoprotective properties of betaine and proline in Eschenichia coli. J. Bacteriol. 174:1586-1593.

Carvalho, A.C.F.B., Schocken-Iturrino, R.P., and Cama, L.F.S.A.M. (1997). Isolation of Campylobacter jejuni from viscera and bile secretion of broiler chickens with diarrhea. Revista de Microbiologia 28:125-128.

Chatzipanagiotou, S., Papavasileiou, E., Lakumenta, A., Makri, A., Nicolaou, C., Chantzis, K., Manganas, S. and Legakis. N. I. (2002). Antimicrobial susceptibility patterns of Campylobacter jejuni strains isolated from hospitalized children in Athens, Greece. J. Antimicrob. Chemother 49: 803-805. 
Christopher, F.M., Smith, G.C. and Vanderzant, C. (1982). Examination of poultry giblets, raw milk and meat for Campylobacter fetus subsp. jejuni. J. Food Prot. 45: 260262.

Chilcott, G. S., and Hughes, K. T. (2000). Coupling of Flagellar Gene Expression to Flagellar Assembly in Salmonella enterica Serovar Typhimurium and Escherichia coli Microbiol. Mol. Biol. Rev. 64: 694-708.

CLSI (2006). Performance standards for antimicrobial susceptibility testing. Supplement M100-S16. Wayne, PA: Clinical and Laboratory Standards Institute.

Colegio, O.R., Griffin, I.V., Grindley, N.D. and Galan. J. E. (2001). In-vitro transposition system for efficient generation of random mutants of Campylobacter jejuni. J. Bacteriol 183: 2384-2388.

Corry, J.E., Post, D.E., Colin, P. and Laisney, M.J. (1995). Culture media for the isolation of Campylobacters. Int. J. Food. Microbiol 26: 43-76.

Crawford, J. M. (1999). The liver and biliary tract, p. 892. In R. S. Cotron, V. Kumar, and T. Collins (ed.), Robbin's pathological basis of disease. W. B. Saunders, Philadelphia, Pa.

Crushell, E., Harty, S., Sharif, F. and Bourke. B. (2004). Enteric Campylobacter: purging its secrets? Pediatr Res 55: 3-12.

Csonka, L. N. (1989). Physiological and genetic responses of bacteria to osmotic stress. Microbiol. Rev. 53: 121-147.

Csonka, L. N., and A. D. Hanson. (1991). Procaryotic osmoregulation-genetics and physiology. Annu. Rev Microbiol 45: 569-581. 
De Ley, J. (1978). Modern molecular methods in bacterial taxonomy: evaluation, application, prospects, p. 347-357. In Proceedings of the $4^{\text {th }}$ international conference of plant pathogenic Bacteria, vol. 1. Gibert-Clarey, Tours, France.

Diker, K.S., Hascelik, G. and Diker. S. (1992). colonization of infant mice with flagellar variants of Camyplobacter jejuni. Acta microbial. Hung. 39: 133-136.

Dodd, C.E.R., Sharman, R.L., Bloomfield, S.F., Booth, I.R. and Steward, G.S.A.B. (1997). Inimical processes: bacterial self destruction and sub-lethal injury. Trend. Food. Sci. Tech. 8: $238-241$.

Elliot, W. H. (1985). Metabolism of bile acids in liver and extrahepatic tissues, p. 30033329. In H. Danielsson and J. Sjovall (ed.), Sterols and bile acids. Elsevier North-Holland Biomedical Press, New York, N.Y.

Fernandez, H., and Pison V. (1996). Isolation of thermotolerant species of Campylobacter from commercial chickens livers. Int. J. Food. Microbiol. 29: 75-80.

Field, L. H., Underwood, J. L., pope, L. M. and Berry. L. J. (1981). Intestinal colonization of neonatal animals by Campylobacter fetus subsp. jejuni. Infect. Immun. 33: 884-892.

Flahaut, S., Hartke, A., Giard, J., Benachour, A., Boutibonnes, P., and Auffray, Y. (1996). Relationship between stress response towards bile salts, acid and heat treatment in Enterococcus faecalis. FEMS. Microbiol. Lett. 138: 49-54.

Florent, A. (1959). Two forms of bovine genital vibriosis: Venereal vibriosis due to V. foetus venerialis, and vibriosis of intestinal origin due to $V$ foetus intestinalis, p. 953-957. proceedings of the $16^{\text {th }}$ International Veterinary congress, Madrid, vol.2 (In French).

Fox, J.G. (1997). The expanding genus of Helicobacter: pathogenic and zoonotic potential. Semin. Gastrointest. Dis 8: 124-141. 
Fox, J.G., (1982). Campylobacteriosis: a "new" disease in laboratory animals. Lab Anim Sci, 32: 625-637.

Franco, D.A., (1988). Campylobacter species: considerations for controlling a foodborne pathogen. J. Food. Prot. 51: 145-153.

Friedman, C.R., Neimann, J., Wegener, H.G. and Tauxe, R.V. (2000). Epidemiology of Campylobacter jejuni infections in the United States and other industrialized nations. In: Nachamkin I., Blaser M.J., (editors). Campylobacter. Washington: ASM Press; p. 121-39.

Epstein, W. (1986). Osmoregulation by potassium transport in Escherichia coli. FEMS Microbiol. Rev. 39: 73-78.

Gaudreau, C., and Gilbert. H. (1997). Comparison of disk diffusion and agar dilution methods for antibiotic susceptibility testing of Campylobacter jejuni subsp. jejuni and Campylobacter coli. J Antimicrob Chemother. 39: 707-712.

Golden, N. J., Camilli, A. and Acheson. D. W. K. (2000). Random transposon mutagenesis of Campylobacter jejuni. Infect. Immun. 68:5450-5453.

Gomez-Garces, J. L., Cogollos, R. and Alos. J. I. (1995). Susceptibilities of fluoroquinolone-resistant isolates of Campylobacter jejuni to 11 oral antimicrobial agents. Antimicrob Agents Chemother 39: 542-544.

Goodwin, C.S., Armstrong, J.A., Chilvers, T., Peters, M., Collins, M.D., Sly, L., McConnell, W., and Harper. W. E. S. (1989). Transfer of Camyplobacter pylori and Camyplobacter mustelae to Helicobacter gen. nov. as Helicobacter pylori comb. nov. and Helicobacter mustelae comb. nov., respectively. Int. J. Syst. Bacteriol. 39: 397- 405. 
Goossens, H., and J. Butzler, (1992). Isolation and identification of Campylobacter spp. pages 93-109 in Campylobacter jejuni: Current Status and future trends. I. Nachamkin, M. J. Blaser, and L. S. Tompkins (Ed.). American Society for Microbiology, Washington, DC.

Goryshin, I.Y., Jendrisak, J., Hoffman, L.M., Meis, R. and Reznikoff, W.S. (2000). Insertional transposon mutagenesis by electroporation of released Tn5 transposition complexes. Nat Biotechnol 18: 97-100.

Goryshin, I.Y., Naumann, T.A., Apodaca, J. and Reznikoff, W.S. (2003). Chromosomal deletion formation system based on Tn5 double transposition: use for making minimal genomes and essential gene analysis. Genome Res 13: 644-653.

Goryshin, I.Y. and Reznikoff, W.S. (1998) Tn5 in vitro transposition. J. Biol. Chem. 273: 7367-7374.

Guerry, P., Aim, R.A., Power, M.E., Logan, S.M. and Trust, T.J. (1991). Role of two flagellin genes in Campylobacter motility. J. Bacteriol. 173: 4757-64.

Guerry, P., Alm, R.A., Power, M.E. and Trust, T.J. (1992). Molecular and structural analysis of Campylobacter flagellin. In Campylobacter jejuni: Current status and future trends. I. Nachamkin, M. J. Blaser, and L. S. Tompkins (Ed.). American Society for Microbiology, Washington, D.C.

Gunn, J. S. (2000). Mechanisms of bacterial resistance and response to bile. Microbes Infect. 2:907-913.

Harvey, S.M., (1980). Hippurate hydrolysis by Campylobacter fetus. J. Clin. Microbiol. 11: $435-437$. 
Hazeleger, W.C, Wouters, J.A., Rombouts, F.M., and Abee, T. (1998). Physiological activity of Campylobacter jejuni far below the minimal growth temperature. Appl Environ Microbiol; 64: 3917-3922.

Hébert, G.A., Hollis, D.G., Weaver, R.E., Lambert, M.A., Blaser, M.J., and Moss, C.W. (1982). 30 years of Campylobacters: biochemical characteristics and a biotyping proposal for Campylobacter jejuni. J. Clin. Microbiol 15: 1065-1073.

Hensel, M and Holden, D. W. (1996). Molecular genetic approach for the study of virulence in both pathogenic bacteria anf fungi. Microbiology 142: 1049-1058.

Hensel, M., Shea, J.E., Baumler, A. J., Gleeson, C., Jones, M.D., Dalton, E. and Holden, D.W. (1995). Simultaneous identification of bactetial virulence genes by nnegative selection. Science 269: 400-403.

Hickey, T.E., Baqar, S., Bourgeois, A.L., Ewing, C.P. and Guerry P. (1999). Campylobacter jejuni-stimulated secretion of interleukin-8 by INT407 cells. Infect Immun 67: 88-93.

Hoge, C. W., Gambel, J. M., Srijan, A., pitarangsi, C. and Echeverria. P. (1998). Trends in antibiotic resistance among diarrhoeal pathogens isolated in Thailand over 15 years. Clin. Infect. Dis. 26:341-345.

Hoppert, M., and Holzenburg, A. (1999). Electron microscopy in microbiology. Bios. Scientific Publications, Oxford, England.

Hu, L., and Kopecko, D. J. (1999). Campylobacter jejuni 81-176 associates with microtubules and dynein during invasion of human intestinal cells. Infect Immun 67: 41714182. 
Hunt, J.M., and Abeyta, C. (1995). Campylobacter. Pages 7.01-7.27 in FDA Bacteriological Analytical Manual. 8th Edition. AOAC International, Gaithersburg, MD.

Hunt, J.M., Abeyta, C. and Tran, T. (1998). Campylobacter. Pages 7.01-7.24 in FDA Bacteriological Analytical Manual. 8th Edition (Revision A). AOAC International, Gaithersburg, MD.

Imfoff, J. F. (1986). Osmoregulation and compatible solutes in eubacteria. FEMS Microbiol. Rev. 39:57-66. Makemason, J. C., and J. W. Hastings. (1979). Glutamate functions in osmoregulation in a marine bacterium. Appl. Environ. Microbiol. 38:178-180.

Jeffrey, J.S., Hunter, A. and Atwill, E.R. (2000). A field-suitable, semisolid aerobic enrichment medium for isolation of Campylobacter jejuni in small numbers. J. Clin. Microbiol. 38:1668-1669.

Jin, S., Joe, A., Lynett, J., Hani, E.K., Sherman, P. and Chan V.L (2001). JlpA, a novel surface-exposed lipoprotein specific to Campylobacter jejuni, mediates adherence to host epithelial cells. Mol Microbiol 39:1225-1236.

Johnson, W.M., and H. lior. (1988). A new heat-labile cytolethal distending tixin (CLDT) produced by Campylobacter spp. Microb. Pathog 4: 115-126.

Karlyshev, A.V., Linton, D., Gregson, N.A., Lastovica, A.J., and Wren, B.W. (2000). Genetic and biochemical evidence of a Campylobacter jejuni capsular polysaccharide that accounts for Penner serotype specificity. Mol Microbiol 35: 529-541.

Karlyshev, A.V., McCrossan, M.V., and Wren, B.W. (2001). Demonstration of polysaccharide capsule in Campylobacter jejuni using electron microscopy. Infect Immun 69: 5921-5924. 
Karlyshev, A. V. and Wren, B. W. (2005). Development and application of an insertional system for gene delivery and expression in Campylobacter jejuni. Appl Environ Microbiol 71: 4004-4013.

Karlyshev, A.V., Oyston, P.C., Williams, K., Clark, G.C., Titball, R.W., Winzeler, E.A., and Wren, B.W. (2001). Application of high-density array-based signature-tagged mutagenesis to discover novel Yersinia virulence-associated genes. Infect. Immun 69: 7810-7819.

Karlyshev A.V., and Wren, B.W. (2001) Detection and initial characterization of novel capsular polysaccharide among diverse Campylobacter jejuni strains using alcian blue dye. J Clin Microbiol 39: 279-284.

Kaufmann, S. H., and ladel, C.H. (1994). Application of knockout mice to the experimental analysis of infections with bacteria and protozoa. Trends Microbiol. 2: 235242 .

Kaufmann, S.H. (1994). Bacterial and protozoal infections in genetically disrupted mice. Curr. Opin. Immunol. 6: 518-525.

Kendall, E.J., and Tanner E.I. (1982) Campylobacter enteritis in general practice. $J$ Hyg 88: $155-163$.

Konkel, M.E., and Joens, L.A. (1989). Adhesion to and invasion of HEp-2 cells by Campylobacter spp. Infect. Immun. 57: 2984-2990.

Konkel, M.E., Monteville, M.R. Rivera-Amill, V. and Joens. L.A. (2001). The pathogenesis of Campylobacter jejuni-mediated enteritis. Curr. Issues Intest. Microbiol. 2: $55-71$. 
Konkel, M.E., Garvism, S.G. Tipton, S.L. Anderson, D.E.J. and Cieplak, W.J. (1997). Identification and molecular cloning of a gene encoding a fibronectin-binding protein (CadF) from Campylobacter jejuni. Mol Microbiol 24: 953-963.

Konkel, M.E., Kim, B.J. Klena, J.D., Young, C.R., and Ziprin. R. (1998). chracterization of thermal stress response of Campylobacter jejuni. Infect. Immune. 66:362366.

Kopecko D.J., Hu, L. and Zaal, K.J. (2001). Campylobacter jejuni-microtubuledependent invasion. Trends Microbiol 9:389-396.

Kustu, S., North, A.K. and Weiss, D.S. (1991). Prokaryotice transcriptional enhancers and enhancer-binding proteins. Trends biochem Sci. 16: 397-402.

Labigne-Roussel, A., Courcoux, P., and Tompkins, L. (1988). Gene disruption and replacement as a feasible approach for mutagenesis of Campylobacter jejuni. J. Bacteriol. 170:1704-8.

Lara-Tejero, M., and Galán, J.E. (2001). CdtA, CdtB, and CdtC form a tripartate complex that is required for cytolethal distending activity. Infect. Immun. 69: 4358-4365.

Labigne-Roussel, A., Harel, J. and Tompkins, L. (1987). Gene transfer from Escherichia coli to Campylobacter species: development of shuttle vectors for genetic analysis of Campylobacter jejuni. J. Bacteriol. 169: 5320-23.

Labigne-Roussel, A., Courcoux, P. and Tompkins. L. (1988). Gene disruption and replacement as a feasible approach for mutagenesis of Campylobacter jejuni. J. Bacteriol. 170:1704-1708. 
Lee, C. Y., Tai, C. L. and Lin, S. C. (1994). Occurrence of plasmids and tetracycline resistance among Campylobacter jejuni and Campylobacter coli isolated from whole market chickens and clinical samples. Int. J. Food Microbiol. 24:161-70

Levy, A.J. (1946). A gastro entritis out-break probably due to a bovine strain of vibrio. Yale J. Biol. Med. 18: 243- 258.

\section{Leirmo, S., C. Harrison, D. S. Caley, R. A. Burgess, and M. T. Record, Jr. (1987).}

Replacement of potassium chloride by potassium glutamate dramatically enhances proteinDNA interactions in vitro. Biochemistry 26: 2095-3001.

Lior, H., Woodward, D.L., Edgar, J.A., Laroche, L.J. and Gill, P. (1982). Serotyping of Campylobacter jejuni by slide agglutination based on heat-labile antigenic factors. J. Clin. Microbiol. 15: 761-768.

Lin, J., M. Akiba, O. Sahin, and Zhang. Q (2005). CmeR functions as a transcriptional repressor for the multidrug efflux pump CmeABC in Campylobacter jejuni. Antimicrob. Agents and Chemother. 49:1067-1075.

Linton, D., A. Lawson, J., Owen, R. J. and Stanley. J. (1997). PCR detection, identification to species level, and fingerprinting of Campylobacter jejuni and Campylobacter coli direct from diarrheic samples. J Clin Microb 35: 2568-2572.

Luber, P., Wagner, J., Hahn, H. and Bartelt. E (2003). Antimicrobial resistance in Campylobacter jejuni and Campylobacter coli strains isolated in 1991 and 2001-2002 from poultry and humans in Berlin, Germany. Antimicrob. Agents Chemother. 47:3825-3830.

Manavathu, E., Hiratsuka, K. and D. Taylor. (1988). Nucleotide sequence analysis and expression of tetracycline-resistance gene from Campylobacter jejuni. Gene. 62:17-26. 
Mead P.S., Slutsker, L., Dietz, V., McCaig, L.F., Bresee, J.S., Shapiro, C., Griffin, P.M., and Tauxe, R.V. (1999). Food-related illness and death in the United States. Emerg Infect Dis, 5: 607-625.

Merops (2002) Merops; The Protease Database, release 6.0, August 30, 2002. http://merops.sanger.ac.uk/.

Migaki, G., and Capen, C.C. (1984). Animal model in biomedical research, p. 667-695. In J.G.Fox , B.J.Cohen, and F. M. Loew (ed.), Laboratory animal Medicine . Acedemic press, Inc., Orlando, Fla.

Miller, J.F., Dower, W.J., and Tompkins, L.S. (1988). High voltage electroporation of bacteria: genetic transformation of Campylobacter jejuni with plasmid DNA. Proc. Natl. Acad. Sci. USA 85: 856-60.

Moran, A.P., and Upton, M.E. (1987). Factors affecting production of coccoid forms by Campylobacter jejuni on solid media during incubation. J. App. Bacteriol 62:527-537.

Morooka, T., Umeda, A., and Amako, K. (1985). Motility as intestinal colonization factor for Campylobacter jejuni. J. Gen. Microbiol.131: 1973-1980.

Moser, I., Schroeder, W., and Salnikow, J. (1997). Campylobacter jejuni major outer membrane protein and a 59-kDa protein are involved in binding to fibronectin and INT 407 cell membranes. FEMS Microbiol Lett 157: 233-238.

MSFFG (2001). UK publicly-funded research relating to Campylobacter. Report of the Microbiological Safety of Food Funders Group (MFSSG), Food Standards Authority, September 10th, 2001, 41 pages.

Murphy, C., Carroll, C., and Jordan, K. N. (2003). Identification of novel stress resistance mechanism in Camyplobacter jejuni. J Appl Microbiol, 95: 704-708. 
Murphy, C., Carroll, C., and Jordan, K.N., (2003). Induction of an adaptive tolerance response in the foodborne pathogen Campylobacter jejuni. FEMS Microbiol Lett, 223: 8993.

Nachamkin, I. (1994). Antimicrobial susceptibilities of Campylobacter jejuni and Campylobacter coli to ciprofloxacin, erythromycin and tetracycline from 1982 to 1992. Med Microbiol Lett 3: 300-305.

Newell, D.G., McBride, H., Saunders, F., Dehele, Y. and Pearson, A.D. (1985). The virulence of clinical and environmental isolates of Campylobacter jejuni. J. Hyg. 94: 4554.

NCCLS (1997). Methods for dilution antimicrobial susceptibility tests for bacteria that grow aerobically, $4^{\text {th }}$ edn. Approved Standard M7-A4. Wayne, PA: National Committee for Clinical Laboratory Standards.

O’Brien, E., D’Souza, R., Gilroy, N., Burgess, M., Lister, S., McLntyre, P., Torvaldsen, S., Moser, K., and Milton. A. (1999). Australia's notifiable disease status, 1997. Commun. Dis. Intell. 23:1-27.

On, S.L.W., Bloch, B., Holmes, B., Hoste, B., and Vandamme, P. (1995). Campylobacter hyointestinalis subsp. lawsonii subsp. nov., isolated from the porcine stomach, and an emended description of Campylobacter hyointestinalis. International J. Systemat. Bacteriol 45: 767-774.

Pace, J.L., Chai, T., Rossi, H.A., and Jiang, X. (1997). Effect of bile on Vibrio parahaemolyticus. Appl. Enviro. Microbiol 63: 2372-2377.

Parkhill J., Wren B.W., Mungall, K., Ketley, J.M., Churcher, C., Basham, D., Chillingworth, T., Davies, R.M., Feltwell, T., Holyrod, S., Jagels, K., Karlyshev, A.V., 
Moule, S., Pallen, M.J., Penn, C.W., Quail, M.A., Rajandream, M.A., Rutherford, K.M., van Vliet, A.H., Whitehead, S., and Barrell, B.G. (2000). The genome sequence of the food-borne pathogen Campylobacter jejuni reveals hypervariable sequences. Nature 403: $665-668$.

Payot S., Dridi S. and Laroche M. (2001). Prevalence and antimicrobial resistance of Campylobacter coli isolated from fattening pigs in France. Vet Microbiol 101: 91-9.

Pei, Z., and Blaser, M.J., (1993). PEB1, the major cell-binding factor of Campylobacter jejuni, is a homolog of the binding component in gram-negative nutrient transport systems. J Biol Chem 268:18717-18725.

Penner, J.L., and Hennessy, J.N. (1980). Passive hemagglutination technique for serotyping Campylobacter fetus subsp. jejuni on the basis of soluble heat-stable antigens. $J$. Clin. Microbiol. 12: 732-737.

Pickett, C.L., Pesci, E.C., Cottle, D.L., Russell, G., Erden, A.N., and Zeytin, H. (1996). Prevelance of cytolethal distending toxin production in Campylobacter jejuni and relatedness of Campylobacter cdtB genes . Infec Immun 64: 2070-2078.

Prats, G., Mirelis, B., lovet, T.L., Munoz, C., Miró, E., and Navarro. F. (2000). Antibiotic resistance trends in enteropathogenic bacteria isolated in 1985-1987 and 19951998 in Barcelona. Antimicrob. Agents Chemother 44:1140-1145.

Purdy, D., Buswell, C.M., Hodgson, A.E., McAlpine, K., Henderson, I., and Leach, S.A. (2000). Characterisation of cytolethal distending toxin (CDT) mutants of Campylobacter jejuni. J Med Microbiol 49: 473-479.

Rhoades, R.A., and Tanner, G.A. (1995). Medical Physiology. Pages 530-570. Little, Brown and Company. New York, NY. RKI, 2006. 
Richardson, P., and S. Park. 1997. Integration of heterologous plasmid DNA into multiple sites on the genome of Campylobacter coli following natural transformation. $J$ Bacteriol 179:1809-12

RKI. Ausgewählte Zoonosen im Jahr 2005: Durch Lebensmittel übertragbare bakterielle gastrointestinale Infektionen. Epidemiologisches Bulletin. 41: 351-356.

Ross, J.I., Eady, E.A. Cove, J.H and Cunliffe. W.J (1998). 16S rRNA mutation associated with tetracycline resistance in a gram-positive bacterium. Antimicrob. Agents Chemother. 42:1702-1705.

Rollins, D.M., and Colwell, R.R. (1986). Viable but nonculturable stage of Campylobacter jejuni and its role in survival in the natural aquatic environment. Appl. Enviro. Microbiol 52: 531-538.

Russell, R. G., M. J. Blaser, J. I. Sarmiento, and J. Fox. (1989). Experimental Campylobacter jejuni infection in Macaca nemestrina. Infect Immun 57:1438-1444.

Shane, S.M., (1997). Campylobacteriosis. Pages 235-245 in Diseases of Poultry. 10th Edition. Clanek, B. W., H. J. Barnes, C. W. Beard, L. R. McDougald, and Y. M. Saif (Ed.). Iowa State University Press, Ames, IA.

Sambrook, J. and Russell, D. (2001). Molecular Cloning: A Laboratory Handbook, 3rd edn. Cold Spring Harbor Laboratory Press, Cold Spring Harbor, N.Y.

Schmidt-Ott, R. Pohl, S. Burghard, S. Weig, M. and Groß. U. (2005). Identification and characterization of a major subgroup of conjugative Campylobacter jejuni plasmids. $J$ Infect 50:12-21. 
Schmidt-Ott, R., Schmidt, H., Feldmann, S., Brass, F., Krone, B., and Groß. U. (2006). Improved serological diagnosis stresses the major role of Campylobacter jejuni in triggering Guillain-Barré syndrome. Clin Vaccine Immunol 13: 779-783.

Sebald, M., and Véron, M. (1963). Teneur enbases de I' ADN et classification des vibrions. Ann Inst Pasteur 105 : 897-910.(In French)

Schnappinger, D., and W. Hillen. (1996). Tetracyclines: antibiotic action, uptake, and resistance mechanisms. Arch Appl Environ Microbiol. 63:3405-3411.

Short, J.M., Fernandez, J.M., Sorge, J.A., and Huse, W.D. (1988). Lambda ZAP: a bacteriophage lambda expression vector with in vivo excision properties. Nucleic Acids Res. 16: 7583- 7600 .

Skerman, V. B. D., McGowan, V., and Sneath, P. H. A. (1980). Approved lists of bacterial names. Int J Systema Bacteriol 30: 225-420.

Skirrow, M.B., and Benjamin, J. (1980). Differentiation of enteropathogenic Campylobacter. Journal of Clin Path 32: 1122-27.

Skirrow, M. B., (1977). Campylobacter enteritis: a "new” disease. Br. Med. J. 2: 9-11.

Smibert, R.M., (1974). Genus II. Campylobacter. Pages 207-211 in Bergey's Manual of Determinative Bacteriology. 8th Edition. R. F. Buchanan and N. F. Gibbons (Ed.). Williams \& Wilkins.

Smibert, R.M., (1978). The genus Campylobacter. Ann Rev Microbiol 32: 673-709.

Smith, T., and Taylor. M. (1919). Some morphological and biological characters of the spirilla ( Vibrio fetus, n. sp.) associated with disease of the fetal membrane in cattle. $J$ exp Med 30: 299-311. 
Steele, M., Marcone, M., Gyles, C., Chan, V.L., and Odumeru. J. (2006). Enzymatic activity of Campylobacter jejuni hippurate hydrolase. Prot. Eng. Desig. \& Select 19: 17-25

Stead, D., and Park, S.F. (2000). Roles of Fe superoxide dismutase and catalase in resistance of Campylobacter coli to freeze-thaw stress. Appl. Environ. Microbiol 66: $3110-3112$.

Stern, N.J., Wojton, B., and Kwiatek, K. (1992). A differential-selective medium and dry ice-generated atmosphere for recovery of Campylobacter jejuni. J Food Protect 55: 514-517.

Steinhauserova, J. Češkova, K. Fojtikova, I. Obrovska (2001) Identification of thermophilic Campylobacter spp. by phenotypic and molecular methods Journal of Applied Microbiology 90: 470-475.

Takkinen, J., Ammon, A., Robstad, O., Breuer, T., and Campylobacter Working Group. (2003). European survey on Campylobacter surveillance and diagnosis 2001. Euro Surveill. 8: 207-13.

Talsma, E., Goettsch, W.G., Nieste, H. L., Schrijnemakers, P.M. and Sprenger. M. J (1999). Resistance in Campylobacter species: increased resistance to fluoroquinolones and seasonal variation. Clin Infect Dis 29: 845-848.

Tauxe, R., (1992). Epidemiology of Campylobacter jejuni infections in the United States and other industrialized nations. In: Nachamkin I, Blaser MJ, Tompkins L (eds) Campylobacter jejuni: Current Status and Future Trends. American Society for Microbiology, New York, pp 9-1922.

Taylor. D.E., (1992). Genetics of Campylobacter and Helicobacter Annu. Rev. Microbiol. 46: $35-64$. 
Taylor, D.E., and Courvalin, P. (1988). Mechanisms of antibiotic resistance in Campylobacter species. Antimicrob Agents Chemother 32:1107-1112.

Thanassi, D. G., Cheng, L. W. and Nikaido. H. (1997). Active efflux of bile salts by Escherichia coli. J. Bacteriol. 179:2512-2518.

Thies, F.L., Hartung, H., and Giegerich. G., (1998). Cloning and expression of the Camyplobacter jejuni ion gene. FEMS Microbiol Lett 165: 329-334.

Thies, F.L., Karch, H., Hartung, H.P., and Giegerich. G. (1999). Cloning, sequencing and molecular analysis of the Camyplobacter jejuni groESL bicistronic operon Microbiol 145: 89-98.

Trieu-Cuot, P., Gerbaud, G., Lambert, T., and Courvalin, P. (1985). In vivo transfer of genetic information between gram-positive and gram-negative bacteria. EMBO J 4: 35833587.

Ursing, J.B., Lior, H. and Owen, R.J. (1994). Proposal of minimal standards for describing new species of the family Campylobacteraceae. Int J Syst Bacteriol 44: 842845.

Vandamme, P., and De Ley, J. (1991). Proposal for a new family, Campylobacteraceae. Int J Syst Bacteriol 41: 451-455.

Vandamme, P., Falsen, E., Rossau, R., Hoste, B., Segers, P., Tytgat, R., and De Ley, J. (1991). Revision of Camyplobacter, Helicobacter, and Wollinella taxonomy: emendation of generic descriptions and proposal of Arcobacter gen. Int J Syst Bacteriol 41: 88-103. Valentine, R. C., Shapiro, B. M. and Stadtman, E. R. (1968). Regulation of glutamine synthetase. XII. Electron microscopy of the enzyme from Escherichia coli. Biochemistry 7:2143-2152. 
Vieira, J., and Messing, J. (1982). The pUC plasmids, an M13 mp7-derived system for insertion mutagenesis and sequencing with synthetic universal primers. Gene 19: 259-68.

Vinzent, R., Dumas, J., and Picard. N. (1947). Serious septicemia during pregnancy due to a Vibrio, followed by abortion. Bull Acad Nat Med 131: 90-92 (In French).

Vanoni M. A., Verzotti, E., Zanetti, G., and Curti, B. (1996). Properties of the recombinant $b$ subunit of glutamate synthase. Eur J Biochem 236: 937-946

Vanoni M. A., Fischer F., Ravasio S., Verzotti E., Edmondson D. E., and Hagen W. H. (1998). The recombinant $a$ subunit of glutamate synthase: spectroscopic and catalytic properties. Biochem 37: 1828-1838

Vuc`kovic' D, Abram M, Doric' M. (1998). Primary Campylobacter jejuni infection in different mice strains. Microb Pathog 24: 263-8.

Watabe, K., Ishikawa, T., Mukohara, Y., and Nakamura, H. (1992) Enzymatic activity of Campylobacter jejuni hippurate hydrolase J. Bacteriol., 174: 962-969.

Wang, W.L., Luechtefeld, N.W., Reller, L.B., and Blaser, M.J. (1980). Enriched Brucella medium for storage and transport of cultures of Campylobacter fetus subsp. jejuni. J Clin Microbiol 12: 479-480.

Wang, Y. (1991). Transformation and antibiotic resistance in Campylobacter species. $\mathrm{PhD}$ thesis. Univ. Alberta, Edmonton, Canada.

Wang, Y., and Taylor, D. E. (1990). Natural transformation of Campylobacter species. J. Bacteriol. 172: 949-55. 
Wang, Y., and Taylor, D.E. (1990). Chloramphenicol resistance in Campylobacter coli nucleotide sequence, expression, and cloning vector construction. Gene 94: 23-28.

Wassenaar, T.M., Bleumink-Pluym, N.M.C., and van der Zeijst, B.A.M. (1991). Inactivation of Campylobacter jejuni flagellin genes by homologous recombination demonstrates that flaA but not flaB is required for invasion. EMBO J 8: 2055-61.

Wassenaar T.M., and Blaser M.J. (1999). Oct Pathophysiology of Campylobacter jejuni infections of humans. Microbes Infect 1: 1023-33.

Whitehouse, C.A., Balbo, P.B., Pesci, E.C., Cottle, D.L., Mirabito, P.M., and Pickett. C.L. (1998). Campylobacter jejuni cytolethal distending toxin causes a G2-phase cell cycle block. Infect.immin 66:1934-1940.

Woolridge, K.G., and Ketley, J.M. (1997). Campylobacter-host cell interactions. Trends Microbiol 5: 96-102 Kopecko DJ, Hu L, Zaal KJ (2001) Campylobacter jejunimicrotubule-dependent invasion. Trends Microbiol 9: 389-396.

Wösten, M.M.S.M., Wagenaar, J.A., and van Putten J.P.M. (2004). The FlgS/FlgR two-component signal transduction system regulates the fla regulon in Campylobacter jejuni. J. Biol. Chem. 279:16214-16222.

Wu, Y.L., Lee, L.H., Rollins, D.M., and Ching, W.M. (1994). Heat shock and alkaline $\mathrm{pH}$-induced proteins of Campylobacter jejuni: Characterization and immunological properties. Infect. Immun.62: 4256-4260.

Yan, W. (1990). Characterization of erythromycin resistance in Campylobacter spp. PhD thesis. Univ. Alberta, Edmonton, Alberta, Canada.

Yao, R., Burr, D.H., Doig, P., Trust, T.J., Niu, H., and Guerry. P. (1994). Isolation of motile and non-motile insertional mutants of Campylobacter jejuni: the role of motility in adherence and invasion of eukaryotic cells. Mol Microbiol 14: 883-893. 
Zilhao, R., Papadopoulou, B.P., and Courvalin. P. (1988). Occurrence of the Campylobacter resistance gene tetO in Enterococcus and streptococcus spp. Antimicrob. Agents chemother. 32:1793-1796. 


\section{Appendix}

ACCESSION M26832 aphA gene

1 gataaaccca gcgaaccatt tgaggtgata ggtaagatta taccgaggta tgaaaacgag

61 aattggacct ttacagaatt actctatgaa gcgccatatt taaaaagcta ccaagacgaa

121 gaggatgaag aggatgagga ggcagattgc cttgaatata ttgacaatac tgataagata

181 atatataata tatctttact accaagacga taaatgcgtc ggaaaagtta aactgcgaaa

241 aaattggaac cggtacgctt atatagaaga tatcgccgta tgtaaggatt tcagggggca

301 aggcataggc agcgcgctta tcaatatatc tatagaatgg gcaaagcata aaaacttgca

361 tggactaatg cttgaaaccc aggacaataa ccttatagct tgtaaattct atcataattg

421 tggtttcaaa atcggctccg tcgatactat gttatacgcc aactttgaaa acaactttga

481 aaaagctgtt ttctggtatt taaggtttta gaatgcaagg aacagtgaat tggagttcgt

541 cttgttataa ttagcttctt ggggtatctt taaatactgt agaaaagagg aaggaaataa

601 taaatggcta aaatgagaat atcaccggaa ttgaaaaaac tgatcgaaaa ataccgctgc

661 gtaaaagata cggaaggaat gtctcctgct aaggtatata agctggtggg agaaaatgaa

721 aacctatatt taaaaatgac ggacagccgg tataaaggga ccacctatga tgtggaacgg

781 gaaaaggaca tgatgctatg gctggaagga aagctgcctg ttccaaaggt cctgcacttt

841 gaacggcatg atggctggag caatctgctc atgagtgagg ccgatggcgt cctttgctcg

901 gaagagtatg aagatgaaca aagccctgaa aagattatcg agctgtatgc ggagtgcatc

961 aggctctttc actccatcga catatcggat tgtccctata cgaatagctt agacagccgc

1021 ttagccgaat tggattactt actgaataac gatctggccg atgtggattg cgaaaactgg

1081 gaagaagaca ctccatttaa agatccgcgc gagctgtatg atttttaaa gacggaaaag

1141 cccgaagagg aacttgtctt ttcccacggc gacctgggag acagcaacat ctttgtgaaa

1201 gatggcaaag taagtggctt tattgatctt gggagaagcg gcagggcgga caagtggtat

1261 gacattgcct tctgcgtccg gtcgatcagg gaggatatcg gggaagaaca gtatgtcgag

1321 ctatttttg acttactggg gatcaagcct gattgggaga aaataaata ttatattta

1381 ctggatgaat tgtttagta cctagattta gatgtctaaa aagctt

ACCESSION AY190525 (tetO) gene,

1 atgaaaataa ttaacttagg cattctggct cacgttgacg caggaaagac aacattaacg

61 gaaagtttat tgtataccag tggtgcaatt gcagaactag ggagcgtaga tgaaggcaca 121 acaaggacag atacaatgaa tttggagcgt caaaggggaa tcactatcca gacagcagtg 181 acatcttttc agtgggagga tgtaaaagtc aacattatag atacgccagg ccatatggat 241 tttttggcgg aagtataccg ttctttatcc gcattagacg gagcagtatt attagttect 301 gcaaaggatg gcatacaggc acagacccgt atactgtttc atgcactaca gataatgaag 361 attccgacaa ttttttcat caataaaatt gaccaagagg ggattgattt gccaatggta 421 tatcgggaaa tgaaagcaaa gctttcttcg gaaattatag tgaagcaaaa ggttgggcag 481 catccccata taaatgtaac ggacaatgac gatatggaac agtgggatgc ggtaattatg 
541 ggaaacgatg aactattaga gaaatatatg tcagggaaac cgtttaaaat gtcagaactg 601 gaacaggaag aaaacaggag attccaaaac ggaacgttat ttcccgttta tcacggaagc 661 gctaaaaaca atctggggat tcggcagctt atagaagtaa ttgccagtaa attttattca 721 tcaacgcctg aaggtcaatc tgaactatgc gggcgggttt ttaagattga atattcaaag 781 aaaaggcggc gttttgttta tgtgcgtata tatagcggaa cattgcattt gagggatgtt 841 attagaatat ctgaaaaaga gaaaataaaa atcacagaga tgtgtgttcc gacaaacggt 901 gaattatatt catccgatac agcctgctct ggtgatattg taattttacc aaatgatgtt 961 ttgcagctaa acagtatttt ggggaacgaa atactgttgc cgcagagaaa atttattgaa 1021 aatcctctcc ctatgctcca aacaacgatt gcagtaaaga aatctgaaca gcgggaaata 1081 ttgcttgggg cacttacaga aatttcagat ggcgaccctc ttttaaaata ttatgtggat 1141 actacaacgc atgagattat actttctttt ttggggaatg tgcagatgga agtcatttgt 1201 gccatccttg aggaaaaata tcatgtggag gcagaaataa aagagcctac tgttatatat 1261 atggaaagac cgcttagaaa agcagaatat accatccaca tagaagtccc gccaaatcct 1321 ttctgggctt ctgtcgggtt gtccatagag ccgctcccta ttggaagcgg agtgcagtat 1381 gaaagcagag tttcacttgg atatttaaat caatcgttcc aaaatgcggt tatggagggg 1441 gttctttatg gctgcgagca ggggctgtat ggatggaaag tgacagactg taaaatctgt 1501 tttgaatatg gattgtatta tagtcctgta agtacccccg cagactttcg gctgctttcc 1561 cctatcgtat tggagcaggc tttaaaaaa gcagggacag aactattaga gccatatctc 1621 cactttgaaa tttatgcacc gcaggaatat ctctcacggg cgtatcatga tgctccaagg 1681 tattgtgcag atattgtaag tactcagata aagaatgacg aggtcattct gaaaggagaa 1741 atccctgcta gatgtattca agaatacagg aacgatttaa cttgtttcac aaatgggcag 1801 ggagtctgct tgacagagtt aaaaggatac cagccagcta ttggtaaatt tattgccaa 1861 ccccgccgcc cgaatagccg tatagataag gttcggcata tgttccacaa gttagcttaa

\section{ACCESSION AASY01000012 REGION: $48614 . . .49633$}

Signal transduction histidine kinase $\mathrm{Cj} 0793$

1 atgaatgaaa gtattttaaa aagtttagat tcaaatgaaa aagaaaccct acaaaaaggc

61 ttagaaagtc ttatagaaca aacttatgta atagaaaatg aatacaaaac tttaaatgaa 121 aactataatt ccttacgcgc aatggttgat gagattatag aggtattgcc tagtgcgctt 181 tggattttag ataaagaaaa aaatattatt ttacaaaatc aagaagcctt gaaaaatcca 241 aaattactta gtatcattag tcttgataaa attcgcgatg agcttgaatt tgaaggtagg 301 ttttatgcgg taaaaatcat agcacataat gaaaaacta tagtttcagc tacagatatt 361 agcgatgaaa aacgcaatga aaggcttgca agcatgggta gtgtagcggc tcatttggca 421 catgagataa gaaatcctat tggatctata tctttgcttg cttcaaccct ttttgctcgt 481 agtgagctta aaaataagca tatagttctt gaaatccaaa aggctattgc tagagtagag 541 cgtatcgtaa attcaacttt actttttact aagggtgtgc acatcaatgc tttaaattt 601 aatcttttag agttaaaaga agagtgtgaa agtgccatta actcttataa tttcacttct 
661 caaatagact ttgaaatatc tttttggat aagcagattt gtgctgataa agctcttctt 721 ggtttggttt tgcaaaattt gatttataat gctattgatg cgatagaaga aagcgaatgt 781 gaaaagccta tgattaaaat tttagcaagt tgtgataatg aaaaaatatg catcagagtg 841 tatgataatg gttgtgaaat aaaagatgag aaattggttt ttgaagcttt taaaacaaca 901 aaacttaaag gcaatggact tggtttgtct ctttctaaag aaatcataaa cgctcataag 961 ggagagttaa gtttcaaag tgatcctaag aattttatt ttaccttacc tttggtgtga

\section{ACCESSION AASY01000003 REGION: 152963...153616}

phosphoribosylformylglycinamidine synthase Cj0955c purL.

1 atgactttag ttttaattat actcgttatt ttggtgtttt actggtatta taaaacttgg 61 ggaaaacagg attttttaaa ctcagctaca agaggagcca aaggctttgc taagggtttt 121 gctcgtgggg ttatggaaga aagaatggat gagtttaaaa ggcgtatgaa ttactatgtt 181 atcgcacttt tggcaaaaat tgcaaaaagt gatggtaggg taagtgaaaa tgaagctgaa 241 atgatcaaag atcttttaga tgcaaatgcc aaagatgaaa aagaaagagc ttttttaaaa 301 gcaagtttta atgaacataa agaaaattta agtgatgctt tttatgtggc aaaagatttt 361 ttaaaagaag tgcctttgcc taaaaatgag cgttttaatg tcttgcgtgt gcttgttttt 421 atggctttaa tcgatgcaga ttttaatgct aaaaagcgtg aaattttaga gcaaatcgct 481 aaagcctttg atatggcaaa aagcgaatta gacgctttta tagcaagtct ttcaaattta 541 aaaagtacta aaaaagaatt aagccttgat gaagcttttg ctattttaga actttcaaat 601 aatgcagatt taaatgcagt aaaaaaacaa taccgcaatt tagcaaaaaa ataa

\section{pBluescript II KS(+), 2961 bp}

The following sequence has been verified for accuracy at the junctions.

1 ctaaattgta agcgttaata ttttgttaaa attcgcgtta aattttgtt aaatcagctc 61 atttttaac caataggccg aaatcggcaa aatcccttat aaatcaaaag aatagaccga 121 gatagggttg agtgttgttc cagtttggaa caagagtcca ctattaaaga acgtggactc 181 caacgtcaaa gggcgaaaaa ccgtctatca gggcgatggc ccactacgtg aaccatcacc 241 ctaatcaagt tttttggggt cgaggtgccg taaagcacta aatcggaacc ctaaagggag 301 ccccogattt agagcttgac ggggaaagcc ggcgaacgtg gcgagaaagg aagggaagaa 361 agcgaaagga gcgggcgcta gggcgctggc aagtgtagcg gtcacgctgc gcgtaaccac 421 cacacccgcc gcgcttaatg cgccgctaca gggcgcgtcc cattcgccat tcaggctgcg 481 caactgttgg gaagggcgat cggtgcgggc ctcttcgcta ttacgccagc tggcgaaagg 541 gggatgtgct gcaaggcgat taagttgggt aacgccaggg ttttcccagt cacgacgttg 601 taaaacgacg gccagtgagc gcgcgtaata cgactcacta tagggcgaat tggagctcca 661 ccgcggtggc ggccgctcta gaactagtgg atcccccggg ctgcaggaat tcgatatcaa 721 gcttatcgat accgtcgacc tcgagggggg gcccggtacc cagcttttgt tccctttagt 
781 gagggttaat tgcgcgcttg gcgtaatcat ggtcatagct gtttcctgtg tgaaattgtt 841 atccgctcac aattccacac aacatacgag ccggaagcat aaagtgtaaa gcctggggtg 901 cctaatgagt gagctaactc acattaattg cgttgcgctc actgcccgct ttccagtcgg 961 gaaacctgtc gtgccagctg cattaatgaa tcggccaacg cgcggggaga ggcggtttgc 1021 gtattgggcg ctcttccgct tcctcgctca ctgactcgct gcgctcggtc gttcggctgc 1081 ggcgagcggt atcagctcac tcaaaggcgg taatacggtt atccacagaa tcaggggata 1141 acgcaggaaa gaacatgtga gcaaaaggcc agcaaaaggc caggaaccgt aaaaaggccg 1201 cgttgctggc gttttccat aggctccgcc cccctgacga gcatcacaaa aatcgacgct 1261 caagtcagag gtggcgaaac ccgacaggac tataaagata ccaggcgttt ccccctggaa 1321 gctccctcgt gcgctctcct gttccgaccc tgccgcttac cggatacctg tccgccttc 1381 tcccttcggg aagcgtggcg ctttctcata gctcacgctg taggtatctc agttcggtgt 1441 aggtcgttcg ctccaagctg ggctgtgtgc acgaaccccc cgttcagccc gaccgctgcg 1501 ccttatccgg taactatcgt cttgagtcca acccggtaag acacgactta tcgccactgg 1561 cagcagccac tggtaacagg attagcagag cgaggtatgt aggcggtgct acagagttct 1621 tgaagtggtg gcctaactac ggctacacta gaaggacagt atttggtatc tgcgctctgc 1681 tgaagccagt taccttcgga aaaagagttg gtagctcttg atccggcaaa caaaccaccg 1741 ctggtagcgg tggtttttt gtttgcaagc agcagattac gcgcagaaaa aaaggatctc 1801 aagaagatcc tttgatcttt tctacggggt ctgacgctca gtggaacgaa aactcacgtt 1861 aagggatttt ggtcatgaga ttatcaaaaa ggatcttcac ctagatcctt ttaaattaaa 1921 aatgaagttt taaatcaatc taaagtatat atgagtaaac ttggtctgac agttaccaat 1981 gcttaatcag tgaggcacct atctcagcga tctgtctatt tcgttcatcc atagttgcct 2041 gactccccgt cgtgtagata actacgatac gggagggctt accatctggc cccagtgctg 2101 caatgatacc gcgagaccca cgctcaccgg ctccagatt atcagcaata aaccagccag 2161 ccggaagggc cgagcgcaga agtggtcctg caactttatc cgcctccatc cagtctatta 2221 attgttgccg ggaagctaga gtaagtagtt cgccagttaa tagtttgcgc aacgttgttg 2281 ccattgctac aggcatcgtg gtgtcacgct cgtcgtttgg tatggcttca ttcagctccg 2341 gttcccaacg atcaaggcga gttacatgat cccccatgtt gtgcaaaaaa gcggttagct 2401 ccttcggtcc tccgatcgtt gtcagaagta agttggccgc agtgttatca ctcatggtta 2461 tggcagcact gcataattct cttactgtca tgccatccgt aagatgcttt tctgtgactg 2521 gtgagtactc aaccaagtca ttctgagaat agtgtatgcg gcgaccgagt tgctcttgcc 2581 cggcgtcaat acgggataat accgcgccac atagcagaac tttaaaagtg ctcatcattg 2641 gaaaacgttc ttcggggcga aaactctcaa ggatcttacc gctgttgaga tccagttcga 2701 tgtaacccac tcgtgcaccc aactgatctt cagcatcttt tactttcacc agcgtttctg 2761 ggtgagcaaa aacaggaagg caaaatgccg caaaaaaggg aataagggcg acacggaaat 2821 gttgaatact catactcttc cttttcaat attattgaag catttatcag ggttattgtc 2881 tcatgagcgg atacatattt gaatgtattt agaaaataa acaaataggg gttccgcgca 2941 catttccccg aaaagtgcca c 


\section{Curriculum Vitae}

\section{Personal record}

Name

Date of birth

Address of Institute

Website

Tel Lab

Email
Javid Iqbal Dasti

October 20, 1978

Institute of Medical Microbiology, Centre for Hygiene and Human Genetics, School of Medicine, University of Göttingen, Kreuzbergring 57, D-37075 Göttingen, Germany.

http://www.bakteriologie.uni-goettingen.de/Index-English.htm (+49) 551395848

javiddashti@yahoo.com

\section{Research Interests}

- Microbial pathogenesis

- Host-Pathogen interaction

- Virulence factors of Campylobacter jejuni

\section{Dissertation title:}

- Identification and characterization of Campylobacter jejuni factors relevant for the infection process.

\section{Awards}

- "PhD Research Scholarship" awarded from German Research Council (DFG).

- "M.Phil Research Scholarship" awarded from Centre of Excellence in Molecular Biology University of the Punjab Lahore Pakistan. 


\section{Education}

August 2003 - February 2007

Janurary2001 - December 2003

Janurary 1997 - December 2001
Ph.D., Molecular Biology

George August University of Göttingen, Germany.

M.Phil, Molecular Biology

Centre of excellence in Molecular Biology, University of the Punjab Lahore, Pakistan.

BSc (Hon), Plant Breeding and Genetics, NWFP Agricultural University of Peshawar, Pakistan. 